INSTITUTO DE PESQUISAS ENERGÉTICAS E NUCLEARES

Autarquia associada à Universidade de São Paulo

\title{
CONTRIBUIÇÃo AO CÁlCULO DO VALOR ALFA NO ESTUDO DE OTIMIZAÇÃO DA RADIOPROTEÇÃO
}

\author{
CLARICE DE FREITAS ACOSTA PEREZ
}

\author{
Tese apresentada como parte dos \\ requisitos para a obtenção do Grau de \\ Doutor em Ciências na Área de \\ Tecnologia Nuclear - Aplicações \\ Orientador: \\ Dr. Gian-Maria A.A. Sordi
}


Aos meus familiares: Ramón, Nazareth, Ailton, Rodrigo, Adriane e ...

Dedico 


\section{AGRADECIMENTOS}

- Ao Dr. Gian-Maria A.A. Sordi, Assessor Técnico Científico da Proteção Radiológica do Instituto de Pesquisas Energéticas e Nucleares - CNEN/SP, meu querido orientador pela dedicação, incentivo, orientação e paciência.

- À Pós-Graduação do Instituto de Pesquisas Energéticas e Nucleares - CNEN/SP, pela oportunidade e incentivo.

- Ao Centro Tecnológico da Marinha em São Paulo - CTMSP, pelas facilidades concedidas.

- Aos meus pais Ramón e Nazareth, ao meu esposo Ailton e meu filho Rodrigo, pela paciência e pelo carinho com que sempre me apoiaram em minha vida profissional.

- Aos amigos M.Sc. Adélia Sahyun, M.Sc. Marcos Rodrigues de Carvalho e Ricardo D’Utra Bitelli pelo apoio e incentivo durante a realização deste trabalho. 


\title{
CONTRIBUIÇÃO AO CÁLCULO DO VALOR ALFA NO ESTUDO DE OTIMIZAÇÃO DA RADIOPROTEÇÃO
}

\author{
Clarice de Freitas Acosta Perez
}

\section{RESUMO}

O valor alfa é um critério extremamente importante, pois determina o tempo que um País levará para atingir suas metas na diminuição da distribuição das doses em trabalhadores envolvidos com fontes de radiação ionizante. Atualmente os paises adotam um valor único para $\alpha$ baseado no Produto Interno Bruto per Capita. Neste trabalho, pretende-se mostrar que seria possível a escolha de uma curva para $\alpha$ ao invés de um único valor. Esta curva por sua vez, seria capaz de fornecer valores para $\alpha$ que estariam vinculados às maiores doses individuais observadas em cada processo de otimização, tanto de projeto quanto de operação. Os valores para a construção das curvas $\alpha$, aqui sugeridos, não dependeriam mais do Produto Interno Bruto per Capita mas seriam função da distribuição das doses individuais máximas e do prazo necessário para atingir a meta de 1/10 do limite de dose anual previsto, isto é, alcançar a região de doses individuais consideradas aceitáveis. Esta nova conceituação do valor alfa viria resolver muitos problemas criados pela teoria atual, entre os quais destacamos:

a) somente pode ser realizada uma otimização para cada conjunto (família) de opções de radioproteção.

b) cada país tem limites restritos diferenciados, que podem causar graves problemas nos intercâmbios internacionais.

c) dificulta o cálculo de prováveis casos de morte em virtude do valor da dose coletiva, considerado indesejável pelos organismos internacionais. 


\title{
CONTRIBUTION TO THE CALCULATION OF THE ALPHA VALUE IN THE STUDY OF OPTIMIZATION ON RADIOLOGICAL PROTECTION
}

\author{
Clarice de Freitas Acosta Perez
}

\begin{abstract}
The Alpha value is an extremely important criterion because it determines the time that each country takes to reach its proposals to decrease the doses to workers involved with ionizing radiation sources. Presently, countries adopt a single value for alpha based in the annual gross national product, GNP, per capita. The aim of this paper is to show that it should be more efficient the selection of a curve for alpha in place of a single value. This curve, in its turn, should allow an alpha value that would be constraint to the greatest individual doses present in each optimization process, applied to design and operation. These maximum individual doses should represent the dose distribution between the workers team. To build the curve, alpha values suggested will not be based on the GNP per capita but on a distribution function of the maximum individual doses and on the time necessary to reach the goal of $1 / 10$ of the annual dose limit, that is, to reach the region where the individual doses are considered acceptable. This new alpha value approach solves several problems risen by the present methodology, among which we emphasize:

a) It can be accomplished only one optimization for each radiological protection option set;

b) each country may have different constraints limits that can create serious problems in the international interchange;

c) it avoids the possibility to calculate the probable death rate due to the collective dose. This type of calculation is undesirable to international organization.
\end{abstract}


1 INTRODUÇÃ

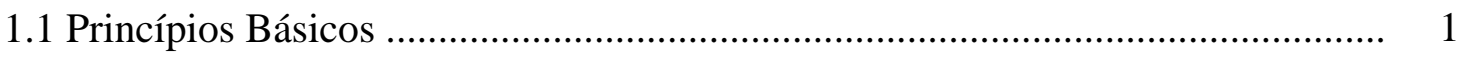

1.2 Finalidades e Objetivos ............................................................................... 5

1.2.1 Introdução ............................................................................................... 5

$\begin{array}{ll}\text { 1.2.2 Finalidade } & 6\end{array}$

1.2.3 Objetivos

1.3 Partes Originais do Presente Trabalho ................................................................. 7

1.4 Justificativa do Presente Trabalho ....................................................................... 7

2 DESCRIÇÃO DAS TÉCNICAS DE AJUDA PARA TOMADA DE DECISÃo 8

2.1 Análise Custo-Benefício Diferencial ........................................................... 8

2.2 Análise Custo-Benefício Integral 10

2.3 Análise Custo-Benefício Expandida ................................................................ 15

2.4 Cálculo do Valor Alfa ............................................................................. 17

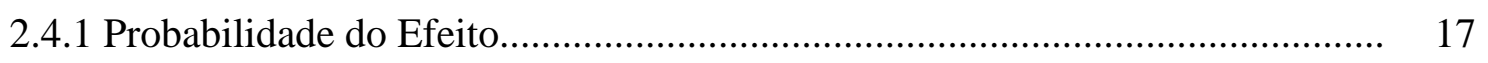

2.4.2 Custo dos efeitos à saúde ........................................................................ 18

2.5 Alguns exemplos internacionais e nacionais do cálculo do valor alfa ............... 21

2.6 Valores de alfa em função da dose equivalente individual ............................... 26

3 O EXEMPLO DA MINA DE URÂNIO ....................................................... 29

3.1 Análise Custo-Eficácia ............................................................................... 30

3.2 Análise Custo-Benefício Integral 31

3.3 Análise Custo-Benefício Expandida.................................................................. 32

4 DESENVOLVIMENTO INICIAL DO TRABALHO .................................. 35

4.1 Estudo de Sensibilidade para o Critério do Valor Alfa ..................................... 36

4.2 As Análises Custo-Benefício e Custo-Benefício Expandida utilizando a

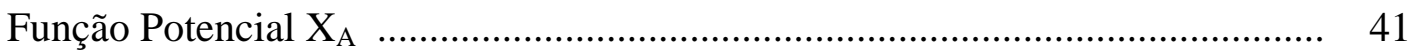

4.3 A utilização de derivadas na otimização da proteção radiológica ..................... 43 
4.4 Exemplo hipotético utilizando a pequena mina e funções diferentes do valor alfa

5 DESENVOLVIMENTO DO MÉTODO ALTERNATIVO ............................. 57

5.1 Descrição do Método ........................................................................................ 5

5.2 Curvas de Alfa ............................................................................................ 58

5.2.1 Curva alfa para aversão ao risco .............................................................. 59

5.2.2 Curva alfa para neutralidade ao risco ............................................................ 60

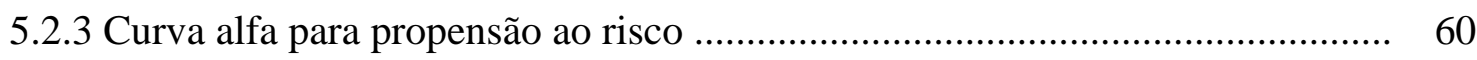

5.3 Aplicação da Técnica ao Exemplo da Mina de Urânio........................................ 61

5.3.1 Valores de Alfa e o Detrimento Modificado .................................................. 61

5.3.2 Função Detrimento Modificado $\mathrm{Z}_{\mathrm{A}}$.......................................................... 62

5.3.3 Custo Anual de Proteção X .............................................................................. 64

5.3.4 Análise Custo Benefício com Detrimento Modificado Z .............................. 65

5.3.5 Aplicação da Técnica ao Exemplo da Mina de Urânio utilizando a

Derivada das Funções ................................................................................. 66

5.4 Aplicação da Técnica a um Exemplo Brasileiro ................................................ 68

5.4.1 Resultados obtidos considerando Alfa Aversão, Neutro e Propenso com

Detrimento Modificado ................................................................................ 68

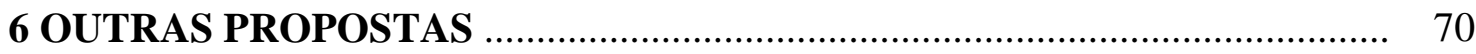

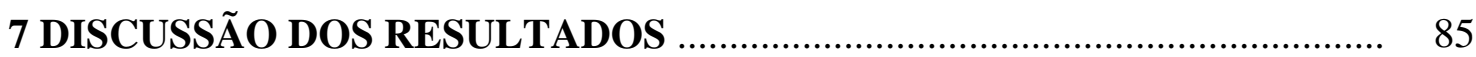

7.1 Discussão dos Resultados obtidos para a mina de urânio ................................... 85

7.2 Discussão dos Resultados obtidos para Gamagrafia ........................................ 89

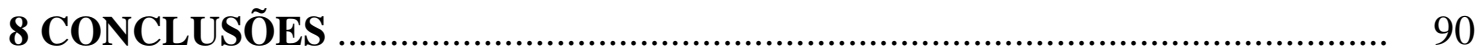

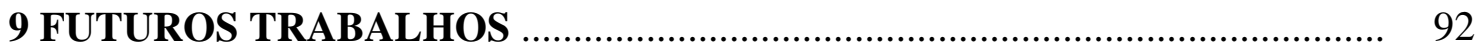

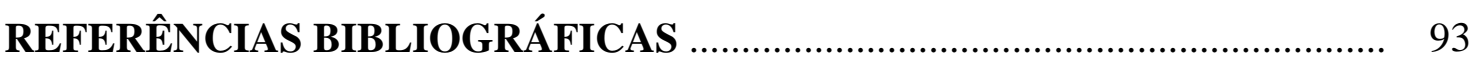




\section{CAPÍTULO 1}

\section{INTRODUÇÃO}

\section{1 - Princípios básicos}

As aplicações envolvendo o emprego de radiação ionizante são inúmeras e fazem parte da vida moderna, são exemplos disso: a produção de energia elétrica em centrais nucleoelétricas que são amplamente utilizadas em alguns países como, por exemplo, a França e o Japão, a Medicina que talvez seja a ciência mais beneficiada, a indústria que obteve melhoria nos processos de fabricação, no controle da qualidade principalmente em setores como o automobilístico, eletro-eletrônico, telecomunicações, a preservação de alimentos, a medicina farmacêutica, etc.

Embora todos saibam dos benefícios da radiação ionizante, o seu crescente emprego nos mais variados setores da sociedade tem contribuído para um incremento no risco potencial à saúde do homem e ao meio ambiente, sobretudo se utilizadas de maneira indevida. Assim, para que o homem possa usufruir ao máximo os benefícios advindos dessas aplicações, a radioproteção tem as funções principais de controlar os malefícios reais, mantendo-os em valores socialmente aceitáveis e de minimizar as exposições potenciais.

Para conseguir isto, devem ser satisfeitos os três princípios básicos de radioproteção ${ }^{(1)(2)}$, a saber:

(a) Qualquer atividade envolvendo radiação ou exposição deve ser justificada em relação a outras alternativas e produzir um benefício líquido positivo para a sociedade. É conhecido como princípio da Justificação.

(b) O projeto, o planejamento do uso e a operação da instalação e de fontes de radiação devem ser feitos de modo a garantir que as exposições sejam tão reduzidas quanto 
(c) Razoavelmente exeqüíveis, levando-se em consideração fatores sociais e econômicos. É conhecido como princípio ALARA, iniciais da expressão inglesa “As Low As Reasonably Achievable” e também como princípio da otimização da proteção radiológica.

(d) As doses individuais dos trabalhadores e de indivíduos do público não devem exceder os limites anuais de dose equivalente estabelecidos. Princípio da Limitação.

Examinando sucintamente o primeiro princípio do sistema de limitação de dose atual, em que nenhuma atividade será adotada a não ser que sua introdução produza um benefício líquido positivo, temos a resposta à questão sobre se vale a pena introduzir uma atividade que envolve radiação ionizante quando já existem outras técnicas que não a utilizam e que tem a mesma finalidade. Por exemplo: "vale a pena introduzir a gamagrafia para verificação de solda se existem outras técnicas como ultra-som, já em uso ?". Se a introdução da técnica que usa radiação ionizante produzir mais benefício do que malefício, é justificada a sua introdução, caso contrário não. Daí ser conhecido como princípio da justificação.

Por este motivo, via de regra, este princípio é de responsabilidade das autoridades governamentais competentes. Isso não significa que não possa ser usada pelos serviços de proteção radiológica quando houver a necessidade de optar entre duas ou mais técnicas. Este tipo de análise para a escolha de uma determinada técnica dentre várias já é conhecida e usada em outros campos do conhecimento humano. Ela é conhecida como Análise Custo-Benefício e pode ser definida como aquela análise que tem o propósito de justificar a presença de uma dada fonte de radiação, considerando seus efeitos totais positivos e negativos bem como avaliar procedimentos alternativos. A equação usada em proteção radiológica para este tipo de análise é relativamente simples e expressa como ${ }^{(3)}$ :

$$
\mathrm{B}=\mathrm{V}-(\mathrm{P}+\mathrm{X}+\mathrm{Y})
$$

onde:

B é o benefício líquido;

$\mathrm{V}$ é o benefício bruto;

P é o custo de produção básica, desde o projeto até a completa eliminação da fonte de radiação; 
$\mathrm{X}$ é o custo para alcançar o grau de proteção e segurança selecionado;

Y é o custo do detrimento total.

Fica entendido como custo do detrimento total o custo do dano biológico total provocado pela introdução de uma fonte de radiação. Para a atividade com radiação ionizante ser aceita, evidentemente, o benefício líquido deve ser maior do que zero senão a atividade será proibida.

O terceiro princípio estabelece um limite superior de risco, para o trabalhador e o público, acima do qual a atividade humana se torna inaceitável, o que não significa que qualquer valor abaixo do limite superior de risco seja aceitável.

O segundo princípio visa, em resumo, o abaixamento das doses nas três categorias em que são divididos os irradiados, a saber: trabalhadores, indivíduos do público e irradiações médicas, a valores mínimos de risco, que sejam aceitos pela população, em função dos benefícios trazidos pelo uso das radiações ionizantes. No caso da categoria de trabalhadores, de conformidade com as recomendações de proteção radiológica da CIPR ${ }^{(1)}$ as doses individuais dos trabalhadores foram divididas em três regiões, a saber:

Doses superiores aos limites anuais: valores inaceitáveis;

Doses entre os limites anuais e 1/10 destes limites: valores toleráveis;

Doses inferiores a 1/10 dos limites anuais: valores aceitáveis.

Como mostrado no gráfico a seguir:

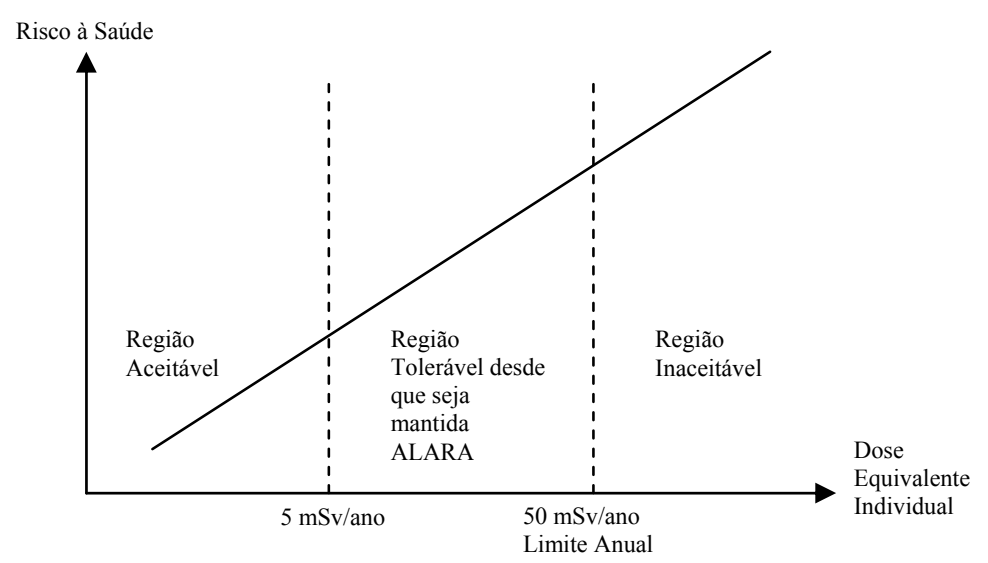

FIGURA 1.1 - Doses Individuais para trabalhadores dividida em regiões 
É exatamente na região tolerável que devemos aplicar o princípio ALARA, fazendo melhorias nas condições de proteção radiológica, tanto de projeto, como nos procedimentos, a fim de reduzir as doses recebidas pelos trabalhadores até a região aceitável. Enquanto que o princípio da Justificação exige que o Benefício Líquido seja positivo, o princípio ALARA pretende limitar as doses em valores suficientemente pequenos de maneira que qualquer esforço na redução do detrimento não seja justificado pelo esforço necessário para alcançá-lo, ou seja, exige que o Benefício Líquido seja máximo. Para atingir tal objetivo, a Comissão Internacional de Proteção Radiológica (CIPR) desenvolveu e sugeriu o uso das técnicas de ajuda para a tomada de decisão que são adotadas atualmente ${ }^{(4)}$.

Em 1983 a CIPR ${ }^{(5)}$ desenvolveu as técnicas de análise custo-benefício integral e análise custo-benefício diferencial aplicadas à proteção radiológica. Ela mostrou também que, para efeito de satisfazer o princípio da otimização, nem sempre é suficiente considerar somente os parâmetros custo da proteção e detrimento biológico, que são os únicos parâmetros utilizados pelas técnicas acima. A necessidade de outros parâmetros fica evidente se perguntarmos, por exemplo:

1 - É preferível, do ponto de vista da otimização, para uma mesma dose coletiva, ter poucos indivíduos irradiados com doses próximas aos limites anuais ou ter muitos indivíduos com pequenas doses.

2 - Devem ser considerados os custos do desconforto provocado pelo uso dos equipamentos de proteção individual (EPI) ou pelo uso de um sistema de ventilação?

Assim, a CIPR publicação $37^{(5)}$ introduz a análise custo-benefício expandida que possibilita acrescentar mais parâmetros. Em 1989 a publicação de número 55 da CIPR (4) além de fazer uma remissiva das técnicas apresentadas na publicação $37^{(5)}$, introduziu mais duas técnicas, a análise de prioridades com atributos múltiplos e a análise com critérios múltiplos excedentes, apresentando também, o problema que envolve uma pequena mina de urânio, para exemplificar cada técnica. 


\section{2 - Finalidade e Objetivos}

\subsubsection{Introdução}

Este trabalho irá abordar, especificamente, as limitações observadas nas técnicas de análise custo-benefício diferencial, análise custo-benefício integral e análises custo-benefício expandidas, que serão examinadas com mais detalhes no capítulo 2 . Nestas três técnicas, o termo alfa tem papel fundamental, pois é ele quem determina o valor a ser investido em proteção e, conseqüentemente, a trajetória adotada para atingir a meta final, que é a região de doses individuais aceitáveis. O que se pode constatar, atualmente, com relação a este termo, porém, é que os paises adotam um valor único para $\alpha$, que pode estar atrelado ao seu Produto Interno Bruto per Capita. Desta forma, existem, no mundo, diferentes valores para alfa. Por outro lado, ainda que os valores de $\alpha$ sejam diferentes para cada país, sua finalidade, que é a redução das doses até a região aceitável, é a mesma em qualquer lugar do planeta. Inferimos então, que seria razoável ter um valor único de alfa para o mundo inteiro.

Outra consideração importante é o fato de que as técnicas de custo benefício diferencial e custo benefício integral estão limitadas a comparações quantitativas entre os custos de proteção e a dose coletiva e, portanto, o fator distribuição das doses individuais máximas não é diretamente considerado e é justamente este que se pretende diminuir até alcançar a região de doses aceitáveis. Para que seja possível considerá-lo, pode-se usar a técnica de análise custo benefício expandida, porém os valores a serem atribuídos aos termos adicionais, ou seja, intervalos de Beta, cabem ao "tomador de decisão".

Outro aspecto importante dessas teorias, é o fato de que todas elas estão pautadas no ponto de máximo da função benefício líquido, porém, o ponto de máximo, visto como opção ótima em um processo de otimização, pode estar bastante afastado da dose individual máxima de $5 \mathrm{mSv} / \mathrm{ano}$, limite da região de dose aceitável, onde não há mais justificativa para o processo de otimização. Assim, se o ponto encontrado numa primeira otimização está muito afastado de $5 \mathrm{mSv} /$ ano, devemos continuar o processo de otimização até que se alcance este valor. Por outro lado, para que seja possível passar para pontos de dose menores, a curvatura das funções associadas aos custos de proteção e ou ao detrimento, que juntas irão compor a função benefício líquido, deverão, em tese, mudar, 
pois, caso contrário, dado que já encontramos o ponto de mínimo dos dois segmentos de reta, intuitivamente, podemos supor que uma próxima otimização seria dispensável a não ser que se mude a família de opções de proteção consideradas.

\subsection{2 - Finalidade}

Por essas razões, este trabalho tem por finalidade mostrar que seria mais eficaz a escolha de uma curva ou de um conjunto de curvas para $\alpha$, ao invés de um único valor. Estas curvas por sua vez, seriam capazes de fornecer valores para $\alpha$ que estariam vinculados às maiores doses individuais observadas em cada processo de otimização, tanto de projeto quanto de operação. Os valores para a construção das curvas para $\alpha$ aqui sugeridos, não dependeriam mais do Produto Interno Bruto per Capita dos países mas seriam função da distribuição das doses individuais máximas praticadas atualmente no mundo e da prioridade que se daria ao prazo necessário para se atingir a meta de $1 / 10$ do limite de dose anual, isto é, alcançar a região de doses individuais consideradas aceitáveis.

\subsection{3 - Objetivos}

1. Ajuste de curvas, em vez de retas, unindo os custos de proteção $X$ das opções, gerando assim funções $X=f(S)$.

2. Determinar o valor de alfa de acordo com a sua definição diferencial $-\frac{d X}{d S}=\alpha$, porém sendo $\alpha=f\left(H_{\text {máx }}\right)$, ou seja, alfa deixa de ser uma constante e passa a ser função da dose individual máxima obtida com as diferentes opções de radioproteção.

3. Definir possíveis curvas de valores alfa de acordo com as atitudes de aversão, neutralidade e propensão ao risco.

4. Criar um método que adapte as técnicas de análise custo-benefício já existentes para comportar as funções definidas para alfa.

5. Propor outras possíveis soluções para a otimização da radioproteção, a partir do método criado, utilizando as técnicas de análise custo benefício. 


\section{3 - Partes originais do presente trabalho}

A não ser pela adoção dos três tipos de atitudes de risco apresentados pela CIPR, na sua publicação $55^{(4)}$, que serão tratados no capítulo 4 , do exemplo da mina de urânio ${ }^{(4)}$ e de um exemplo nacional, utilizados para apresentar a técnica desenvolvida, este trabalho é completamente original, como poderá ser constatado a partir do capítulo 4.

\section{4 - Justificativa do presente trabalho}

A otimização das instalações radiativas e nucleares é uma exigência tanto das recomendações internacionais ${ }^{(1,2)}$ como da norma brasileira CNEN-NN-3.01 ${ }^{(6)}$. Por esta razão, aplicamos a metodologia aqui desenvolvida tanto em um exemplo internacional como em um brasileiro, referente à otimização do sistema de radioproteção em instalações radiográficas de gamagrafia ${ }^{(7)}$.

Para melhor compreensão deste trabalho, iremos, no próximo capítulo, apresentar sucintamente as três técnicas acima citadas, e no seguinte, apresentar o exemplo da mina de urânio adotado pela CIPR, publicação $55^{(4)}$. No capítulo 4 , desenvolveremos a metodologia proposta neste trabalho e, no capítulo 5, nos dois exemplos, internacional e nacional, serão aplicadas à metodologia desenvolvida para uma visão ampla das alterações sofridas. 


\section{CAPÍTULO 2}

\section{DESCRIÇÃO DAS TÉCNICAS DE AJUDA PARA A TOMADA DE DECISÃO}

\section{1 - Análise Custo-Benefício Diferencial}

A análise custo-benefício diferencial pretende mostrar que uma atividade envolvendo a radiação ionizante está sendo executada com os valores de dose efetiva suficientemente pequenos, em outras palavras, de detrimento suficientemente pequeno, e que qualquer ulterior redução na dose efetiva não justificará o incremento do custo requerido para efetuá-la.

Esta análise ${ }^{(4)}$ está associada ao fato de se requerer que uma atividade, envolvendo radiação ionizante, seja conduzida em um valor de dose efetiva preferencial a outro. Neste caso, as informações a serem consideradas, são:

a) diferenças nos detrimentos ao se passar de um valor de dose efetiva para outro;

b) diferença no custo de todos os produtos ou serviços necessários para conduzir a atividade proposta num valor da dose efetiva preferencial a outro.

Em outras palavras, poder-se-ia dizer que enquanto o princípio da justificação requer que o benefício líquido B seja positivo, o princípio da otimização para uma situação específica de exposição à radiação ionizante requer que o benefício líquido seja máximo. Examinando a equação (1.1) verifica-se que B será máximo no ponto que correspondente a $(\mathrm{X}+\mathrm{Y})$ mínimo, uma vez que o benefício bruto auferido $\mathrm{V}$ e o custo de produção $\mathrm{P}$ podem ser considerados constantes. Neste caso devemos ter:

$$
(X+Y)_{\text {mín }}
$$


tendo que obedecer a dois vínculos:

1 - os limites anuais de dose;

2 - B seja positivo;

senão a atividade estaria proibida.

Tanto $\mathrm{X}$ como $\mathrm{Y}$ dependem da dose efetiva coletiva, que se torna a variável independente para encontrar o valor de B máximo. Neste caso, diferenciando e igualando a zero a equação (1.1) com relação à dose efetiva coletiva $\mathrm{S}$, isto é, a soma de todas as doses do grupo de indivíduos irradiados, temos:

$$
\frac{d B}{d S}=\frac{d V}{d S}-\left(\frac{d P}{d S}+\frac{d X}{d S}+\frac{d Y}{d S}\right)=0
$$

$\mathrm{O}$ valor do benefício bruto à sociedade $\mathrm{V}$ e o custo desta atividade $\mathrm{P}$ (exceto o custo relativo a radioproteção) são independentes do grau de proteção e conseqüentemente independentes do valor de dose equivalente coletiva, portanto:

$$
\begin{aligned}
& \frac{d V}{d S}=0 \text { e } \frac{d P}{d S}=0 \text { e a equação se reduz a: } \\
& \frac{d B}{d S}=-\left(\frac{d X}{d S}+\frac{d Y}{d S}\right)=0 \text { ou }-\frac{d X}{d S}=\frac{d Y}{d S}
\end{aligned}
$$

A equação (2.3) traduz que o benefício líquido máximo é obtido quando um incremento infinitesimal no custo de radioproteção corresponde a uma diminuição igual no custo do detrimento à população e vice-versa. A CIPR assume que existe uma relação linear entre dose e efeito biológico, isto é o mesmo que supor uma relação linear entre a variação de detrimento na saúde e a variação da dose equivalente coletiva. Neste caso 
podemos dizer que, a um incremento no compromisso de dose equivalente coletiva corresponde um incremento linear no custo do detrimento de $\mathrm{Y}$, isto é:

$$
-\frac{d X}{d S}=\frac{d Y}{d S}=\alpha(\text { constante })
$$

onde $\alpha$ expressa o custo do detrimento por unidade de dose efetiva coletiva, calculada, geralmente, a partir do Produto Interno Bruto (PIB) per Capita de cada país.

Neste caso, o valor alfa deve ser pensado como aquele que estabelecido pela autoridade competente de cada país, representa o custo do detrimento por unidade de dose coletiva, igual, também, ao custo de proteção e segurança por unidade de dose coletiva no ponto considerado, o máximo que a autoridade competente do país pode exigir do empreendedor na otimização do custo da radioproteção por unidade de dose coletiva ${ }^{(3,4,8)}$.

Esta técnica, como podemos perceber, trata os termos custo da proteção X e detrimento Y como funções diferenciáveis e, por este motivo, é conhecida como análise custo-benefício diferencial. O sinal de menos que acompanha o custo de proteção diferencial é justificado pelo fato de que se aumentarmos o custo do detrimento, diminuiremos o custo de proteção e vice-versa, ou seja, se uma função é crescente a outra é decrescente. Considerando que a opção que atende à equação (2.3) pode não existir na prática, temos que a solução ótima será a opção que apresentar resultado menor ou igual a alfa $^{(8)}$.

$$
\left|\frac{d X}{d S}\right| \leq \alpha
$$

Isto é, quando a função dos custos não é contínua e monotônica, vale a expressão (2.5), que deve a ser escrita como:

$$
\left|\frac{\Delta X}{\Delta S}\right| \leq \alpha
$$




\section{2 - Análise Custo-Benefício Integral}

Partindo da equação (2.4), podemos escrever:

$$
\frac{d Y}{d S}=\alpha \text { ou } d Y=\alpha d S
$$

e integrando ambos os membros:

$$
\int d Y=\alpha \int d S \text { ou } Y=\alpha S+c
$$

Como, quando a dose efetiva coletiva for nula o custo do detrimento também será nulo, c é nulo e a equação será:

$$
Y=\alpha S
$$

Desta maneira, da equação (2.2) pode-se escrever:

$$
(X+\alpha S)_{\min }
$$

conhecida como condição custo-benefício integral para uso em otimização. Matematicamente poder-se-ia pensar que esta equação integral, em que Y foi substituído por $\alpha S$, somente é válida no entorno da opção $\mathrm{X}$, ótima, uma vez que resulta da derivada no ponto ótimo $\frac{d X}{d S}$. No entanto, de acordo com a CIPR ${ }^{(5)}$, isto não é verdade, como mostraremos a seguir. Começaremos definindo alguns termos necessários à demonstração, fornecidos pela própria CIPR na publicação $22^{(3)}$.

Risco, R, é a probabilidade de sofrer um efeito deletério como resultado de uma dose de radiação, para um dado indivíduo. Se $r_{i}$ é o coeficiente de probabilidade de sofrer o i-ésimo efeito, então: 


$$
R=1-\prod_{i}\left(1-r_{i}\right)
$$

Detrimento na população, $G$, é definido como o valor esperado, (conceito matemático), do dano provocado por uma dose de radiação considerando-se não unicamente as probabilidades de cada tipo de efeito deletério, mas, também, a gravidade dos efeitos. Assim, se $p_{i}$ é a probabilidade de sofrer o i-ésimo efeito, cuja gravidade é expressa por um fator de ponderação $g_{i}$, então, o detrimento $G_{k}$, num grupo k, composto de $N_{k}$ pessoas, é:

$$
G_{k}=N_{k} \sum_{i} p_{i, k} g_{i, k}
$$

Dose efetiva coletiva, $S_{k}^{H, c}$, sobre um grupo k constituído de $N_{k}$ pessoas, que receberam, cada uma delas, uma dose efetiva média $\overline{H_{k}}$, é dada por:

$$
S_{k}^{H, c}=N_{k} \overline{H_{k}}
$$

O símbolo c representa a dose comprometida para o caso de exposição interna.

Resta agora, verificarmos a relação entre o detrimento no grupo k, e a dose efetiva coletiva recebida por este grupo.

Pela hipótese da linearidade de cada efeito deletério, com relação à dose, podemos escrever $p_{i, k}=r_{i, k} \overline{H_{k}}$, onde, $r_{i, k}$, é o coeficiente de probabilidade de risco do iésimo efeito sobre o grupo $\mathrm{k}$ e $\overline{H_{k}}$ é a dose efetiva média recebida por cada indivíduo do grupo k, supondo que a gravidade do efeito é independente de sua freqüência.

Substituindo esta última expressão do detrimento, na equação (2.9), vem:

$$
G_{k}=N_{k} \sum_{i} r_{i, k} \bar{H}_{k} g_{i, k}=N_{k} \overline{H_{k}} \sum_{i} r_{i, k} g_{i, k}
$$


Mas, pela equação (2.10), temos $S_{k}^{H, c}=N_{k} \overline{H_{k}}$ que se substituído na expressão (2.11), vem:

$$
G_{k}=S_{k}^{H, c} \sum_{i} r_{i, k} g_{i, k}
$$

onde, o somatório é uma constante independente da dose efetiva coletiva $S_{k}^{H, c}$.

Após estas definições, vamos demonstrar o asserido inicialmente ${ }^{(5)}$. O custo monetário do detrimento, $G_{k}$, num grupo de $N_{k}$ indivíduos, pode ser calculado a partir da equação (2.12)

$$
Y=G_{k} \varepsilon
$$

onde, Y, é o custo monetário do detrimento $G_{k}$ e $\varepsilon$ é o custo atribuído ao detrimento unitário. Substituindo-se a equação (2.13) em (2.12), vem:

$$
Y_{k}=\varepsilon S_{k}^{H, c} \sum_{i} r_{i, k} g_{i, k}
$$

Por outro lado da equação (2.6), temos: $Y_{k}=\alpha S_{k}^{H, c}$ que substituindo-se na equação (2.14), vem:

$$
\alpha=\varepsilon \sum_{i} r_{i, k} g_{i, k}
$$

e isto é válido para qualquer opção de custo de proteção, $X$, independente de quão próximo ou longe esteja a opção daquela considerada a ótima dada pela equação (2.5). Os coeficientes de probabilidade de risco e de gravidade, foram determinados pela $\operatorname{CIPR}^{(9,10)}$.

Como descritos nas publicações da ICRP- $22^{(3)}, 37^{(5)}, 55^{(4)}$ e de Stokell ${ }^{(8)}$, se os únicos fatores diretamente pertinentes para os propósitos de otimização forem os custos financeiros das medidas protetoras a serem implantadas e os valores de dose coletiva associados, então, uma análise custo-benefício integral ou diferencial simples pode ser 
implementada, transformando a dose efetiva coletiva num valor monetário, fazendo uso do valor de referência do custo do detrimento por unidade de dose efetiva coletiva $\alpha$.

A análise, então, procede pela soma do custo de proteção $\mathrm{X}$ com o custo do detrimento $\mathrm{Y}$, de modo a obter-se um custo total $(X+\alpha S)$. A solução analítica corresponde à opção de radioproteção que fornece o menor custo total.

No Brasil, $\alpha$ equivale, em unidades monetárias nacionais, a US\$10.000/Svpessoa ${ }^{(6)}$. Esse valor foi assumido pela CNEN, por tratar-se do valor médio do intervalo de variação entre US\$ 1.000/Sv-pessoa e US\$ 25.000/Sv-pessoa, existente entre os diferentes países do mundo. A CIPR sugeriu, para os países que não tivessem determinado o seu próprio valor, que adotassem este valor médio. Posteriormente, Sordi et al determinaram o valor no nosso país, fazendo inclusive, uma projeção para os próximos 20 anos, e determinaram o equivalente a US\$ 3.500/Sv-pessoa para o ano $2004^{(11)}$ e US\$ $3.200 / \mathrm{Sv}$-pessoa para o ano $2000^{(12)}$. O mesmo valor foi obtido por Suzuki ${ }^{(13)}$ quando realizou um estudo dos níveis de ação em casos de acidentes em instalações nucleares e radiativas. Sordi determinou estes valores, utilizando o formalismo sugerido pela CIPR e Suzuki utilizou o formalismo do OIEA. Com a tabela 2.1, podemos fazer uma comparação entre os resultados obtidos por Suzuki ${ }^{(13)}$ US\$ 3.268/Sv-pessoa, com os oficiais US\$ $10.000 / \mathrm{Sv}$-pessoa e ainda com os preconizados pelo OIEA. Vê-se que alguns valores encontrados para as medidas de ação com alfa real são inferiores aos valores preconizados pelo OIEA, e os valores adotados pelo nosso país, são extremamente restritivos quando comparados com o real. 
TABELA 2.1 - Níveis genéricos de intervenção estimados, por Suzuki ${ }^{(13)}$, para o Brasil, para o alfa oficial de US\$10.000/Sv-pessoa adotado no Brasil e os recomendados pelo OIEA

\begin{tabular}{|c|c|c|c|}
\hline $\begin{array}{l}\text { Medida de } \\
\text { proteção }\end{array}$ & $\begin{array}{l}\text { Brasil } \\
(\mathrm{mSv})\end{array}$ & $\begin{array}{l}\text { Oficial } \\
(\mathrm{mSv})\end{array}$ & $\begin{array}{l}\text { OIEA } \\
(\mathrm{mSv})\end{array}$ \\
\hline Abrigo & $6^{\mathrm{a}}$ & $2^{\mathrm{a}}$ & $10^{\mathrm{a}}$ \\
\hline Evacuação & $25^{\mathrm{b}}$ & $9^{\mathrm{b}}$ & $50^{\mathrm{b}}$ \\
\hline \multirow[t]{2}{*}{ Relocação temporária } & $116^{\mathrm{c}}$ & $38^{\mathrm{c}}$ & $30^{\mathrm{c}}$ \\
\hline & $53^{\mathrm{d}}$ & $18^{\mathrm{d}}$ & $10^{\mathrm{d}}$ \\
\hline Reassentamento & $1250^{\mathrm{e}}$ & $410^{\mathrm{e}}$ & $1000^{\mathrm{e}}$ \\
\hline \multicolumn{4}{|c|}{${ }^{\text {a }}$ dose evitada em menos de 2 dias. } \\
\hline \multicolumn{4}{|c|}{${ }^{\mathrm{b}}$ dose evitada em menos de uma semana } \\
\hline \multicolumn{4}{|l|}{ c dose evitada no primeiro mês. } \\
\hline \multicolumn{4}{|c|}{ d dose evitada em um mês subseqüente. } \\
\hline${ }^{\mathrm{e}}$ dose evitada no tempo de vi & & & \\
\hline
\end{tabular}

\section{3 - Análise Custo-Benefício Expandida}

A técnica de análise custo-benefício é estritamente limitada a comparações quantitativas entre os custos de proteção e a dose efetiva coletiva. A fim de incluir outros fatores pertinentes na técnica analítica, é possível estender o quadro inicial da análise custo-benefício $^{(5)}$.

Um dos fatores de proteção radiológica visto como um propósito pertinente na tomada de decisão é se as doses individuais são grandes ou pequenas. Isto pode ser expresso como uma diferença entre uma dose efetiva coletiva originada de um grande número de doses individuais pequenas e a mesma dose efetiva coletiva para uma pequena população exposta a valores maiores, especialmente aqueles que se aproximam aos limites de dose. 
Para incorporar este julgamento, uma maneira seria via análise custo-benefício expandida, modificando-se o valor atribuído ao custo do detrimento por unidade de dose efetiva coletiva, isto é, o valor de alfa. O valor básico (ou termo $\alpha$ ) deve ser acrescido de outros termos na avaliação do custo do detrimento. Desta maneira, o valor de alfa passa a ser acrescido de termos adicionais que dependem dos valores das doses individuais envolvidas.

Esta nova componente no custo do detrimento pode ser expressa por um termo adicional introduzido pela CIPR na ICRP $37^{(5)}$ e, mais tarde, definida numa forma simplificada na ICRP $42^{(14)}$ como:

$$
Y=\alpha S+\sum_{j} \beta_{j} S_{j}
$$

onde:

- $\mathrm{S}_{\mathrm{j}}$ - é a dose coletiva originada de uma dose per capita $\mathrm{H}_{\mathrm{j}}$, liberada em $\mathrm{N}_{\mathrm{j}}$ indivíduos do jésimo grupo de doses individuais;

- $\beta_{\mathrm{j}}$ - é o valor monetário adicional, atribuído pelo "tomador de decisão", ao custo do detrimento por unidade de dose efetiva coletiva no grupo j-ésimo, que recebeu doses num intervalo especificado.

A título de exemplo, podemos, para o fator de distribuição de doses individuais, adotar como critério adicional os termos beta, como segue:

$$
\begin{aligned}
& \beta_{1} \rightarrow(\quad<5 \mathrm{mSv})=\mathrm{US} \$ \quad 0 \quad(\mathrm{~Sv} \text {-pessoa })^{-1} \\
& \beta_{2} \rightarrow(5-15 \mathrm{mSv})=\mathrm{US} \$ 40.000 \quad(\mathrm{~Sv} \text {-pessoa })^{-1} \\
& \beta_{3} \rightarrow(15-40 \mathrm{mSv})=\mathrm{US} \$ 80.000 \quad(\mathrm{~Sv} \text {-pessoa })^{-1} \\
& \beta_{4} \rightarrow(40-50 \mathrm{mSv})=\mathrm{US} \$ 120.000(\mathrm{~Sv} \text {-pessoa })^{-1}
\end{aligned}
$$


onde $\beta_{1}$ abarca o intervalo de doses que se encontram na região aceitável, $\beta_{2}$ o intervalo que abrange valores entre $1 / 10$ e $3 / 10$ do limite anual, $\beta_{3}$ o intervalo em que temos certeza de que as doses são inferiores ao limite anual, considerando o erro na medida, e $\beta_{4}$ o intervalo de doses inferiores ao limite anual mas que, se forem considerados os erros na medida pode deixar dúvidas de que as doses realmente tomadas sejam inferiores aos limites anuais.

$\mathrm{O}$ custo do detrimento $\mathrm{Y}$ é, então, a soma do termo $\alpha$, levando em conta a dose coletiva, e os termos $\beta$, levando em consideração a distribuição da dose individual, como mostrado no exemplo. A solução analítica corresponde à opção de radioproteção que fornece o menor custo total, ou seja $(X+Y)_{\min }$.

\section{4 - Cálculo do Valor Alfa}

O valor alfa $(\alpha)$ pode ser definido como o valor monetário da dose coletiva unitária e pode ser expresso de maneira simples como segue:

$\alpha=\sum_{i}$ (probabilidade do i-ésimo efeito por dose coletiva unitária)x(custo do detrimento associado ao i-ésimo efeito)

Desta maneira, o alfa ( $\alpha$ ) é formado por dois termos, a "probabilidade do efeito" e o "custo do efeito".

\subsection{1 - Probabilidade do efeito}

A CIPR em sua publicação de $1977^{(15)}$ usou um coeficiente de risco para os cânceres fatais de $1,25 \times 10^{-2} \mathrm{~Sv}^{-1}$. Além disso, o risco a danos hereditários graves foi julgado ser de $4 \times 10^{-3} \mathrm{~Sv}^{-1}$ para as duas primeiras gerações e $8 \times 10^{-3} \mathrm{~Sv}^{-1}$ para todas as gerações após a exposição. Estas estimativas de risco referiam-se ao membro médio de uma população de trabalhadores composta de um número igual de homens e mulheres, quando está sendo uniformemente irradiado o corpo inteiro. 
Estes números originaram-se de estudos de várias populações expostas, principalmente do acompanhamento das investigações a respeito dos sobreviventes japoneses das bombas atômicas e, também, de estudos sobre dados de efeitos hereditários derivados de experiências com animais. Estes coeficientes de risco foram àqueles usados na maioria das avaliações para determinar o sievert-pessoa.

O Comitê Científico das Nações Unidas sobre Efeitos da Radiação Atômica (CCNUERA), realizou recentemente, uma reavaliação, usando dados atualizados provenientes dos estudos dos sobreviventes das bombas atômicas de Hiroshima e Nagasaki ${ }^{(16)}$ e de modelos revisados. Estas informações foram levadas em consideração pelo CIPR e publicadas nas recomendações da publicação $60^{(1)}$, nas quais consta $\mathrm{o}$ seguinte: $\mathrm{O}$ risco de câncer fatal após a irradiação de corpo inteiro é de $5 \% \mathrm{~Sv}^{-1}$ para a população de todas as idades e de $4 \% \mathrm{~Sv}^{-1}$ para a população com idade entre 18 e 65 anos. Tendo recebido os dados sobre os efeitos hereditários, a CIPR decidiu para os fatores de risco, para todas as futuras gerações de $1 \% \mathrm{~Sv}^{-1}$ para uma população com todas as idades e de $0,6 \% \mathrm{~Sv}^{-1}$ para uma população que se encontra em idade de trabalhador, por causa das diferentes distribuições etárias. A CIPR reconheceu que o detrimento provocado pela exposição à radiação é um conceito complexo que combina a probabilidade, a gravidade e o tempo de incubação do malefício e não é representado facilmente por uma única variável. A quantificação do detrimento é exigida para vários propósitos diferentes, a saber: para recomendar limites de dose, para os fatores de ponderação de tecidos selecionados, e para fornecer uma base para quantificar o valor da dose coletiva unitária a ser usada nos estudos de otimização.

A CIPR concluiu que os muitos aspectos de detrimento e seus múltiplos propósitos tornam a seleção de uma única abordagem indesejável.

Para recomendar os limites de dose e selecionar os fatores de ponderação do tecido, a CIPR considerou as taxas de cânceres fatais e não fatais, com fatores de ponderação baseados na letalidade e nos anos de vida perdidos, e as enfermidades hereditárias. Contudo, a mesma CIPR não forneceu recomendações a respeito de como deve ser definido o detrimento para propósitos de otimização. 


\subsection{2 - Custo dos efeitos à saúde}

Existem vários métodos disponíveis para o cálculo do custo atribuído ao detrimento da saúde e os principais serão discutidos a seguir ${ }^{(17)}$. Com exceção da abordagem do capital humano, todos estes métodos consideram outros aspectos além dos custos econômicos à sociedade pela perda prematura da vida.

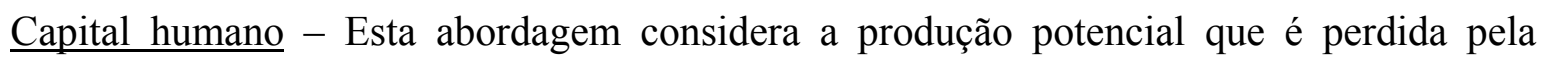
sociedade causada pela morte prematura de um indivíduo. Normalmente, também são realizadas algumas estimativas de qualquer custo a ser acrescentado, por exemplo, as despesas médicas associadas com a morte. O valor calculado, usando esta abordagem, torna-se o mínimo, do que seria gasto para evitar a morte prematura, pois ele é puramente econômico e não permite a inclusão de qualquer outro valor mais subjetivo, como danos morais, quais sejam, o desgosto, a dor e o sofrimento tanto da vítima como dos familiares ou amigos. Na verdade, mesmo como um valor básico, freqüentemente é aumentado com valores de julgamentos relativos aos custos sociais.

Principio da compensação legal - Este argumenta que a discussão da recompensa imposta pelos tribunais pela finalidade industrial, de algum modo reflete a visão da sociedade no que tange à compensação. O problema no uso desta abordagem é que o prêmio pela morte prematura recompensa unicamente os parentes. Alternativamente, poder-se-ia usar valores compensatórios para enfermidades muito graves que psicologicamente se equivalem à morte. Contudo, existem outros inconvenientes como:

a) considerada incompleta e preconcebida por causa de ter sido julgada improcedente;

b) a habilidade de provar negligência pode alterar completamente a compensação se nenhuma negligência pode ser compartilhada, então, não pode ser dada nenhuma compensação e quando pode ser comprovada uma negligência excepcional, então, podem ser perdidas compensações excepcionais com propósitos punitivos, particularmente quando tem sido considerável a perda de vida; e

c) as atividades legais existem para compensar "até onde o dinheiro pode" e, portanto, podem subestimar o custo total. 
A Comissão Real do Reino Unido sobre Responsabilidades Civis e Compensação para Prejuízos Pessoais ${ }^{(18)}$ examinou as falhas na legislação britânica e concluiu que os prêmios do tribunal não refletem, necessariamente, a visão da sociedade sobre compensações.

Analogias aos prêmios angariados por seguro - Estas não apresentam nenhum efeito direto sobre o risco de mortalidade, mas meramente cobrem as conseqüências da morte, compensando outros. Desta maneira, os prêmios dos seguros tendem a refletir o interesse das pessoas para com os seus dependentes, em vez de fazer uma avaliação de sua própria vida.

Inferência Pública ou Preferência Revelada - Este método está baseado nas análises retrospectivas de decisões sobre a proteção que já tenham sido implementadas e na avaliação de quanto já foi gasto para reduzir o risco. O argumento é que os tomadores de decisão, por exemplo, os políticos, são representantes da sociedade e que, portanto, esta implícito em suas decisões "um valor da vida" socialmente aceitável. Contudo, este método está limitado às alternativas consideradas e, também, às decisões do tomador que pode não estar consciente que estava envolvida uma escolha de segurança. Muitos estudos foram efetuados e forneceram um amplo intervalo de resultados que tendem a ser peculiares do estudo ${ }^{(19)}$. Para extrair um único "valor da vida" deste espectro, torna-se necessário alguma espécie de normalização para os fatores sociais e políticos envolvidos. Um exercício deste tipo, em seu próprio contexto, implicaria no uso de valores de julgamento. Finalmente, também seria essencial examinar com que bases foram tomadas as decisões - que informação estava disponível? Era completa ou correta?

Disposição a pagar, DAP - Este envolve a determinação, por avaliação, de quanto os indivíduos estão dispostos a pagar para evitar uma pequena alteração no risco. Muitos economistas acham esta metodologia, teoricamente, mais consistente.

Um princípio fundamental para tomar decisões sociais é que as preferências informadas forneceriam uma chave de entrada para as decisões partilhadas com o setor público. Os economistas, em bem estar, favorecem a abordagem DAP, pois, são 
consideradas aquelas preferências informadas por aqueles que serão afetados pela decisão específica.

Novamente, foram realizados alguns estudos, mas, também, foi levantado um amplo intervalo de valores ${ }^{(19)}$. O principal problema reside na comunicação ao entrevistado do significado do risco. A alteração no risco deve ser bastante grande para tornar significativo o risco familiar e a escolha deve usar verbas expressivas. Portanto, pode ser muito difícil empreender um levantamento para investigar riscos específicos.

No Reino Unido, a Junta Nacional de Radioproteção e o HSE têm colaborado num estudo destinado a quantificar a abordagem DAP. O projeto, finalmente, foi abandonado por causa das dificuldades fundamentais na comunicação de qualquer significado das alterações de risco envolvidas.

Por causa da exigüidade de confiabilidade dos dados da DAP, pelas razões acima expostas, a abordagem capital humano, geralmente, foi usada para avaliar o detrimento à saúde provocado pela radiação. Esta abordagem é puramente econômica e não permite outros valores mais subjetivos. Por este motivo, os valores do capital humano são vistos como valores básicos, ou em outras palavras, a verba mínima que seria gasta para evitar uma morte prematura.

A seguir resumir-se-á quatro exemplos de avaliação do detrimento à saúde, usando a abordagem capital humano; o primeiro faz parte das recomendações da CIPR, o segundo do OIEA, e os outros dois foram usados no Reino Unido e na França, respectivamente.

\section{5 - Alguns exemplos internacionais e nacionais do calculo do valor alfa}

Exemplo 1- Abordagem da Comissão Internacional de Proteção Radiológica-CIPR

Em 1983, a CIPR num relatório sobre o uso da análise custo-benefício na otimização $^{(5)}$, introduziu uma formulação geral para avaliar o detrimento que foi subseqüentemente atualizado em $1984^{(14)}$ para: 


$$
Y=\alpha S+\sum_{j} \beta_{j} \cdot N_{j} \cdot f_{j} \cdot\left(H_{j}\right)
$$

onde:

$\alpha$ - custo por unidade de dose coletiva

$\mathrm{S}-$ dose coletiva

$\beta_{\mathrm{j}}$ - custo de outros componentes do detrimento

$\mathrm{N}_{\mathrm{j}}$ - número de indivíduos do j-ésimo grupo

$\mathrm{F}_{\mathrm{j}}$ - função das doses individuais

$\mathrm{H}_{\mathrm{j}}$ - dose individual média dos $\mathrm{N}_{\mathrm{j}}$ indivíduos do j-ésimo grupo.

Desta maneira, $\alpha$ (alfa) é o valor monetário fornecido para concretizar o detrimento estocástico à saúde, por unidade de dose coletiva. Beta $(\beta)$ é um fator modificador que depende da distribuição das doses individuais dentro da dose coletiva mas, por outro lado, não é precisamente definido.

Exemplo 2 - Abordagem do Organismo Internacional de Energia Atômica - OIEA ${ }^{(20)}$

Esta abordagem foi recomendada num guia de segurança do OIEA que descreve a evolução de um valor internacional mínimo da unidade de dose coletiva para ser aplicado nos limites das emissões radiativas. Foram formuladas as quatro hipóteses que seguem, para refletir o impacto da perda de vida esperada resultante de uma dose coletiva de $1 \mathrm{~Sv}$.pessoa. (Os fatores de risco são aqueles usados na publicação CIPR $26^{(15)}$.

1- A perda média da vida sadia causada por um câncer letal induzido pela radiação é de cerca de 15 anos.

2- A perda média de vida provocada por uma enfermidade hereditária que causa um prejuízo grave é de cerca de 30 anos.

3- O fator de risco para o fator de câncer é $1,25 \times 10^{-2}$ por Sv-pessoa.

4- O fator de risco para a indução de dano hereditário para todas as gerações é de $0,8 \times 10^{-2}$ por Sv.pessoa.

Usando estas hipóteses, a perda de vida esperada causada por 1 Sv-pessoa foi avaliada como a probabilidade de contrair um efeito somático ou hereditário, multiplicado pela perda de vida esperada causada por estes efeitos: 


$$
\left(1,25 \times 10^{-2} \times 15\right)+\left(0,8 \times 10^{-2} \times 30\right)=0,43 \text { anos }
$$

Utilizando os novos valores da CIPR, publicação $60^{(1)}$, teríamos:

$$
\left(5 \times 10^{-2} \times 15\right)+\left(1,33 \times 10^{-2} \times 30\right)=1,05 \text { anos }
$$

O próximo passo é encontrar um equivalente monetário para a perda de um ano de vida. O método baseia-se no produto interno bruto (PIB) per capita, pois, é um indicador do padrão de vida de um país especificado.

O uso do PIB leva implícita a hipótese de que durante o transcurso de um ano, todos os indivíduos contribuirão para o aumento médio da riqueza do país, com uma quantidade igual ao PIB per capita e, que por causa da natureza probabilística dos efeitos nocivos à saúde, não é necessário avaliar pormenorizadamente a contribuição real de cada indivíduo. Ao detrimento à saúde foi incorporado um componente não letal, somando-se o custo do cuidado médico adicional por Sv-pessoa. Se o cuidado médico adicional for representado por $\mathrm{C}$, então:

$$
\alpha=\left(0,43 \times P I B_{\text {anual per capita }}\right)+C
$$

Supondo que C não seja grande, o principal componente de alfa $(\alpha)$ será o termo que contém o PIB anual per capita e este variará bastante de país para país. Por exemplo, em 1983, o "World Bank Atlas"(21) apresentou uma variação no PIB anual per capita de US\$ 260 a US\$ 12.680 com um valor médio de US\$ 2.740, ver tabela. O valor mínimo selecionado pela OIEA para as aplicações nas emissões radiativas, para os paises de renda pequena foi de US\$ 3.000 por Sv-pessoa, considerando os preços de 1983. 
TABELA 2.2 - PIB para diferentes áreas do mundo Extraído do World Bank Atlas

\begin{tabular}{ccc}
\hline Paises e Outras Regiões & PIB $_{(\text {anual per capita) }}$ & $0,43 \times$ IB $_{(\text {anual per capita) }}$ \\
& US\$S\$ & US \\
\hline América do Norte & 12680 & 5450 \\
Japão & 10080 & 4330 \\
Oceania & 8620 & 3550 \\
Indonésia & 530 & 230 \\
Europa & 8170 & 3510 \\
Oriente (Médio) & 5980 & 2570 \\
União Soviética & 4040 & 1740 \\
América do Sul & 2160 & 930 \\
América Central & 1980 & 830 \\
(Incluindo México) & 810 & 350 \\
Africa & 300 & 130 \\
China & 260 & 110 \\
India & 653 & 280 \\
Sudeste Asiático & 2740 & 1180 \\
Mundo & & \\
\hline & & \\
\hline
\end{tabular}

Exemplo 3- Abordagem da Junta Nacional de Radioproteção (National Radiation Protection Board) ${ }^{(22)}$ da Inglaterra

Em seu conceito, o método é semelhante àquele usado pelo OIEA, porém em sua estrutura é mais complexo e pormenorizado. Os cálculos são baseados em quatro fatores:

1- Custo esperado causado pelo detrimento hereditário

2- Perda esperada de produção causada por cânceres não fatais

3- Perda esperada de produção causada por morte prematura

4- Gastos médios esperados pela indução de cânceres.

O custo do detrimento hereditário inclui os custos dos cuidados médicos e a perda de produção econômica causada pela incidência de enfermidades e pela mortalidade. 
O custo da incidência de enfermidades, câncer não fatal, foi baseado na hipótese de que cada câncer resultaria numa perda de um ano de produção econômica.

As perdas econômicas causadas pelas mortes prematuras e os custos médicos causados pela indução de câncer pela radiação foram computados calculando o número esperado de cânceres que ocorreram com uma dose coletiva de 1 Sv-pessoa, uniformemente distribuída sobre toda a população. A população foi dividida em intervalos de idade. Foi calculado o número de cânceres esperados que aparecerão após períodos de tempo especificados, para ambos os sexos, usando modelos de risco para a indução de câncer por radiação e tabelas de vida do Reino Unido, considerando as causas de morte competidoras $^{(23)}$.

A perda esperada de produção causada pela morte prematura por câncer fatal foi estimada separadamente das demais fazendo uso da expressão seguinte:

$$
\sum_{n=0}^{N} \frac{P \cdot Q}{(1+r)^{n}}
$$

onde,

P é a probabilidade de um trabalhador ter continuado ativo durante um tempo de $n$ anos;

N é o tempo de vida que resta;

Q é a renda bruta anual;

R é a taxa de compensação (expressa em fração).

Esta somatória foi realizada formulando várias hipóteses com relação à população trabalhadora e às taxas de compensação. Multiplicando esta perda de produção pelo número de cânceres esperados e somando sobre todos os intervalos de idade e períodos de tempo, obtém-se a pera total de produção esperada por unidade de dose coletiva.

Os custos médicos para os cânceres induzidos foram calculados a partir dos gastos médios estimados para um caso de câncer no "National Health Service" do Reino 
Unido. Supõe-se que estes gastos tenham sido efetivados no ano em que foi registrado o câncer. Foi calculada a soma dos quatro componentes e esta representa o valor monetário da dose coletiva, alfa $(\alpha)$.

Exemplo 4 - Abordagem do Centro de Estudos sobre a Avaliação da Proteção no Domínio Nuclear (Centre D'Études sur l'Évaluation de la Protection dans le Domain Nucléare) da França $^{(24)}$.

Este método é mais direto do que os anteriores, porém está baseado nos mesmos princípios. $\mathrm{O}$ valor alfa foi avaliado em duas partes distintas $\alpha_{1}$ e $\alpha_{2}$. Inicialmente, supõe-se um fator de risco de $2 \times 10^{-2}$ por Sv-pessoa para um efeito grave à saúde, o custo do Sv-pessoa foi calculado multiplicando este risco por um valor prédetermiando da vida, assim:

$$
\alpha_{1}=0,02 \cdot V_{1}
$$

onde,

$\alpha_{1}$ é o custo do Sv-pessoa, para efeitos fatais e genéticos graves à saúde $\mathrm{V}_{1}$ é o valor da vida

O valor pré-determinado da vida foi obtido por meio de um levantamento bibliográfico na literatura e, também, pelo auxílio do CEPN que contemplou primordialmente a metodologia humana, ainda que os estudos examinados não contemplem os riscos atribuídos à radiação. Dessa maneira, não foi considerada a fase inicial latente do detrimento induzido pela radiação e nem a origem do risco.

A segunda componente $\alpha_{2}$ considera a incidência da enfermidade. Esta foi calculada a partir do custo para o tratamento dos cânceres e de um fator de risco para a indução do câncer de $2,5 \times 10^{-2} \mathrm{~Sv}^{-1}$, e de um fator de $1,3 \times 10^{-2}$ para cânceres não fatais, supondo um período de tratamento de 3 meses e a correspondente perda de produção baseada no PIB, assim:

$$
\alpha_{2}=\left(2,5 \times 10^{-2} \times \text { custo médio do câncer }\right)+\left(1,3 \times 10^{-2} \times 0,25 \times P I B_{\text {per capita }}\right)
$$

$\mathrm{O} \alpha_{\text {total }}$ é a soma destas duas componentes, $\alpha_{1}$ e $\alpha_{2}$. 


\section{6 - Valores de alfa em função da dose equivalente individual}

Recentemente, uma publicação do $\operatorname{OIEA}^{(25)}$, mostrou que em desobediência às recomendações internacionais de manter um único valor de alfa para cada país, algumas entidades, em vários países, adotaram diferentes valores alfa para diferentes doses individuais máximas, eliminando, desta maneira, o critério dos valores beta. Aqui transcrevemos a tabela mostrada na publicação da OIEA.

TABELA 2.3 - Valor monetário do Sv-pessoa aplicado por diferentes entidades

\begin{tabular}{|c|c|c|c|}
\hline País & Entidade & $\begin{array}{l}\text { Ano de } \\
\text { adoção }\end{array}$ & $\begin{array}{c}\text { Valor monetário do Sv-pessoa } \\
\text { em dólares americanos }\end{array}$ \\
\hline \multirow[t]{5}{*}{ Alemanha } & Proposta da VGB & 1996 & $<1 \mathrm{mSv}$ : valor nulo \\
\hline & & & 1-10mSv: 170000 \\
\hline & & & $10-20 \mathrm{mSv}:$ valor cresce \\
\hline & & & linearmente até o limite de 1695 \\
\hline & & & 000 equivalente a $20 \mathrm{mSv}$ \\
\hline \multirow[t]{6}{*}{ Bélgica } & SCK-CEN & 1995 & $<1 \mathrm{mSv}: 27000$ \\
\hline & & & 1-2mSv: 67000 \\
\hline & & & 2-5mSv: 267000 \\
\hline & & & 5-10mSv: 667000 \\
\hline & & & $10-20 \mathrm{mSv}: 1333000$ \\
\hline & & & 20-50 mSv : 5333000 \\
\hline \multirow[t]{4}{*}{ Canadá } & Darlington: sistema & - & Até 1500000 \\
\hline & dependente da & & Exemplo: trabalhadores em geral: \\
\hline & categoria dos & & 150 000, equipes de manutenção \\
\hline & trabalhadores & & em reatores: 1130000 \\
\hline
\end{tabular}

continua 


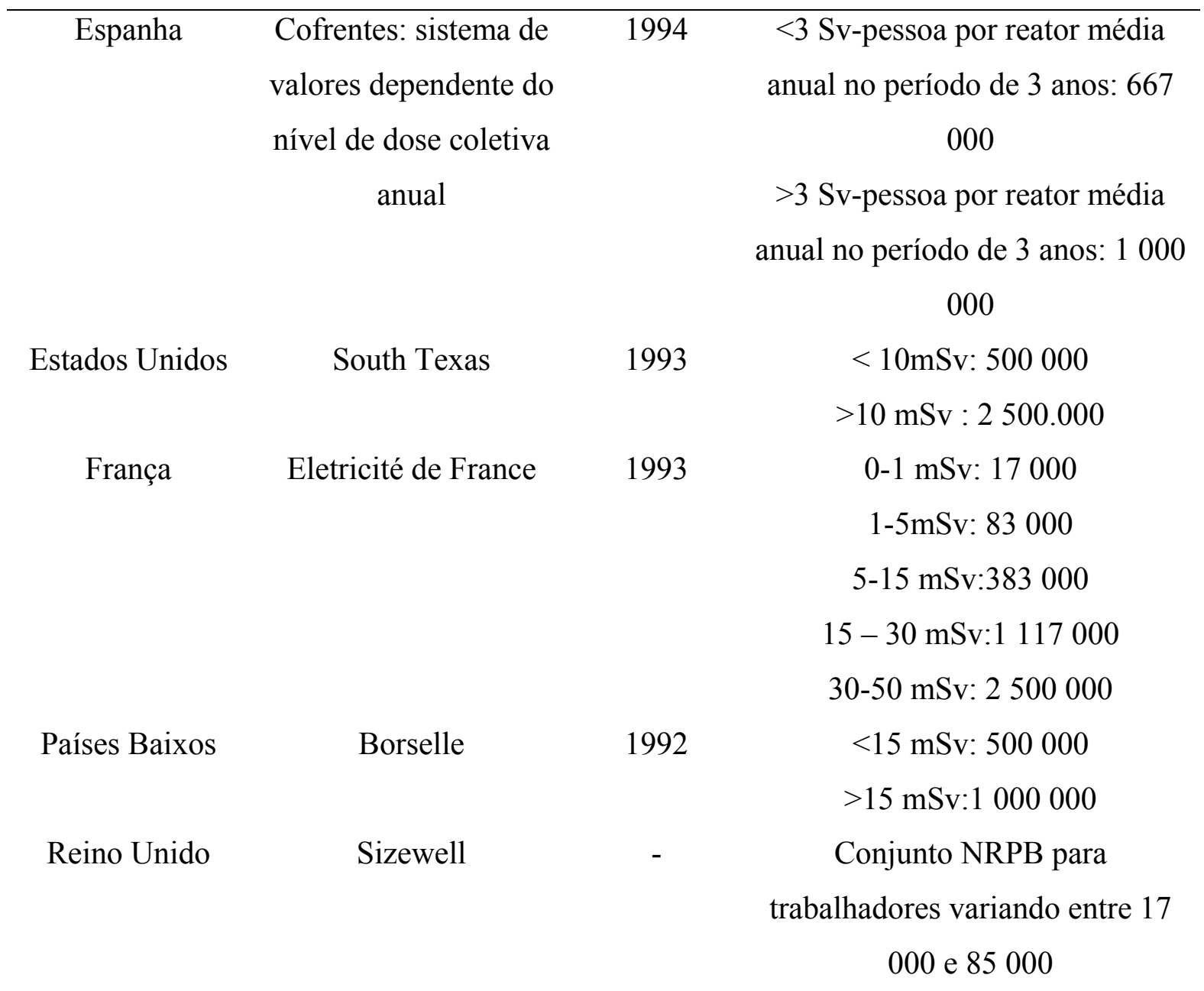

Nota: SCK-CEN: Studiecentrum voor Kernenergie/Centre d'étude de l'énergie nucléaire.

VGB:Technische Vereinigung der Grosskraftwerkbetreiber. NRPB National Radiological Protection Board 


\section{CAPÍTULO 3}

\section{O EXEMPLO DA MINA DE URÂNIO}

A CIPR em sua publicação de número $55^{(4)}$ utiliza, como exemplo, o projeto de um sistema de ventilação para proteger trabalhadores numa pequena mina de urânio. Os fatores considerados são o custo de proteção anual, a dose coletiva ocupacional anual originada pela radiação gama externa e pela inalação de partículas de urânio e filhos do radônio, a distribuição de dose individual e o desconforto associado com a alta taxa de ventilação nas galerias ou locais de permanência. O caso básico, ou opção zero, foi eliminado em função de um grupo de trabalhadores exceder o limite de dose. Foram consideradas cinco opções de radioproteção compostas de dezessete mineiros distribuídos em três grupos, de acordo com o seu grau de ocupação nas várias zonas da mina. $\mathrm{O}$ primeiro e o segundo grupo são compostos de quatro mineiros cada e o terceiro grupo é composto de nove mineiros. Na tabela 3.1 são mostradas as doses individuais médias e as doses coletivas para cada opção.

TABELA 3.1 - Dados para as opções consideradas no exemplo da mina de urânio

\begin{tabular}{ccccccc}
\hline Opção & $\mathbf{0}$ & $\mathbf{1}$ & $\mathbf{2}$ & $\mathbf{3}$ & $\mathbf{4}$ & $\mathbf{5}$ \\
\hline Dose Coletiva S (Sv-pessoa) & 0,686 & 0,561 & 0,357 & 0,335 & 0,196 & 0,178 \\
\hline Dose Individual Média $\overline{\mathbf{H}}$ (mSva $^{-\mathbf{1}}$ ) & & & & & & \\
\hline Grupo I - (4 trabalhadores) & 55,2 & 40,8 & 28,4 & 26,0 & 17,5 & 15,8 \\
Grupo II - (4 trabalhadores) & 41,8 & 34,5 & 22,3 & 21,0 & 12,6 & 11,3 \\
Grupo III - (9 trabalhadores) & 33,1 & 28,9 & 17,1 & 16,3 & 8,4 & 7,8 \\
\hline
\end{tabular}

Os custos de proteção anuais associados a cada opção são apresentados na tabela 3.2. 
TABELA 3.2 - Custo de proteção Anual das opções

\begin{tabular}{cc}
\hline Opção & X (US\$) \\
\hline 1 & $10.400,00$ \\
2 & $17.200,00$ \\
3 & $18.500,00$ \\
4 & $32.200,00$ \\
5 & $35.500,00$ \\
\hline
\end{tabular}

\section{1 - Análise Custo-Eficácia}

Como cada opção tem um valor de custo de proteção e conseqüentemente de dose coletiva, o conjunto das opções é visto como um conjunto de pontos, sendo que tais pontos são ligados de forma linear, conforme pode ser visto na figura 3.1.

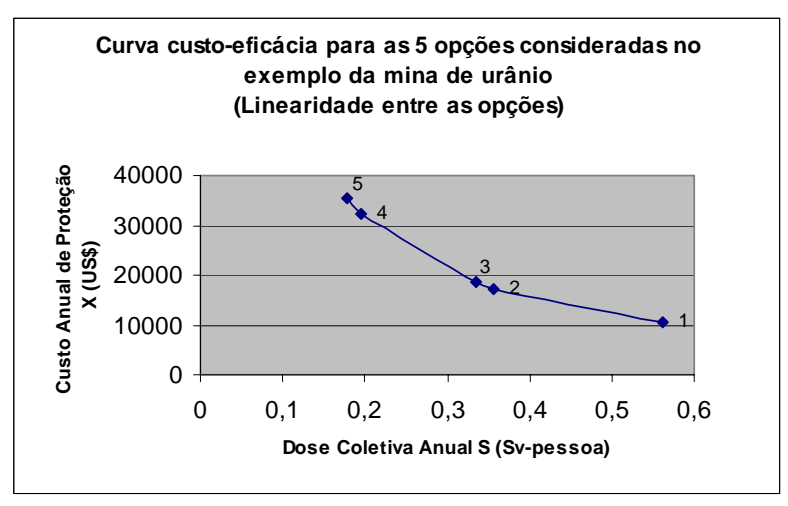

Fonte: ICRP-55 Figura 6

FIGURA 3.1 - Curva custo eficácia conforme CIPR publicação de número $55^{(4)}$

Uma primeira análise é feita utilizando a técnica de custo-eficácia, técnica que tem por objetivo analisar a razão das variações nos custos e nas doses coletivas quando passamos de uma opção para a próxima opção. Desta maneira, o aumento do custo para ir de uma opção para a seguinte é $\Delta \mathrm{X}$, a correspondente diminuição na dose coletiva é $\Delta \mathrm{S}$, e o quociente $\Delta \mathrm{X} / \Delta \mathrm{S}$ é chamado de razão custo-eficácia. De acordo com a CIPR, neste exemplo e em muitos outros casos, a razão custo-eficácia cresce progressivamente quando as opções mudam de 1 a 5 e nem a tendência e nem a razão fornecem uma base para determinar a opção ótima. A análise realizada pela Comissão é mostrada na tabela 3.3. 
TABELA 3.3 - Dados para as opções considerando o exemplo da mina

\begin{tabular}{cccccc}
\hline Opção & S (Sv-pessoa) & $X(\mathrm{US} \$)$ & $\begin{array}{c}\Delta \mathrm{X} \\
\left(X_{i}-X_{(i-1)}\right)\end{array}$ & $\begin{array}{c}\Delta \mathrm{S} \\
\left(S_{(i-1)}-S_{i}\right)\end{array}$ & $\begin{array}{c}\Delta \mathrm{X} / \Delta \mathrm{S} \\
\text { US\$ (Sv-pessoa })^{-1}\end{array}$ \\
\hline 1 & 0,561 & $10.400,00$ & & & \\
2 & 0,357 & $17.200,00$ & $6.800,00$ & 0,204 & $33.333,33$ \\
3 & 0,335 & $18.500,00$ & $1.300,00$ & 0,022 & $59.090,91$ \\
4 & 0,196 & $32.200,00$ & $13.700,00$ & 0,139 & $98.561,15$ \\
5 & 0,178 & $35.500,00$ & $3.300,00$ & 0,018 & $183.333,33$ \\
\hline
\end{tabular}

Fonte: CIPR-55 Tabela 2

\section{2 - Análise Custo-Benefício Integral}

Nesta análise, foram considerados os custos de proteção anual, mostrados na tabela 3.2 e o custo do detrimento Y, que é o produto da dose coletiva de cada opção pelo valor alfa, onde $\alpha=20.000,00$ US\$ (Sv-pessoa) $)^{-1}$. A solução ótima será a que apresentar $(X+Y)_{\min }$.

Nas tabela 3.4 e figura 3.2, são apresentados os resultados encontrados na publicação CIPR número $55^{(4)}$.

TABELA 3.4 - Resultados da Análise custo benefício, de acordo com a CIPR número $55^{(4)}$

\begin{tabular}{ccccc}
\hline Opção & $\begin{array}{c}\mathrm{S} \\
(\text { Sv-pessoa })\end{array}$ & $\begin{array}{c}\mathrm{X} \\
(\mathrm{US} \$)\end{array}$ & $\begin{array}{c}\mathrm{Y} \\
(\mathrm{US} \$)\end{array}$ & $\begin{array}{c}\mathrm{X}+\mathrm{Y} \\
(\mathrm{US} \$)\end{array}$ \\
\hline 1 & 0,561 & $10.400,00$ & $11.220,00$ & $\underline{\mathbf{2 1 . 6 2 0 , 0 0}}$ \\
2 & 0,357 & $17.200,00$ & $7.140,00$ & $24.340,00$ \\
3 & 0,335 & $18.500,00$ & $6.700,00$ & $25.200,00$ \\
4 & 0,196 & $32.200,00$ & $3.920,00$ & $36.120,00$ \\
5 & 0,178 & $35.500,00$ & $3.560,00$ & $39.060,00$
\end{tabular}

Fonte: ICRP-55 Tabela 3

A solução analítica é a opção de número 1em negrito e sublinhado na tabela. 


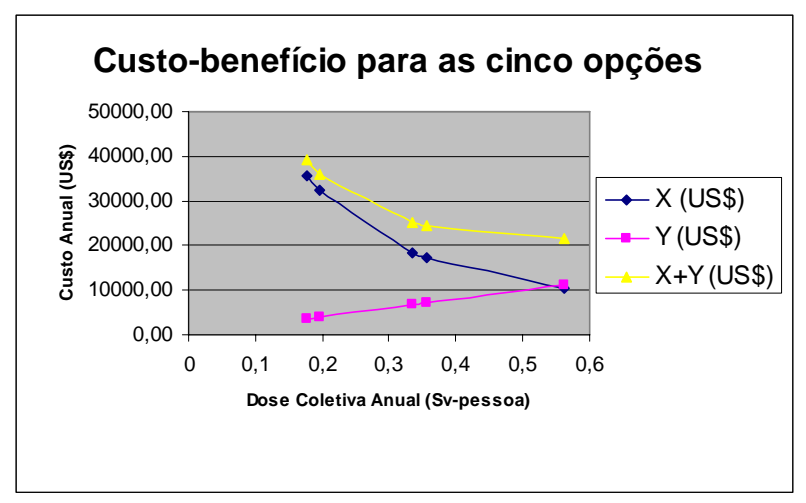

Fonte: ICRP-55 Figura 7

FIGURA 3.2- Segmentos de retas unindo as opções consideradas no exemplo da mina de urânio

\section{3 - Análise Custo-Benefício Expandida}

A técnica de análise custo-benefício é estritamente limitada a comparações quantitativas entre os custos de proteção e a dose coletiva. A fim de incluir outros fatores importantes na técnica analítica é possível estender a delimitação do quadro inicial da análise custo-benefício para aquela expandida.

Considerando que a otimização da proteção radiológica pretende abaixar as doses individuais até alcançar a região aceitável, como foi descrito na seção 1.1, a distribuição da dose individual torna-se um atributo importante e, portanto ele será considerado nesta análise.

Para incorporar este atributo, a ICRP número $55^{(4)}$ usou a análise custobenefício expandida modificando o valor monetário dado à dose coletiva unitária. Ao valor básico foram acrescentados outros termos para a avaliação do custo do detrimento. Valores diferentes foram dados à dose coletiva unitária dependendo dos valores das doses individuais envolvidas. 
Esta nova componente no custo do detrimento pode ser expressa por mais um termo introduzido pela CIPR ${ }^{(5)}$ e mais tarde definida numa forma simplificada na ICRP $42^{(14)}$, já apresentada na seção 2.3 , como:

$$
Y=\alpha S+\sum_{j} \beta_{j} S_{j}
$$

onde:

- $\mathrm{S}_{\mathrm{j}}$ - é a dose coletiva originada de uma dose per caput $\mathrm{H}_{\mathrm{j}}$ liberada em $\mathrm{N}_{\mathrm{j}}$ indivíduos do $\mathrm{j}$ ésimo grupo

$-\beta_{\mathrm{j}}$ - é o valor monetário adicional, atribuído pelo "tomador de decisão",dado à dose coletiva unitária no grupo j-ésimo.

De acordo com o exemplo envolvendo a mina de urânio a CIPR ${ }^{(4)}$, adotou os seguintes valores adicionais para o fator de distribuição de doses individuais:

$$
\begin{array}{lrrr}
\alpha & =\mathrm{US} \$ 20.000 & (\mathrm{~Sv}-\text { pessoa })^{-1} \\
\beta_{1}(\quad<5 \mathrm{mSv})=\mathrm{US} \$ & 0 & (\mathrm{~Sv} \text {-pessoa })^{-1} \\
\beta_{2}(5-15 \mathrm{mSv})=\mathrm{US} \$ 40.000 & (\mathrm{~Sv} \text {-pessoa })^{-1} \\
\beta_{3}(15-50 \mathrm{mSv})=\mathrm{US} \$ 80.000 & (\mathrm{~Sv} \text {-pessoa })^{-1}
\end{array}
$$

O custo do detrimento Y, é então a soma do termo levando em conta a dose coletiva total e aqueles levando em consideração a distribuição da dose individual. A tabela com os resultados e o gráfico apresentados pela CIPR ${ }^{(4)}$, são mostrados na tabela 3.5 e figura 3.3 . 
TABELA 3.5 - Dados das opções consideradas no exemplo da mina de urânio e sua solução

\begin{tabular}{cccccc}
\hline & & & $\mathrm{Y}$ & $\mathrm{Y}$ & \\
Opção & S (Sv-pessoa) & X (US\$) & $\begin{array}{c}\text { Termo } \alpha S \\
\text { (US\$) }\end{array}$ & $\begin{array}{c}\text { Termo } \Sigma \beta S \\
(\mathrm{US} \$)\end{array}$ & $\mathrm{X}+\mathrm{Y}$ (US\$) \\
\hline 1 & 0,561 & $10.400,00$ & $11.200,00$ & $44.900,00$ & $66.000,00$ \\
2 & 0,357 & $17.200,00$ & $7.100,00$ & $28.600,00$ & $53.000,00$ \\
3 & 0,335 & $18.500,00$ & $6.700,00$ & $26.800,00$ & $52.000,00$ \\
4 & 0,196 & $32.200,00$ & $3.900,00$ & $10.700,00$ & $\underline{\mathbf{4 7 . 0 0 0 , 0 0}}$ \\
5 & 0,178 & $35.500,00$ & $3.600,00$ & $9.600,00$ & $49.000,00$ \\
\hline
\end{tabular}

A solução analítica é a opção de número 4 em negrito e sublinhada na tabela.

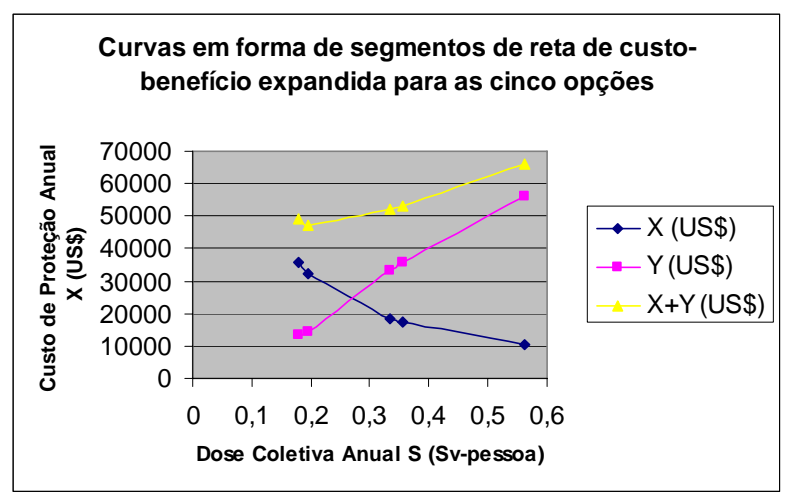

FIGURA 3.3 - Curvas em forma de segmentos de reta das opções consideradas no exemplo da mina de urânio 


\section{CAPÍTULO 4}

\section{DESENVOLVIMENTO INICIAL DO TRABALHO}

$\mathrm{Na}$ CIPR publicação número $55^{(4)}$ o custo de proteção anual é visto como um conjunto de pontos, onde cada ponto corresponde a uma opção, sendo tais pontos ligados de forma linear. Isto fica evidente quando a CIPR $55^{(4)}$ apresenta o gráfico do custo de proteção anual em função da dose coletiva anual e une as cinco opções do exemplo da mina por segmentos de retas, conforme mostrado na figura 3.1 .

É bom lembrar que as opções de proteção radiológica disponíveis são geralmente discretas porém, existem situações, como por exemplo os cálculos de blindagens, em que o conjunto das opções disponíveis pode constituir uma função contínua.

O exemplo da pequena mina, cujo gráfico pode ser visto na figura 3.1, considera as opções mostradas na tabela 4.1 .

TABELA 4.1 - Dados para as opções considerando o exemplo da mina

\begin{tabular}{c|c|c|c|c|c}
\hline Opção & S (Sv-pessoa) & $\mathrm{X}(\mathrm{US} \$)$ & $\begin{array}{c}\Delta \mathrm{X} \\
\left(X_{i}-X_{(i-1)}\right)\end{array}$ & $\begin{array}{c}\Delta \mathrm{S} \\
\left(S_{(i-1)}-S_{i}\right)\end{array}$ & $\begin{array}{c}\Delta \mathrm{X} / \Delta \mathrm{S} \\
\mathrm{US} \$(\text { Sv-pessoa) })^{-1}\end{array}$ \\
\hline 1 & 0,561 & $10.400,00$ & & & \\
2 & 0,357 & $17.200,00$ & $6.800,00$ & 0,204 & $33.333,33$ \\
3 & 0,335 & $18.500,00$ & $1.300,00$ & 0,022 & $59.090,91$ \\
4 & 0,196 & $32.200,00$ & $13.700,00$ & 0,139 & $98.561,15$ \\
5 & 0,178 & $35.500,00$ & $3.300,00$ & 0,018 & $183.333,33$ \\
\hline
\end{tabular}

Fonte: CIPR-55 Tabela 2 
Observa-se que $\Delta \mathrm{X} / \Delta \mathrm{S}$ é expresso por US\$/Sv-pessoa, ou seja, é interpretado como o custo para reduzir a dose coletiva no intervalo, ou ainda, se a função fosse contínua, seria o coeficiente de variação da função em um dado ponto, dentro do intervalo no qual o ponto está inserido.

\section{1 - Estudo de sensibilidade para o critério do valor alfa}

É razoável supor que possa não haver uma relação de linearidade entre as opções de proteção disponíveis. Com este raciocínio, utilizando o mesmo exemplo usado pela CIPR envolvendo a mina de urânio, foi construída a função matemática que melhor se ajusta aos custos das opções de proteção radiológica em função de suas doses coletivas, isto é, $X=f(S)$. A determinação do valor alfa de cada opção foi obtida pela derivada no ponto correspondente a cada opção, o que corresponde à equação diferencial da otimização, equação (2.4).

Desta maneira determinou-se, em primeira instância, a função:

$$
X=f(S)
$$

para, em seguida, derivá-la em cada ponto que define cada opção de proteção radiológica,

$$
-\frac{d X}{d S}=f^{\prime}(S)
$$

e determinar os seus valores em $x_{1}, \ldots ., x_{n}$, que representam as diferentes opções. Utilizando o programa Microsoft Excel, para o exemplo da mina, ensaiamos as seguintes funções: linear, polinomial, logarítmica, exponencial e potencial. Os gráficos, suas fórmulas e o respectivo coeficiente de determinação $\mathrm{R}^{2(26)}$, que representa a proporção da variação de $\mathrm{X}$ explicada pela variação de $\mathrm{S}$, podem ser visualizados nas figuras de 4.2 a 4.6. 


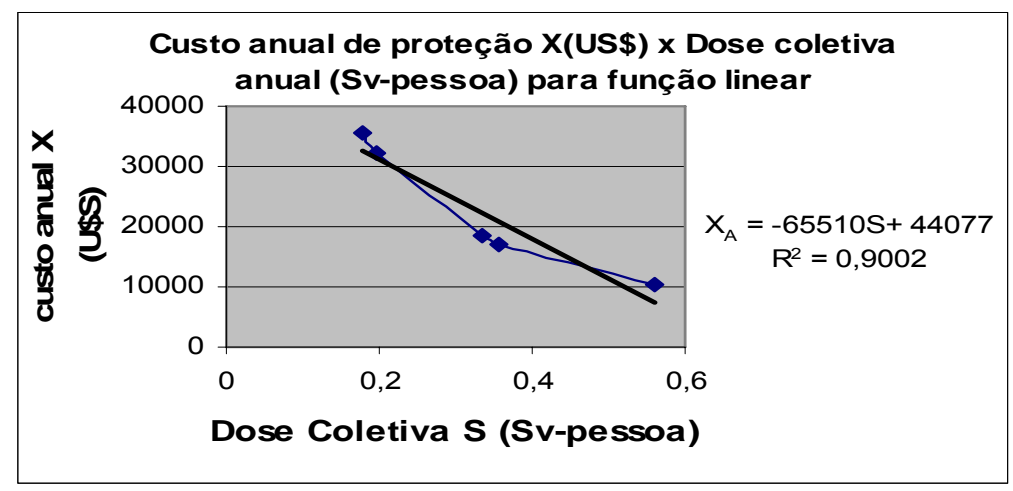

FIGURA 4.1 - Aproximação dos pontos para a função linear

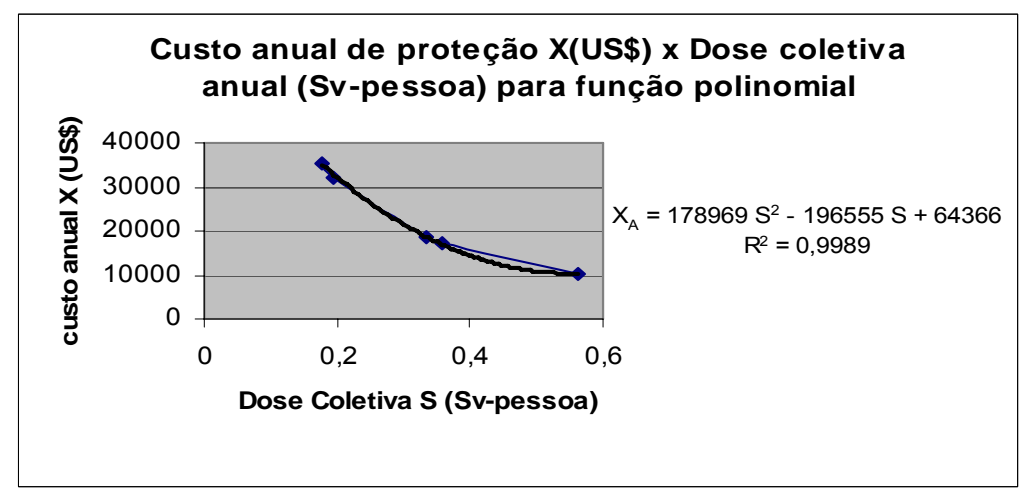

FIGURA 4.2 - Aproximação dos pontos para a função polinomial

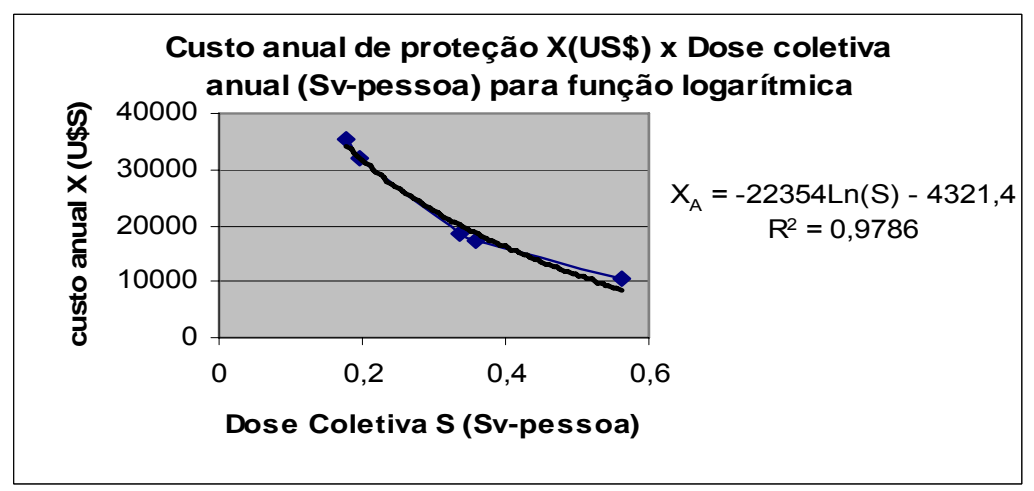

FIGURA 4. 3 - Aproximação dos pontos para a função logarítmica 


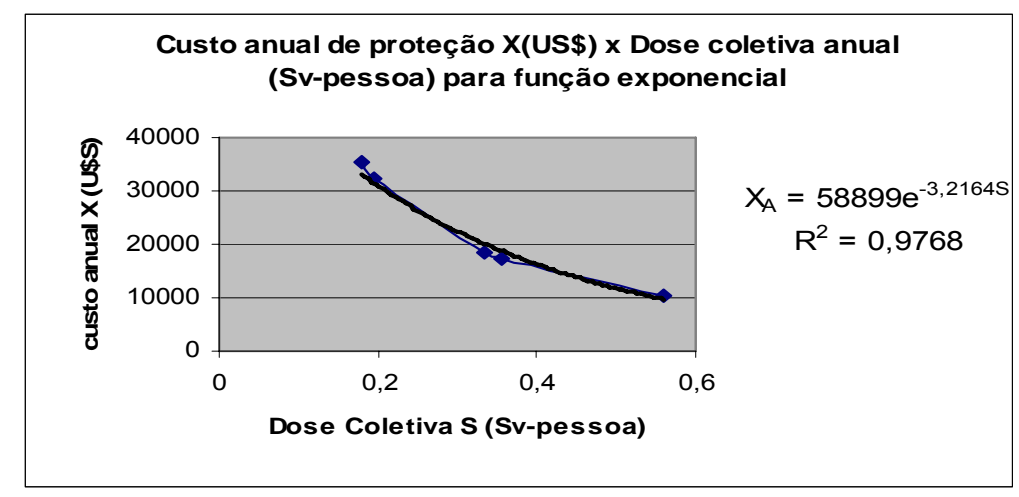

FIGURA 4.4 - Aproximação dos pontos para a função exponencial

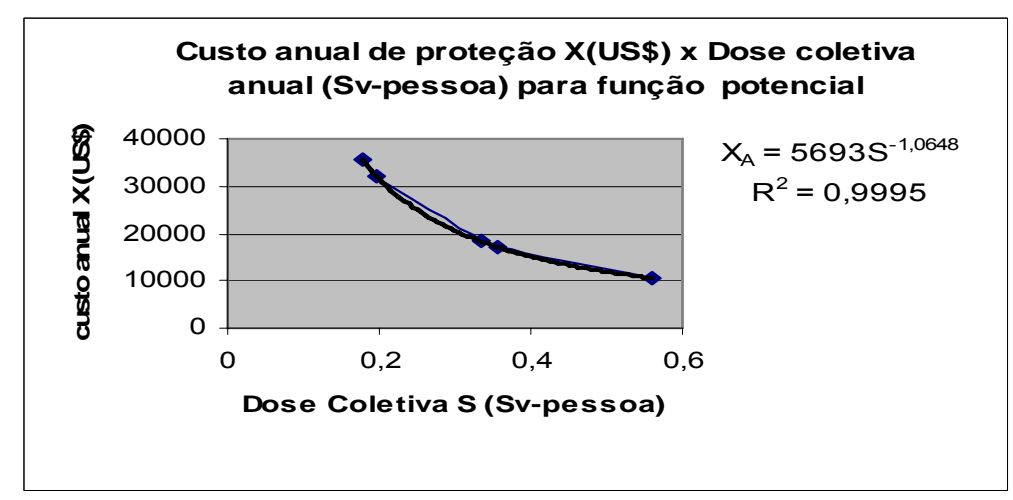

FIGURA 4.5 - Aproximação dos pontos para a função potencial

Observamos que a função que melhor se ajusta aos pontos é a função Potencial, portanto assumimos que a função custo anual de proteção $\left(\mathrm{X}_{\mathrm{A}}\right)$ será uma Potência cuja fórmula é dada por:

$$
X_{A}=5693 S^{-1,0648}
$$

onde,

$\mathrm{X}_{\mathrm{A}}=$ Custo Anual de Proteção, em US\$;

$\mathrm{S}=$ Dose Coletiva Anual, em Sv-Pessoa. 
Então, a derivada da função custo de proteção anual $-\frac{d X_{A}}{d S}$ é dada por:

$$
-\frac{d X_{A}}{d S}=6061,9064 S^{-2,0648}
$$

A tabela 4.2 apresenta os valores do custo das opções fornecidos pela CIPR, os valores do custo das opções ajustadas pela função potencial $\mathrm{X}_{\mathrm{A}}$ e da derivada da função $-\frac{d X_{A}}{d S}$ nas opções disponíveis.

TABELA 4.2 - Valores do custo das opções para a função potência $\mathrm{X}_{\mathrm{A}} \mathrm{e}$ da derivada da função $-\frac{d X_{A}}{d S}$ nas opções disponíveis

\begin{tabular}{ccccc}
\hline Opção & S (Sv-pessoa) & $\mathrm{X}(\mathrm{US} \$)$ & $\mathrm{X}_{\mathrm{A}}$ (US\$) & $\begin{array}{c}-\frac{d X_{A}}{d S} \\
\mathrm{US} \$(\text { Sv-pessoa) }\end{array}$ \\
\hline 1 & 0,561 & $10.400,00$ & $10.535,27$ & $\mathbf{1 9 . 9 9 6 , 3 5}$ \\
2 & 0,357 & $17.200,00$ & $17.047,48$ & $\mathbf{5 0 . 8 4 6 , 3 6}$ \\
3 & 0,335 & $18.500,00$ & $18.242,04$ & $\mathbf{5 7 . 9 8 2 , 4 7}$ \\
4 & 0,196 & $32.200,00$ & $32.281,00$ & $\mathbf{1 7 5 . 3 7 1 , 4 5}$ \\
5 & 0,178 & $35.500,00$ & $35.767,94$ & $\mathbf{2 1 3 . 9 6 4 , 6 4}$ \\
\hline
\end{tabular}

Sordi ${ }^{(27)}$, assumindo uma linearidade entre as opções, determinou, no estudo de sensibilidade do valor alfa, os intervalos em que cada opção de proteção radiológica, no exemplo da mina, se manteria ótima. Os valores por ele encontrados estão na segunda coluna da tabela 4.3. Nesta tabela, é possível observar que, para valores de alfa menores do que US\$ 33.333,33, prevalece a opção 1 com sendo ótima. Se tomarmos o segmento de reta que une as opções 1 e 2, teremos a equação $X=-33.333,33 S+29.099,99$ e, portanto, 
a derivada desta função será $-\frac{d X}{d S}=33.333,33$, ou seja, para qualquer valor de $\mathrm{S}$ entre as opções 1 e 2 assume-se que o valor de alfa será o mesmo. Por outro lado, apenas a título de comparação, criamos intervalos assumindo a derivada da função $\mathrm{X}_{\mathrm{A}}$, considerando, como um critério de análise, o ponto médio das doses entre as opções como sendo o ponto onde se justificaria passar de uma opção para outra, conforme pode ser observado na terceira coluna da tabela 4.3. Nota-se, neste caso, que a adoção do ponto médio entre as opções, fornece resultados muito próximos aos encontrados pelos segmentos de reta.

Todavia, quando usamos a derivada $-\frac{d X_{A}}{d S}$, temos condições de calcular a variação do custo em função da dose coletiva nos diferentes pontos e, assim, não teríamos mais a necessidade de trabalhar com intervalos, sendo suficiente calcularmos a derivada em qualquer ponto de interesse. Os valores encontrados para cada opção, calculados pela derivada, estão representados na quarta coluna da tabela 4.3. Ver também tabela 4.2 última coluna.

TABELA 4.3 - Comparação entre os intervalos obtidos para o problema da mina, pela técnica de segmentos de reta, pela curva ajustada e valor da derivada da função potencial em cada opção.

\begin{tabular}{cccc}
\hline & Segmentos de retas dos & Pontos médios dos & Ponto da opção \\
Opção & intervalos & intervalos & \\
& US $/($ Sv-pessoa $)$ & $-\frac{d X_{A}}{d S}$ & $-\frac{d X_{A}}{d S}$ \\
& & $\mathrm{US} \$ /($ Sv-pessoa $)$ & $\mathrm{US} \$ /(\mathrm{Sv}$-pessoa $)$ \\
\hline 1 & $\alpha \leq 33.333,33$ & $\alpha \leq 30.262,05$ & $\mathbf{1 9 . 9 9 6 , 3 5}$ \\
2 & $33.333,33<\alpha \leq 59.090,91$ & $30.262,05<\alpha \leq 54.240,65$ & $\mathbf{5 0 . 8 4 6 , 3 6}$ \\
3 & $59.090,91<\alpha \leq 98.561,15$ & $54.240,65<\alpha \leq 93.713,20$ & $\mathbf{5 7 . 9 8 2 , 4 7}$ \\
4 & $98.561,15<\alpha \leq 183.333,3$ & $93.713,20<\alpha \leq 193.246,07$ & $\mathbf{1 7 5 . 3 7 1 , 4 5}$ \\
5 & $\alpha>183.333,33$ & $\alpha>193.246,07$ & $\mathbf{2 1 3 . 9 6 4 , 6 4}$ \\
\hline
\end{tabular}




\section{2 - As análises custo-benefício e custo-benefício expandida utilizando a função potencial $\mathbf{X}_{\mathbf{A}}$}

As técnicas mais simples de ajuda para a tomada de decisão recomendadas pela $\mathrm{CIPR}^{(4)}$ para a otimização da proteção radiológica são aquelas fornecidas pela análise custo-benefício, que podem ser resumidas pelas seguintes equações

$$
\begin{gathered}
\left|\frac{d X}{d S}\right| \leq \alpha \\
\mathrm{e} \\
\frac{d Y}{d S}=\alpha
\end{gathered}
$$

conhecidas como custo-benefício diferencial e as condições

$$
(X+Y)_{\min } \quad \text { ou } \quad(X+\alpha S)_{\min }
$$

conhecida como custo-benefício integral, pois $Y=\alpha S$ advém da integração da equação (4.6) do custo-benefício diferencial.

De conformidade com as recomendações de proteção radiológica da $\operatorname{CIPR}^{(1)}$ as doses individuais dos trabalhadores foram divididas em três regiões, a saber:

a) doses superiores aos limites anuais: valores inaceitáveis;

b) doses entre os limites anuais e 1/10 destes limites: valores toleráveis;

c) doses inferiores a 1/10 dos limites anuais: valores aceitáveis.

A otimização da proteção radiológica fazendo uso das técnicas de ajuda para a tomada de decisão é exigida na região tolerável e tem a intenção precípua de diminuir as 
doses até alcançar a região aceitável, conforme detalhado no item 1.1 Neste caso, a distribuição das doses individuais dos trabalhadores torna-se um atributo importante para avaliar o decréscimo de suas doses.

Partindo destes fatos, pensou-se, para o exemplo da pequena mina, introduzir a função potencial discutida no item 4.1 tanto na análise custo-benefício integral como na análise custo-benefício expandida que acrescenta o atributo distribuição das doses individuais, e mostrar os resultados fazendo uso das derivadas.

Na tabelas 3.4 e 4.4 são apresentados os resultados obtidos pela CIPR e utilizando a função potencial para a técnica de análise custo benefício.

TABELA 4.4 - Dados das opções consideradas no exemplo da mina de urânio e sua solução conforme publicação $\operatorname{CIPR}^{(4)}$ e utilizando a curva potencial ajustada $\left(\mathrm{X}_{\mathrm{A}}\right)$ para técnica de análise custo benefício

\begin{tabular}{ccccccc}
\hline Opção & $\begin{array}{c}\mathrm{S} \\
\text { (Sv-pessoa) }\end{array}$ & $\begin{array}{c}\mathrm{X}_{\mathrm{A}} \\
(\mathrm{US} \$)\end{array}$ & $\begin{array}{c}\mathrm{X} \\
(\mathrm{US} \$)\end{array}$ & $\begin{array}{c}\mathrm{Y} \\
(\mathrm{US} \$)\end{array}$ & $\begin{array}{c}\mathrm{X}_{\mathrm{A}}+\mathrm{Y} \\
(\mathrm{US} \$)\end{array}$ & $\begin{array}{c}\mathrm{X}+\mathrm{Y} \\
(\mathrm{US} \$)\end{array}$ \\
\hline 1 & 0,561 & $10.535,27$ & $10.400,00$ & $11.220,00$ & $\underline{\mathbf{2 1 . 7 5 5 , 2 7}}$ & $\underline{\mathbf{2 1 . 6 2 0 , 0 0}}$ \\
2 & 0,357 & $17.047,48$ & $17.200,00$ & $7.140,00$ & $24.187,48$ & $24.340,00$ \\
3 & 0,335 & $18.242,04$ & $18.500,00$ & $6.700,00$ & $24.942,04$ & $25.200,00$ \\
4 & 0,196 & $32.281,00$ & $32.200,00$ & $3.920,00$ & $36.201,00$ & $36.120,00$ \\
5 & 0,178 & $35.767,94$ & $35.500,00$ & $3.560,00$ & $39.327,94$ & $39.060,00$ \\
\hline
\end{tabular}

A solução analítica é a opção de número 1 em negrito e sublinhada em ambas as situações.

Na tabela 4.5 são apresentados os resultados obtidos pela CIPR para a técnica de análise custo benefício expandida, e os resultados obtidos com a curva de custo de proteção anual $\left(\mathrm{X}_{\mathrm{A}}\right)$ ajustada para uma função potencial. 
TABELA 4.5 Dados das opções consideradas no exemplo da mina de urânio utilizando a curva ajustada $\left(\mathrm{X}_{\mathrm{A}}\right)$ e, conforme publicação da $\mathrm{CIPR}^{(4)}$ para técnica de análise custo benefício expandida

\begin{tabular}{|c|c|c|c|c|c|c|c|}
\hline Opção & $\begin{array}{c}\text { S } \\
\text { (Sv-pessoa) }\end{array}$ & $\begin{array}{c}\mathrm{X}_{\mathrm{A}} \\
\text { (US\$) }\end{array}$ & $\begin{array}{c}\mathrm{X} \\
\text { (US\$) }\end{array}$ & $\begin{array}{c}\mathrm{Y} \\
\text { Termo } \alpha \mathrm{S} \\
\text { (US\$) }\end{array}$ & $\begin{array}{c}\mathrm{Y} \\
\text { Termo } \\
\Sigma \beta S \\
\text { (US\$) }\end{array}$ & $\begin{array}{l}X+Y \\
(U S \$)\end{array}$ & $\begin{array}{l}X_{A}+Y \\
(U S \$)\end{array}$ \\
\hline 1 & 0,561 & $10.535,27$ & $10.400,00$ & $11.200,00$ & $44.900,00$ & $66.000,00$ & $66.635,27$ \\
\hline 2 & 0,357 & $17.047,48$ & $17.200,00$ & $7.100,00$ & $28.600,00$ & $53.000,00$ & $52.747,48$ \\
\hline 3 & 0,335 & $18.242,04$ & $18.500,00$ & $6.700,00$ & $26.800,00$ & $52.000,00$ & $51.742,04$ \\
\hline 4 & 0,196 & $32.281,00$ & $32.200,00$ & $3.900,00$ & $10.700,00$ & $\underline{47.000,00}$ & $\underline{47.610,00}$ \\
\hline 5 & 0,178 & $35.767,94$ & $35.500,00$ & $3.600,00$ & $9.600,00$ & $49.000,00$ & $48.967,94$ \\
\hline
\end{tabular}

Novamente como imaginávamos os resultados obtidos são iguais àqueles apresentados pela CIPR $^{(4)}$, ou seja, a opção 4 em negrito e sublinhada continua sendo a melhor.

\section{3 - A utilização de Derivadas na Otimização da Proteção Radiológica}

A derivada da função custo de proteção anual $-\frac{d X_{A}}{d S}$, é dada por:

$$
-\frac{d X_{A}}{d S}=6061,9064 S^{-2,0648}
$$

Por outro lado, pela equação (4.6), temos:

$$
\frac{d Y}{d S}=\alpha
$$


Sendo conhecido o valor de alfa, temos:

$$
\frac{d Y}{d S}=20.000,00 \text { US\$ } / \text { Sv-pessoa }
$$

para o exemplo da pequena mina.

Considerando como fatores pertinentes o custo de proteção anual e o custo do detrimento anual, conforme foi considerado na análise custo benefício, vemos, da tabela 4.6, que a solução analítica ótima continua sendo a opção 1, em negrito e sublinhada, que é a opção onde $\left|\frac{d X}{d S}\right| \leq \alpha$ da equação 4.5.

TABELA 4.6 - Dados das opções consideradas no exemplo da mina de urânio utilizando a curva ajustada $\left(\mathrm{X}_{\mathrm{A}}\right)$ e sua derivada

\begin{tabular}{cccc}
\hline & $\mathrm{S}$ & $\mathrm{X}_{\mathrm{A}}$ & $-\frac{d X_{A}}{d S}$ \\
Opção & $($ Sv-pessoa $)$ & $(\mathrm{US} \$)$ & $\mathrm{US} \$ /(\mathrm{Sv}$-pessoa) \\
\hline 1 & 0,561 & $10.535,27$ & $\underline{\mathbf{1 9 . 9 9 6 , 3 5}}$ \\
2 & 0,357 & $17.047,48$ & $50.846,36$ \\
3 & 0,335 & $18.242,04$ & $57.982,47$ \\
4 & 0,196 & $32.281,00$ & $175.371,45$ \\
5 & 0,178 & $35.767,94$ & $213.964,64$
\end{tabular}

A figura 4.6 mostra as derivadas $-\frac{d X_{A}}{d S} \quad e \frac{d Y}{d S}$ 


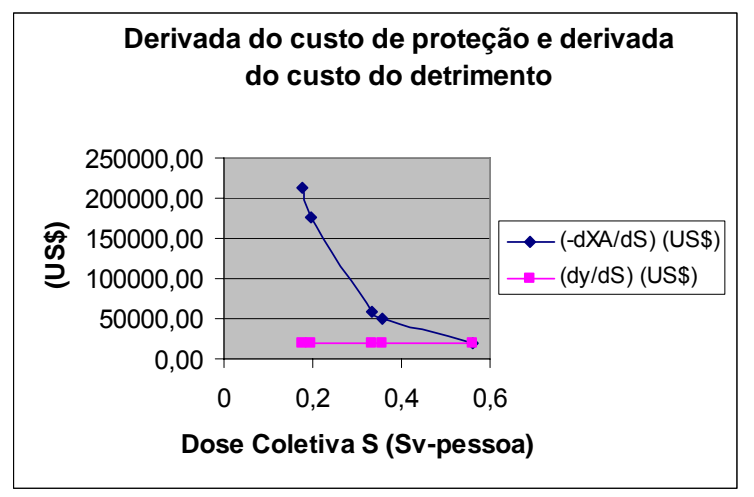

FIGURA 4.6 - Derivadas das funções custo de proteção e custo do detrimento

De acordo com o exemplo envolvendo a mina de urânio, a $\mathrm{CIPR}^{(4)}$ adotou, para a análise custo benefício expandida, os seguintes valores adicionais para o fator de distribuição de doses individuais:

$$
\begin{array}{lrll}
\alpha & =\mathrm{US} \$ 20.000 & (\mathrm{~Sv}-\text { pessoa })^{-1} \\
\beta_{1}(<5 \mathrm{mSv})=\mathrm{US} \$ & 0 & (\mathrm{~Sv} \text {-pessoa })^{-1} \\
\beta_{2}(5-15 \mathrm{mSv})=\mathrm{US} \$ 40.000 & (\mathrm{~Sv} \text {-pessoa })^{-1} \\
\beta_{3}(15-50 \mathrm{mSv})=\mathrm{US} \$ 80.000 & (\mathrm{~Sv} \text {-pessoa })^{-1}
\end{array}
$$

O custo do detrimento $\mathrm{Y}$, é então a soma do termo alfa levando em conta a dose coletiva, e os termos $\beta$, levando em consideração a distribuição da dose individual. Utilizando os mesmos fatores adicionais acima descritos, os dados das opções do exemplo da pequena mina apresentados na tabela 3.1 e fazendo uso da técnica das derivadas dos custos, obteremos os resultados apresentados na tabela 4.7. 
TABELA 4.7 - Dados das opções consideradas no exemplo da mina de urânio utilizando a análise das derivadas dos custos

\begin{tabular}{cccccc}
\hline & $\mathrm{S}$ & $\mathrm{X}_{\mathrm{A}}$ & $-\frac{d X_{A}}{d S}$ & $\frac{d Y}{d S}$ & $\frac{d Y}{d S}$ \\
Opção & $($ Sv-pessoa) & $(\mathrm{US} \$)$ & (US\$) & $(\mathrm{US \$})$ & (US\$) \\
\hline 1 & 0,561 & $10.535,27$ & $19.996,35$ & $60.000,00$ & $100.000,00$ \\
2 & 0,357 & $17.047,48$ & $50.846,36$ & $60.000,00$ & $100.000,00$ \\
3 & 0,335 & $18.242,04$ & $\underline{\mathbf{5 7 . 9 8 2 , 4 7}}$ & $60.000,00$ & $100.000,00$ \\
4 & 0,196 & $32.281,00$ & $175.371,45$ & $60.000,00$ & $100.000,00$ \\
5 & 0,178 & $35.767,94$ & $213.964,64$ & $60.000,00$ & $100.000,00$ \\
\hline
\end{tabular}

Observa-se que não foi apresentada $\frac{d Y}{d S}=20.000,00$ pois não existe nenhuma dose individual inferior a $5 \mathrm{mSv}$. A figura 4.7 mostra as derivadas $\frac{d X_{A}}{d S}, \frac{d Y}{d S}(60.000)$ e $\frac{d Y}{d S}(100.000)$.

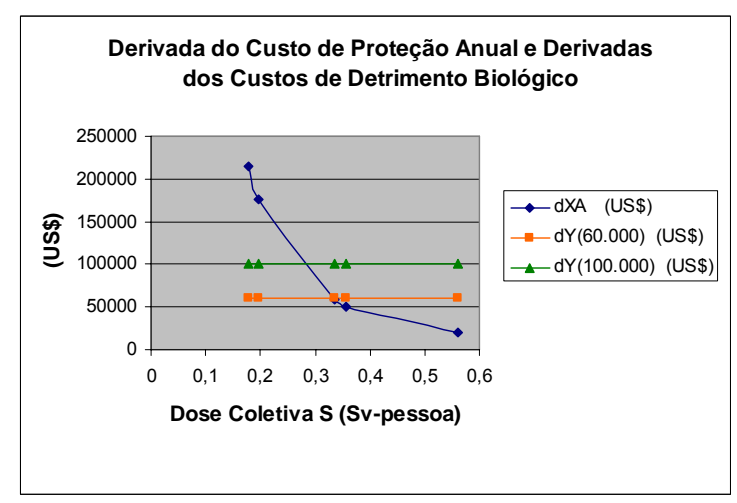

FIGURA 4.7 - Derivadas das funções custo de proteção e custo do detrimento

Considerando como fatores pertinentes o custo de proteção anual, o custo do detrimento anual e a distribuição das doses individuais, conforme foi considerado na 
análise custo benefício expandido, vemos, da tabela 4.7 que a solução analítica ótima, ou seja, o ponto onde $\left|\frac{d X}{d S}\right| \leq \alpha$ é a opção 3 , em negrito e sublinhada.

Observamos que a função, $\mathrm{Y}$, custo do detrimento, torna-se desnecessária quando atribuímos valores constantes para alfa e betas, pois suas derivadas são constantes. O que interessa então é a derivada de $\frac{d X}{d S}$ nos pontos, que junto com o valor atribuído a alfa e betas, fornecem a opção ótima.

Os resultados encontrados deixam claro que o fator predominante na escolha da opção é o valor atribuído ao alfa e aos betas e que, portanto, um único valor para alfa e betas, como é sugerido atualmente, talvez seja pouco eficaz para a otimização.

Outra questão importante é que o cálculo de $\alpha$, na maioria das vezes, pode estar atrelado ao PIB, podendo fornecer diferentes valores de alfa para cada país, embora o objetivo final, que é diminuição das doses até níveis admissíveis, seja o mesmo para qualquer lugar do planeta. Além disso, pode produzir dois fatos indesejáveis, a saber:

a) Os limites vinculados a cada prática ou categoria de trabalhadores assumem valores diferentes em cada país, em função do valor alfa adotado e, portanto a trajetória de decréscimo das doses individuais em função do tempo é diferente para cada um. Este fato pode produzir conflitos legais internacionais no intercâmbio de trabalhadores. Se um trabalhador de uma instituição for para outro país onde, durante o período de trabalho, o limite vinculado for superior ao do país de origem e este contrair um câncer, num litígio legal a primeira pergunta que surgirá será: por que se mandou um trabalhador para um país que não oferece as mesmas condições de segurança?

b) Com a definição de $\frac{d Y}{d S^{H, C}}=\alpha$, e sendo a probabilidade de morte por Sv, fornecida pela CIPR $^{(1)}$, todo mundo calcula o custo da vida humana contrariamente ao que é preconizado pela CIPR e OIEA.

A equação proposta neste trabalho, isto é $-\frac{d X}{d S^{H, C}}=\alpha\left(H_{\text {máx }}\right)$ evita ambos os problemas. 
É sabido que as técnicas Custo-Benefício são baseadas na dose coletiva e que, portanto, a distribuição individual das doses não é contemplada nestas análises. Porém, se de fato pretende-se otimizar as doses, até se alcançar a região aceitável, a distribuição da dose individual torna-se muito importante.

Com este raciocínio, idealizamos um conjunto de valores para o termo alfa que dependeriam da distribuição individual de doses. Para melhor exemplificar, serão usados os valores aditivos de alfa propostos pela técnica de análise custo-benefício expandida para o exemplo da mina. De acordo com a $\mathrm{CIPR}^{(4)}$, valores diferentes foram dados à dose coletiva unitária dependendo dos valores de dose individuais envolvidos. Conforme o exemplo da mina de urânio, foi adotado o seguinte critério adicional para o fator de distribuição de doses individuais:

$$
\begin{array}{llll}
\alpha & =\mathrm{US} \$ 20.000 & (\mathrm{~Sv}-\text { pessoa })^{-1} \\
\beta_{1}(<5 \mathrm{mSv})=\mathrm{US} \$ & 0 & (\mathrm{~Sv}-\text { pessoa })^{-1} \\
\beta_{2}(5-15 \mathrm{mSv})=\mathrm{US} \$ 40.000 & (\mathrm{~Sv} \text {-pessoa })^{-1} \\
\beta_{3}(15-50 \mathrm{mSv})=\mathrm{US} \$ 80.000 & (\mathrm{~Sv} \text {-pessoa })^{-1}
\end{array}
$$

Com base nos valores acima, poderíamos sugerir os valores para alfa mostrados na tabela 4.8 e na figura 4.8 .

TABELA 4.8 - Valores de $\alpha$ baseado no critério adicional para o fator de distribuição de doses individuais proposto na $\mathrm{CIPR}^{(4)}$

Intervalos para Doses Individuais Anuais Valor de $\alpha$

\begin{tabular}{cc}
$\mathbf{S v ~ a}^{\mathbf{- 1}}$ & US\$ (Sv-pessoa) $)^{-1}$ \\
\hline$H \leq 0,005$ & $20.000,00$ \\
$0,005<H \leq 0,015$ & $60.000,00$ \\
$0,015<H \leq 0,05$ & $100.000,00$ \\
\hline
\end{tabular}




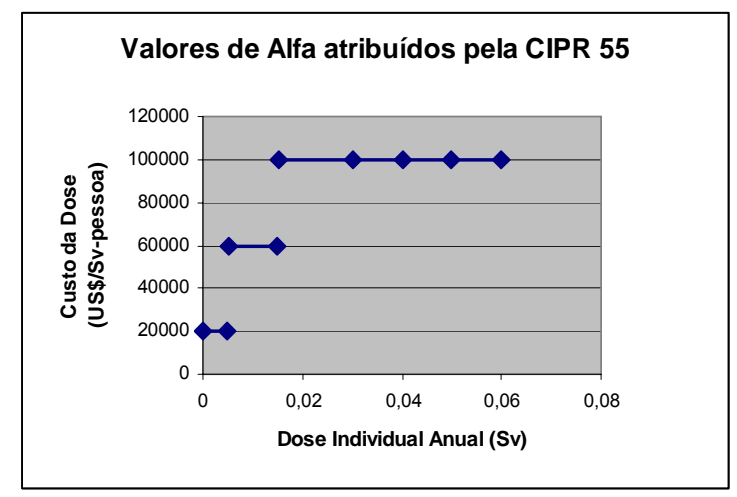

FIGURA 4.8 - Valores de $\alpha$ baseado no critério adicional para o fator de distribuição de doses individuais proposto na $\mathrm{CIPR}^{(4)}$

Como o enfoque agora não está na dose coletiva e sim no grupo ou no indivíduo que recebe as maiores doses, escolheremos o valor de alfa adequado para cada opção utilizando os dados da tabela 3.1, como mostrado na tabela 4.9.

TABELA 4.9 - Valores de $\alpha$ baseado no critério adicional para o fator de distribuição de doses individuais proposto na $\mathrm{CIPR}^{(4)}$ para cada opção.

Intervalos para Doses Individuais Anuais Valor de a Opção

\begin{tabular}{ccc}
$\mathbf{S v ~}^{\mathbf{- 1}}$ & $\mathbf{U S \$}(\mathbf{S v}-\mathbf{p e s s o a})^{\mathbf{- 1}}$ & \\
\hline$H \leq 0,005$ & $20.000,00$ & --- \\
$0,005<H \leq 0,015$ & $60.000,00$ & --- \\
$0,015<H \leq 0,05$ & $100.000,00$ & $1,2,3,4,5$ \\
\hline
\end{tabular}

Em virtude das maiores doses individuais, no exemplo da mina, em todas as opções, encontrarem-se acima de $0,015 \mathrm{~Sv} \mathrm{a}^{-1}$, o valor de alfa a ser usado é unicamente o de US\$ 100.000,00 Sv-pessoa a ${ }^{-1}$, conforme apresentado na tabela 4.10 e figura 4.9. Desta tabela vê-se que a opção 3 é a solução analítica. 
TABELA 4.10 - Dados das opções considerando os valores de $\alpha$ proposto na $\operatorname{CIPR}^{(4)}$

\begin{tabular}{ccccc}
\hline & & & $-\frac{d X_{A}}{d S}$ & $\alpha$ \\
Opção & (Sv-pessoa) & $(\mathrm{US} \$)$ & US\$(Sv-pessoa) $)^{-1}$ & $\mathrm{US}_{\mathrm{A}}(\mathrm{Sv}-\text { pessoa })^{-1}$ \\
\hline 1 & 0,561 & $10.535,27$ & $19.996,35$ & $100.000,00$ \\
2 & 0,357 & $17.047,48$ & $50.846,36$ & $100.000,00$ \\
3 & 0,335 & $18.242,04$ & $\underline{\mathbf{5 7 . 9 8 2 , 4 7}}$ & $100.000,00$ \\
4 & 0,196 & $32.281,00$ & $175.371,45$ & $100.000,00$ \\
5 & 0,178 & $35.767,94$ & $213.964,64$ & $100.000,00$ \\
\hline
\end{tabular}

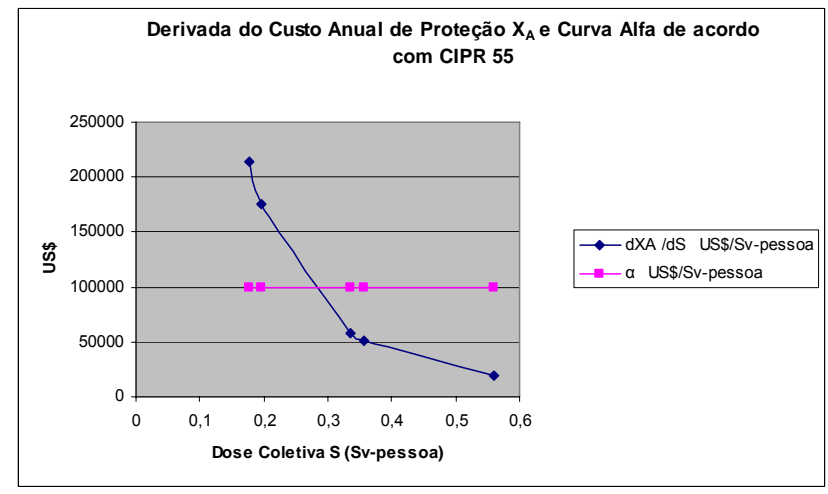

FIGURA 4.9 - Derivada do custo anual de proteção e curva alfa

\section{4 - Exemplo hipotético, utilizando a pequena mina e funções diferentes do valor alfa}

A título de exemplo, vamos atribuir valores fixos de alfa nas extremidades dos intervalos das doses individuais máximas. As extremidades dos intervalos das doses individuais foram escolhidos considerando alguns patamares estabelecidos pela CIPR, a saber:

a) doses individuais máximas inferiores a $5 \mathrm{mSv} \mathrm{a}^{-1}$, isto é, zona de doses consideradas aceitáveis pela $\mathrm{CIPR}^{(1)}, \alpha=0$. 
b) doses iguais a 1/10 do limite anual, correspondente ao limiar do nível de registro, $\alpha$ $=$ US\$10.000,00. Corresponde também ao valor médio de alfa calculado sobre todos os países e o valor de $1 / 10$ do limite anual, corresponde ao valor da dose anual média de todos os trabalhadores.

c) doses entre $1 / 10$ do limite anual e 3/10 do limite anual a variação do valor alfa é linear e supomos o valor de US\$20.000,00 quando $\mathrm{H}=10 \mathrm{mSv}$, que corresponde ao valor adotado pelos Estados Unidos e pela Comunidade Européia e o valor de US\$ $30.000,00$ quando $\mathrm{H}=15 \mathrm{mSv}$.

d) doses entre $15 \mathrm{mSv}^{-1}$ e $35 \mathrm{mSv}^{-1}$, a variação é quadrática, assumindo o valor de US\$ 80.000,00 em 35 mSv.

e) doses entre $35 \mathrm{mSv} \mathrm{a}^{-1}$ e $50 \mathrm{mSv} \mathrm{a}^{-1}$, a variação é exponencial, assumindo o valor de US\$200.000,00 em $50 \mathrm{mSv}$.

O que acabamos de expor está representado nas tabela 4.11, 4.12 e na figura 4.10. 
TABELA 4.11 - Sugestão de valores para a construção da curva $\alpha$

\begin{tabular}{|c|c|c|c|}
\hline $\begin{array}{c}\text { Intervalos para } \\
\text { Doses Individuais } \\
\text { Máximas Anuais* }\end{array}$ & $\begin{array}{c}H \\
\text { Dose Individual } \\
\text { Máxima Anual } \\
\text { (Sv) }\end{array}$ & $\begin{array}{c}\text { Valor de } \alpha \\
\text { US\$ (Sv a) })^{-1}\end{array}$ & $\begin{array}{c}\text { Justificativa da } \\
\text { escolha para o } \\
\text { valor } \alpha\end{array}$ \\
\hline$H_{\max }<\frac{L A}{10}$ & $<0,005$ & 0 & $\begin{array}{l}\text { Objetivo atingido: } \\
\text { região de dose } \\
\text { aceitável }\end{array}$ \\
\hline $\begin{array}{c}H_{\max }=\frac{L A}{10} \\
\text { Nível de Registro }\end{array}$ & 0,005 & $10.000,00$ & $\begin{array}{c}\text { Valor de dose } \\
\text { média individual } \\
\text { mundial, de acordo } \\
\text { com a CIPR }^{(6)}\end{array}$ \\
\hline$\frac{L A}{10}<H \leq \frac{3 L A}{10}$ & 0,015 & $30.000,00$ & $\begin{array}{c}\text { Valor de } \alpha \text { para os } \\
\text { EUA e a Europa } \\
1,5 \text { vezes valor de } \alpha \\
\text { para os EUA e a } \\
\text { Europa }\end{array}$ \\
\hline $\begin{array}{c}\frac{3 L A}{10}<H \leq L A \\
\text { Nível de }\end{array}$ & 0,035 & $80.000,00$ & $\begin{array}{l}4 \text { vezes valor de } \alpha \\
\text { para os EUA e a } \\
\text { Europa }\end{array}$ \\
\hline $\begin{array}{c}\text { Investigação até o } \\
\text { LA }\end{array}$ & 0,050 & $200.000,00$ & $\begin{array}{c}10 \text { vezes valor de } \alpha \\
\text { para os EUA e a } \\
\text { Europa }\end{array}$ \\
\hline
\end{tabular}

*LA - Limite Anual de Dose 
É evidente que os valores da tabela 4.11 são sugestões e podem ser alterados, porém, cabe lembrar que a trajetória com a qual se atingirá a meta está diretamente ligada aos valores de $\alpha$, que nos possibilitarão definir a curva da função alfa, e, de acordo com a $\mathrm{CIPR}^{(4)}$, podem representar aversão, neutralidade e propensão ao risco, conforme figura 4.11 .

TABELA 4.12 - Funções sugeridas para a construção da curva $\alpha$

\begin{tabular}{ccc}
\hline $\begin{array}{c}\text { Intervalos para } \\
\text { Doses individuais } \\
\text { Máximas anuais } \\
H \text { (Sv) }\end{array}$ & Função $\alpha$ contínua por intervalos & $\begin{array}{c}\text { Curva que } \\
\text { descreve a } \\
\text { função } \alpha\end{array}$ \\
\hline$H<0,005$ & 0 & Constante \\
$0,005 \leq H \leq 0,015$ & $\alpha=2 \times 10^{6} H$ & Linear \\
$0,015<H \leq 0,035$ & $\alpha=3763259,32 H^{2}+604475,04 H+12738,96$ & Quadrática \\
$0,035<H \leq 0,050$ & $\alpha=9431,12 e^{61,086 H}$ & Exponencial \\
\hline
\end{tabular}

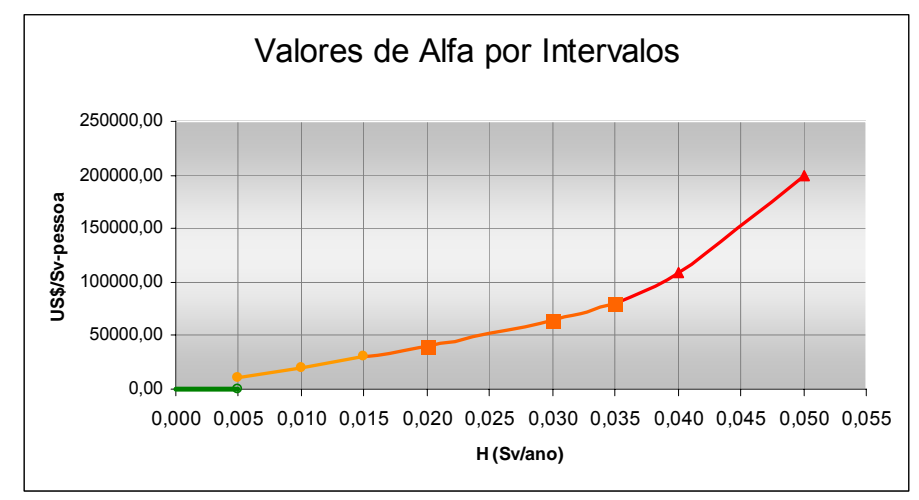

FIGURA 4.10 - As curvas de alfa sugeridas 
Aplicamos estas funções no exemplo da pequena mina e consideramos a distribuição das doses conforme a análise custo benefício expandida, porém usando a técnica da derivada.

Como o enfoque agora não está na dose coletiva e sim no grupo que recebe as maiores doses, escolheremos o valor de alfa, para cada opção, com base no grupo que recebe as maiores doses, como exposto na tabela 4.13 .

TABELA 4.13 - Valores de $\alpha$ para cada opção.

\section{Intervalos para}

Doses individuais

anuais

\section{Função $\alpha$ por intervalos}

$H$ (Sv)

\begin{tabular}{|c|c|c|}
\hline$H<0,005$ & 0 & \\
\hline $0,005 \leq H \leq 0,015$ & $\alpha=2 \times 10^{6} H$ & \\
\hline $0,015<H \leq 0,035$ & $\alpha=3763259,32 H^{2}+604475,04 H+12738,96$ & $2,3,4,5$ \\
\hline $0,035<H \leq 0,050$ & $\alpha=9431,12 e^{61,086 H}$ & 1 \\
\hline
\end{tabular}

O resultado dos valores de alfa encontram-se na tabela 4.14 e, pela equação $\left|\frac{d X}{d S}\right| \leq \alpha$, vêse que a solução analítica é a opção 2. Os valores dos custos anuais de proteção e os valores alfa, são mostrados na figura 4.11. 
TABELA 4.14 - Valores de $\alpha$ em função da dose individual máxima e derivada do custo

\begin{tabular}{ccccc}
\hline & & & $-\frac{d X_{A}}{d S}$ & $\alpha$ \\
Opção & (Sv-pessoa) & $(\mathrm{US} \$)$ & $\mathrm{US} \$(\text { Sv-pessoa) })^{-1}$ & $\mathrm{US} \$\left(\right.$ Sv-pessoa) $^{-1}$ \\
\hline 1 & 0,561 & $10.535,27$ & $\mathbf{1 9 . 9 9 6 , 3 5}$ & $114.014,28$ \\
2 & 0,357 & $17.047,48$ & $\mathbf{5 0 . 8 4 6 , 3 6}$ & $\underline{\mathbf{6 0 . 2 6 1 , 9 5}}$ \\
3 & 0,335 & $18.242,04$ & $\mathbf{5 7 . 9 8 2 , 4 7}$ & $53.897,42$ \\
4 & 0,196 & $32.281,00$ & $\mathbf{1 7 . 5 3 7 1 , 4 5}$ & $34.843,38$ \\
5 & 0,178 & $35.767,94$ & $\mathbf{2 1 . 3 9 6 4 , 6 4}$ & $31.685,18$ \\
\hline
\end{tabular}

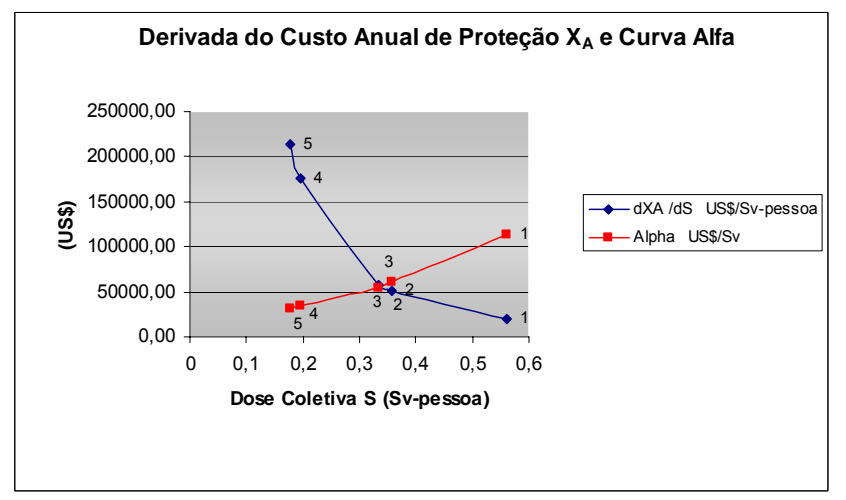

FIGURA 4.11 - Derivada do custo anual de proteção e curva alfa

Como a filosofia apresentada é aplicável a qualquer tipo de curva, poderíamos pensar em funções que representem aversão, propensão e neutralidade ao risco, conforme figura 4.12. Tal idéia já foi utilizada pela CIPR, porém em outro contexto. 


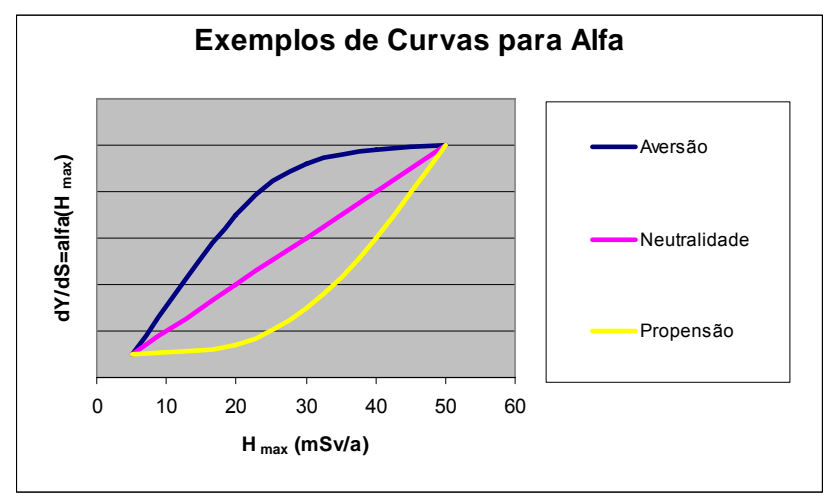

FIGURA 4.12 - Exemplos de curvas alfa representando atitudes de aversão, propensão e neutralidade ao risco

Embora esteja claro que o cerne das questões de otimização está na derivada da função custo de proteção associada aos diferentes valores atribuídos ao termo alfa, na prática, a maioria dos problemas serão discretos e, portanto, a função $\mathrm{Y}$, custo do detrimento, terá sua importância, caso não se queira ajustar as opções para uma função contínua. A partir deste raciocínio, foi desenvolvido, neste trabalho, um método alternativo de cálculo, capaz de resolver as questões até o momento, observadas. Este método será mostrado no capítulo 5 . 


\section{CAPÍTULO 5}

\section{DESENVOLVIMENTO DO MÉTODO ALTERNATIVO}

\section{1 - Descrição do Método}

O que pretendemos neste trabalho é incorporar o fator distribuição de doses individuais ao detrimento sem que seja necessário estender o quadro inicial da análise custo-benefício. Com esta finalidade criamos o detrimento modificado $\mathrm{Z}$, definido por:

$$
Z=f\left(H_{\max }\right) S
$$

onde,

- $f\left(H_{\max }\right)=\alpha$ é a função que atribui valores monetários para uma dose coletiva unitária, isto é, 1Sv-pessoa, em função da dose individual máxima $H_{\max }$ observada em cada opção de radioproteção;

- S é a dose coletiva de cada opção de radioproteção.

Uma vez definido o detrimento modificado $(Z)$ para cada opção, temos que a opção ótima de radioproteção será o ponto onde:

$$
(X+Z)_{\min } \quad(5.2) \quad \text { portanto } \quad\left(X+f\left(H_{\max }\right) S\right)_{\min }
$$

Notemos que tanto $\mathrm{Z}$ quanto $\mathrm{X}$ são definidos apenas nos pontos onde existem opções, porém, se quiséssemos aproximar os pontos para as funções contínuas de custo anual de 
proteção $\left(\mathrm{X}_{\mathrm{A}}\right)$ e de detrimento modificado $\left(\mathrm{Z}_{\mathrm{A}}\right)$, teríamos que a opção ótima de radioproteção seria o ponto onde:

$$
-\frac{d X_{A}}{d S}=\frac{d Z_{A}}{d S} \quad(5.4) \quad \text { ou } \quad\left|\frac{d X_{A}}{d S}\right| \leq \frac{d Z_{A}}{d S}
$$

Note que $\frac{d Z_{A}}{d S} \neq f\left(H_{\max }\right)$, pois o ponto onde $\alpha=f\left(H_{\max }\right)$ equivale a uma dose coletiva de $1 \mathrm{~Sv}$ e, portanto, é necessário fazer uma regra de três simples para se determinar o valor de $Z$ na opção com valor de dose coletiva. Os valores obtidos para $Z$ em cada opção, podem ser ajustados para a função detrimento modificado $\mathrm{Z}_{\mathrm{A}}$ que não será necessariamente linear. Observe que esta questão da possível não linearidade do detrimento, que acabamos de expor, também poderá ocorrer com a técnica de análise custo benefício expandida, conforme está sugerida pela ICRP ${ }^{(4),(5)}$, uma vez que alfa deixa de ter um valor constante e passa a ser somado a outros valores que são funções das doses individuais máximas.

\section{2 - Curvas de Alfa}

Conforme já mencionado, os valores para a construção das curvas $\alpha$ a serem sugeridos não dependeriam mais do Produto Interno Bruto per Capita dos países nem de qualquer outro método conhecido para o cálculo do valor alfa, mas seriam função da distribuição das doses individuais máximas praticadas atualmente no mundo e da prioridade que se daria ao prazo necessário para se atingir a meta de 1/10 do limite de dose anual, isto é, alcançar a região de doses individuais consideradas aceitáveis.

Infelizmente não dispomos de tais dados mundiais para confeccionar a curva ideal, mas para tornar clara esta nossa visão do valor de alfa, usaremos o exemplo do sistema de ventilação da mina de urânio apresentado pela $\operatorname{CIPR}^{(4)}$, os valores por ela atribuídos aos termos alfa e beta, na técnica de ajuda para a tomada de decisão conhecida como custo-benefício expandida e o conceito de curvas que podem representar aversão, neutralidade e propensão ao risco, por ela também preconizadas, para, em seguida, apresentar um conjunto de curvas alfa hipotéticas. A seguir, apresentamos as três curvas hipotéticas. 
5.2.1 - Curva de Alfa para Aversão ao Risco $\alpha_{\text {aversão }}=f\left(H_{\max }\right)$

Para o ajuste desta curva usamos o ponto médio dos intervalos de beta sugeridos pela ICRP ${ }^{(4)}$ para o exemplo da pequena mina de urânio, conforme tabela 5.1.

TABELA 5.1 - Pontos escolhidos para o ajuste da curva de alfa para risco adverso.

\begin{tabular}{ccc}
\hline & $\begin{array}{c}\text { Dose Individual Máxima } \\
\text { baseada no Ponto Médio }\end{array}$ & $\begin{array}{c}\text { Custos considerando- } \\
\text { Intervalo de beta de acordo com a } \\
\text { do Intervalo sugerido pela } \\
\text { ICRP para Análise Custo } \\
\text { benefício expandida } \\
\text { beta no intervalo } \\
\text { (US } \$)\end{array}$ \\
\hline$\beta_{1}(\mathrm{mSv} / \mathrm{ano})$ & $20.000,00$ \\
$\beta_{2}(5-15 \mathrm{mSv})=\mathrm{US} \$ 40.000$ & 2,50 & $60.000,00$ \\
$\beta_{3}(15-50 \mathrm{mSv})=\mathrm{US} \$ 80.000$ & 10,00 & $100.000,00$ \\
\hline
\end{tabular}

Com estes pontos ajustamos a curva da figura 5.1,

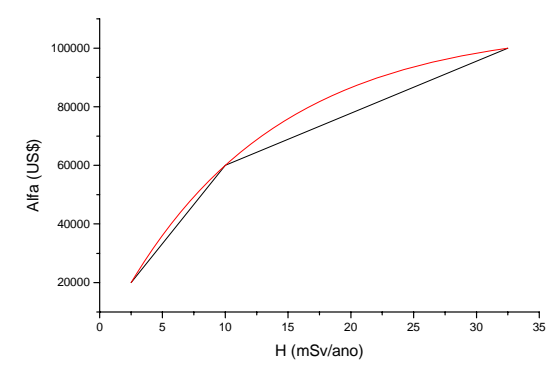

FIGURA 5.1 - Curva de Alfa para Aversão ao Risco

cuja fórmula é dada por: $\quad \alpha_{\text {Adverso }}=107659,52-87659,52 e^{-\frac{H_{\max }-2,50}{12,31}}$ 
5.2.2 - Curva de Alfa para Neutralidade ao Risco $\alpha_{\text {Neutro }}=f\left(H_{\max }\right)$

Pela curva de aversão ao risco que acabamos de encontrar, temos que, quando $\mathrm{H}=50 \mathrm{mSv}, \quad \alpha=f(50)=U S \$ 105.811,60$ e, pelo mesmo critério adotado acima, para aversão ao risco, temos que, quando $\mathrm{H}=2,5 \mathrm{mSv} / \mathrm{ano} \alpha=f(2,5)=U S \$ 20.000,00$. Por estes dois pontos ajustamos uma reta.

$$
\alpha_{\text {neutro }}=1806,56 H_{\max }+15483,60
$$

\subsection{3 - Curva de Alfa para Propensão ao Risco $\alpha_{\text {Propenso }}=f\left(H_{\max }\right)$}

Para esta curva adotamos os dois mesmos pontos da curva de neutralidade ao risco, ou seja, os dois pontos pertinentes conhecidos com a curva de aversão ao risco, e ajustamos para uma exponencial cuja fórmula e o gráfico, são mostrados na figura 5.2.

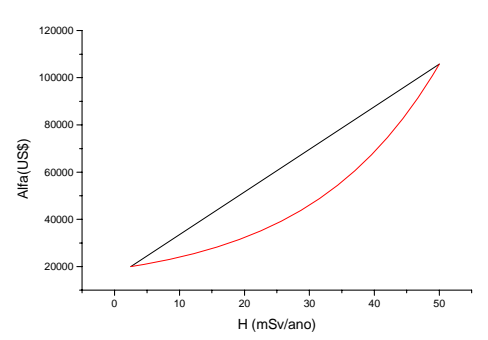

FIGURA 5.2 - Curva de Alfa para Propensão ao Risco

$$
\alpha_{\text {propenso }}=11198,78+7767,10 e^{\frac{H_{\max }}{20,00}}
$$

A Figura 5.3 mostra as três curvas. 


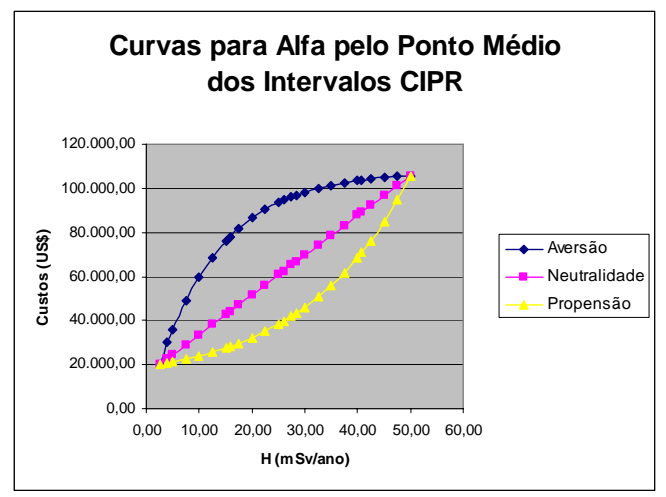

FIGURA 5.3 - Curvas de Alfa

\section{3 - Aplicação da Técnica ao exemplo da mina de urânio}

\subsection{1 -Valores de Alfa e o Detrimento Modificado (Z)}

As Curvas de Alfa fornecem o valor a ser pago pelo risco individual máximo por opção, expresso pela dose individual máxima obtida em cada opção de projeto. Os resultados obtidos, com a aplicação das curvas de alfa, nas opções do problema da mina de Urânio, proposto pela CIPR 55(4), são apresentados na tabela 5.2.

TABELA 5.2 - Valores de Alfa para as 5 opções da mina de urânio

\begin{tabular}{cccccc}
\hline opção & $\begin{array}{c}\mathrm{H}_{\max } \\
\text { mSv/ano }\end{array}$ & $\begin{array}{c}\mathrm{S} \\
(\mathrm{Sv} \text {-pessoa) }\end{array}$ & $\begin{array}{c}\alpha_{\text {avers̃o }} \\
\text { US\$/Sv-pessoa }\end{array}$ & $\begin{array}{c}\alpha_{\text {neutro }} \\
\text { US\$/Sv-pessoa }\end{array}$ & $\begin{array}{c}\alpha_{\text {propenso }} \\
\text { US\$/Sv-pessoa }\end{array}$ \\
\hline 1 & 40,800 & 0,561 & $103.754,86$ & $89.191,25$ & $70.932,43$ \\
2 & 28,400 & 0,357 & $96.967,67$ & $66.789,90$ & $43.332,18$ \\
3 & 26,000 & 0,335 & $94.666,08$ & $62.454,16$ & $39.698,55$ \\
4 & 17,500 & 0,196 & $81.741,47$ & $47.098,40$ & $29.831,07$ \\
5 & 15,800 & 0,178 & $77.903,29$ & $44.027,25$ & $28.312,77$ \\
\hline
\end{tabular}

Como conhecemos os valores de alfa, podemos calcular os detrimentos modificados $\mathrm{Z}$, definidos pela equação 5.1 como $Z=f\left(H_{\max }\right) S$ ou, dado que $\alpha=f\left(H_{\max }\right)$, então $Z=\alpha S$, cujos valores estão apresentados na tabela 5.3. 
TABELA 5.3 - Valores do detrimento modificado Z para as 5 opções da mina de urânio

\begin{tabular}{cccccc}
\hline opção & $\begin{array}{c}\mathrm{H}_{\max } \\
\mathrm{mSv} / \text { ano }\end{array}$ & $\begin{array}{c}\mathrm{S} \\
(\mathrm{Sv} \text {-pessoa) }\end{array}$ & $\begin{array}{c}Z=\alpha_{\text {aversão }} S \\
\mathrm{US} \$\end{array}$ & $\begin{array}{c}Z=\alpha_{\text {neutro }} S \\
\mathrm{US} \$\end{array}$ & $\begin{array}{c}Z=\alpha_{\text {propenso }} S \\
\text { US\$ }\end{array}$ \\
\hline 1 & 40,800 & 0,561 & $58.206,47$ & $50.036,29$ & $39.793,09$ \\
2 & 28,400 & 0,357 & $34.617,46$ & $23.844,00$ & $15.469,59$ \\
3 & 26,000 & 0,335 & $31.713,14$ & $20.922,14$ & $13.299,01$ \\
4 & 17,500 & 0,196 & $16.021,33$ & $9.231,29$ & $5.846,89$ \\
5 & 15,800 & 0,178 & $13.866,79$ & $7.836,85$ & $5.039,67$ \\
\hline
\end{tabular}

\subsection{2 - Função detrimento modificado $\mathrm{Z}_{\mathrm{A}}$}

Sabemos que Z é definido apenas nos pontos onde existem opções, porém, para podermos apresentar

$$
\begin{gathered}
-\frac{d X_{A}}{d S}=\frac{d Z_{A}}{d S} \\
\text { e }\left|\frac{d X_{A}}{d S}\right| \leq \frac{d Z_{A}}{d S}
\end{gathered}
$$

aproximamos os pontos para uma função, aqui denominada função detrimento modificada $\left(\mathrm{Z}_{\mathrm{A}}\right)$, para alfas de aversão, neutralidade e propensão ao risco. Para tanto, analogamente ao que foi feito no capítulo 4, foram testadas as seguintes funções: linear, polinomial, logarítmica, exponencial e potencial. A função que melhor se ajustou aos pontos foi a polinomial. As funções, seus graus de determinação ${ }^{(26)}$ são apresentados a seguir:

Para $\alpha_{\text {aversão }}$,temos: $Z_{A}=4654,32 S^{2}+112241,23 S-6219,58$ onde $R^{2}=0,999943$ 
Para $\alpha_{\text {neutro }}$, temos: $Z_{A}=110724,13 S^{2}+28247,74 S-647,04$ onde $R^{2}=0,999827$

Para $\alpha_{\text {propenso }}$, temos: $Z_{A}=165259,43 S^{2}-31678,75 S+5557,20$ onde $R^{2}=0,999877$

e os valores estão na tabela 5.4.

TABELA 5.4 - Valores da função ajustada detrimento modificado $Z_{\mathrm{A}}$ para as 5 opções da mina de urânio

\begin{tabular}{|c|c|c|c|c|c|}
\hline opção & $\begin{array}{c}\mathrm{H}_{\max } \\
\mathrm{mSv} / \text { ano }\end{array}$ & $\begin{array}{c}\mathrm{S} \\
(\mathrm{Sv}- \\
\text { pessoa })\end{array}$ & $\begin{array}{c}\text { Para } \alpha_{\text {aversão }} \\
Z_{A} \\
\text { US\$ }\end{array}$ & $\begin{array}{c}\text { Para } \alpha_{\text {neutro }} \\
Z_{A} \\
\text { US\$ }\end{array}$ & $\begin{array}{c}\text { Para } \alpha_{\text {propenso }} \\
Z_{A} \\
\text { US\$ }\end{array}$ \\
\hline 1 & 40,800 & 0,561 & $58.212,56$ & $50.047,26$ & $39.795,76$ \\
\hline 2 & 28,400 & 0,357 & $34.443,73$ & $23.549,16$ & $15.309,89$ \\
\hline 3 & 26,000 & 0,335 & $31.903,56$ & $21.242,04$ & $13.490,93$ \\
\hline 4 & 17,500 & 0,196 & $15.958,50$ & $9.143,14$ & $5.696,71$ \\
\hline 5 & 15,800 & 0,178 & $13.906,83$ & $7.889,28$ & $5.154,40$ \\
\hline
\end{tabular}

Para as funções citadas, calculamos suas respectivas derivadas,

para $\alpha_{\text {aversão }}$,temos: $\frac{d Z_{A}}{d S}=9308,64 S+112241,23$

para $\alpha_{\text {neutro }}$, temos: $\frac{d Z_{A}}{d S}=221448,26 S+28247,74$

para $\alpha_{\text {propenso }}$, temos: $\frac{d Z_{A}}{d S}=330518,86 S-31678,75$

e os valores decorrentes estão na tabela 5.5. 
TABELA 5.5 - Valores da derivada da função ajustada detrimento modificado $Z_{\mathrm{A}}$ para as 5 opções da mina de urânio

\begin{tabular}{cccccc}
\hline \multirow{2}{*}{ opção } & & & Para $\alpha_{\text {averão }}$ & Para $\alpha_{\text {neutro }}$ & Para $\alpha_{\text {propenso }}$ \\
& $\mathrm{H}_{\max }$ & $\mathrm{S}$ & $\frac{d Z_{A}}{d S}$ & $\frac{d Z_{A}}{d S}$ & $\frac{d Z_{A}}{d S}$ \\
& & & $\mathrm{USS}$ & $\mathrm{US} \$$ & $\mathrm{US} \$$ \\
\hline 1 & 40,800 & 0,561 & $117.463,38$ & $152.480,33$ & $153.741,60$ \\
2 & 28,400 & 0,357 & $115.564,41$ & $107.304,94$ & $86.315,93$ \\
3 & 26,000 & 0,335 & $115.359,62$ & $102.433,08$ & $79.044,53$ \\
4 & 17,500 & 0,196 & $114.065,72$ & $71.651,81$ & $33.102,53$ \\
5 & 15,800 & 0,178 & $113.898,17$ & $67.665,74$ & $27.153,20$ \\
\hline
\end{tabular}

\subsection{3 -Custo Anual de Proteção Radiológica (X)}

Os custos de proteção, para o exemplo da mina, estão apresentados nas tabelas 3.1 e 3.2 .

Para que seja possível mostrar toda a técnica, ou seja, o ponto onde $(X+Z)_{\min }$

e, também, o ponto onde $\left|\frac{d X_{A}}{d S}\right| \leq \frac{d Z_{A}}{d S} \quad$ (5.5) ajustamos as opções de custos de proteção radiológica $(\mathrm{X})$, que sabemos que são discretas, para um função contínua ${ }^{(26)}$. Para tanto, foram testadas as seguintes funções: linear, polinomial, logarítmica, exponencial e potencial. A função que melhor se ajustou aos pontos foi a potencial, conforme mostrado no capítulo 4 .

Em seguida, derivamos esta função e encontramos seu respectivo valor em cada ponto que define as cinco opções de proteção radiológica para a mina de urânio. Os valores de $X_{A}$ e de $-\frac{d X_{A}}{d S}$ para as opções são apresentado na tabela 5.6. 
TABELA 5.6 - Valores do custo das opções para a função potência $X_{A}$ e da derivada da função nos pontos $-\frac{d X_{A}}{d S}$

\begin{tabular}{cccc}
\hline Opção & S (Sv-pessoa) & $\mathrm{X}_{\mathrm{A}}$ (US\$) & $\begin{array}{c}-\frac{d X_{A}}{d S} \\
\end{array}$ \\
& & $\mathrm{US} \$ /($ Sv-pessoa) \\
\hline 1 & 0,561 & $10.535,27$ & $19.996,35$ \\
2 & 0,357 & $17.047,48$ & $50.846,36$ \\
3 & 0,335 & $18.242,04$ & $57.982,47$ \\
4 & 0,196 & $32.281,00$ & $175.371,45$ \\
5 & 0,178 & $35.767,94$ & $213.964,64$ \\
\hline
\end{tabular}

\subsection{4 - Análise Custo Benefício com o detrimento modificado (Z)}

Nas tabelas 5.7, 5.8 e 5.9, são apresentados os resultados da análise considerando os valores de alfa para aversão, neutralidade e propensão ao risco utilizando o detrimento modificado Z. A solução ótima será o ponto onde $(X+Z)_{\min }$ ou $\left(X+f\left(H_{\max }\right) S\right)_{\min }$ que está em negrito e sublinhada em cada tabela.

TABELA 5. 7 - Solução analítica considerando $\alpha_{\text {aversão }}$

\begin{tabular}{ccccc}
\hline Opção & S (Sv-pessoa) & $\mathrm{X}_{\mathrm{A}}$ (US\$) & $\mathrm{Z}$ (US\$) & $\mathrm{X}+\mathrm{Z}$ (US\$) \\
\hline 1 & 0,561 & $10.535,27$ & $58.206,47$ & $68.741,74$ \\
2 & 0,357 & $17.047,48$ & $34.617,46$ & $51.664,93$ \\
3 & 0,335 & $18.242,04$ & $31.713,14$ & $49.955,18$ \\
4 & 0,196 & $32.281,00$ & $16.021,33$ & $\underline{\mathbf{4 8 . 3 0 2 , 3 2}}$ \\
5 & 0,178 & $35.767,94$ & $13.866,79$ & $49.634,73$ \\
\hline
\end{tabular}


TABELA 5.8 - Solução analítica considerando $\alpha_{\text {neutro }}$

\begin{tabular}{ccccc}
\hline Opção & S (Sv-pessoa) & $\mathrm{X}_{\mathrm{A}}$ (US\$) & Z (US\$) & $\mathrm{X}+\mathrm{Z}$ (US\$) \\
\hline 1 & 0,561 & $10.535,27$ & $50.036,29$ & $60.571,56$ \\
2 & 0,357 & $17.047,48$ & $23.844,00$ & $40.891,47$ \\
3 & 0,335 & $18.242,04$ & $20.922,14$ & $\underline{\mathbf{3 9 . 1 6 4 , 1 9}}$ \\
4 & 0,196 & $32.281,00$ & $9.231,29$ & $41.512,28$ \\
5 & 0,178 & $35.767,94$ & $7.836,85$ & $43.604,79$ \\
\hline
\end{tabular}

TABELA 5.9 - Solução analítica considerando $\alpha_{\text {propenso }}$

\begin{tabular}{ccccc}
\hline Opção & S (Sv-pessoa) & $\mathrm{X}_{\mathrm{A}}$ (US\$) & $\mathrm{Z}$ (US\$) & $\mathrm{X}+\mathrm{Z}$ (US\$) \\
\hline 1 & 0,561 & $10.535,27$ & $39.793,09$ & $50.328,36$ \\
2 & 0,357 & $17.047,48$ & $15.469,59$ & $32.517,06$ \\
3 & 0,335 & $18.242,04$ & $13.299,01$ & $\underline{\mathbf{3 1 . 5 4 1 , 0 6}}$ \\
4 & 0,196 & $32.281,00$ & $5.846,89$ & $38.127,89$ \\
5 & 0,178 & $35.767,94$ & $5.039,67$ & $40.807,62$ \\
\hline
\end{tabular}

\subsection{5 - Aplicação da técnica ao exemplo da mina de urânio utilizando a derivada das} funções

Nas tabela 5.10, 5.11 e 5.12, são apresentados os resultados da análise considerando os valores de alfa para aversão, neutralidade e propensão ao risco utilizando a derivada das funções. A solução ótima será o ponto onde $\left|\frac{d X_{A}}{d S}\right| \leq \frac{d Z_{A}}{d S}$ que está em negrito e sublinhada em cada tabela. 
TABELA 5.10 - Solução analítica considerando $\alpha_{\text {aversão }}$

\begin{tabular}{cccc}
\hline Opção & S (Sv-pessoa) & $-\frac{d X_{A}}{d S}$ & $\frac{d Z_{A}}{d S}$ \\
& & US\$/Sv-pessoa & US\$/Sv-pessoa \\
\hline 1 & 0,561 & $19.996,35$ & $117.463,38$ \\
2 & 0,357 & $50.846,36$ & $115.564,41$ \\
3 & 0,335 & $\underline{\mathbf{5 7 . 9 8 2 , 4 7}}$ & $\underline{\mathbf{1 1 5 . 3 5 9 , 6 2}}$ \\
4 & 0,196 & $175.371,45$ & $114.065,72$ \\
5 & 0,178 & $213.964,64$ & $113.898,17$ \\
\hline
\end{tabular}

TABELA 5.11 - Solução analítica considerando $\alpha_{\text {neutro }}$

\begin{tabular}{cccc}
\hline Opção & S (Sv-pessoa) & $-\frac{d X_{A}}{d S}$ & $\frac{d Z_{A}}{d S}$ \\
& & US\$/Sv-pessoa & US\$/Sv-pessoa \\
\hline 1 & 0,561 & $19.996,35$ & $152.480,33$ \\
2 & 0,357 & $50.846,36$ & $107.304,94$ \\
3 & 0,335 & $\underline{\mathbf{5 7 . 9 8 2 , 4 7}}$ & $\underline{\mathbf{1 0 2 . 4 3 3 , 0 8}}$ \\
4 & 0,196 & $175.371,45$ & $71.651,81$ \\
5 & 0,178 & $213.964,64$ & $67.665,74$ \\
\hline
\end{tabular}

TABELA 5.12 - Solução analítica considerando $\alpha_{\text {propenso }}$

\begin{tabular}{cccc}
\hline Opção & S (Sv-pessoa) & $-\frac{d X_{A}}{d S}$ & $\frac{d Z_{A}}{d S}$ \\
& & US\$/Sv-pessoa & US\$/Sv-pessoa \\
\hline 1 & 0,561 & $19.996,35$ & $153.741,60$ \\
2 & 0,357 & $50.846,36$ & $86.315,93$ \\
3 & 0,335 & $\underline{\mathbf{5 7 . 9 8 2 , 4 7}}$ & $\underline{\mathbf{7 9 . 0 4 4 , 5 3}}$ \\
4 & 0,196 & 175371,45 & $33.102,53$ \\
5 & 0,178 & $213.964,64$ & $27.153,20$ \\
\hline
\end{tabular}




\section{4 - Aplicação da Técnica a um exemplo brasileiro}

Utilizamos o exemplo extraído de uma tese de doutorado, realizada no IPEN, referente à otimização do sistema de radioproteção em instalações radiográficas de gamagrafia $^{(7)}$. O exemplo considera uma instalação fechada, com teto, que opera com uma fonte de Ir-192 de atividade 7,4 TBq e um total de 4 trabalhadores. Destes quatro trabalhadores, três recebem doses individuais equivalentes às doses do público, em função da facilidade existente em se locomoverem para as áreas livres, durante as irradiações. No trabalho, foram idealizadas 36 opções de proteção radiológica envolvendo uma rica combinação dos seguintes materiais como blindagem: concreto, barita, cerâmica, chumbo e ferro. Os custos de proteção foram anualizados, considerando-se vida útil de 20 anos, de acordo com a tabela Price, sem juros e com juros de 3\%, 6\%, $9 \%$ e $12 \%$ a.a.

Neste trabalho, foram eliminadas opções que tinham custos diferentes, mas forneciam doses equivalente individuais e coletivas iguais. A taxa de juros utilizada foi de $12 \%$ ao ano.

\subsection{1 - Resultados obtidos considerando Aversão, Neutralidade e Propensão ao risco com Detrimento Modificado}

TABELA 5.13 - Solução analítica considerando $\alpha_{\text {aversão }}$

\begin{tabular}{ccccccc}
\hline $\begin{array}{c}\text { Opões } \\
\text { selecionadas }\end{array}$ & $\begin{array}{c}\mathrm{H}_{\max } \\
\mathrm{mSv} / \text { ano }\end{array}$ & $\begin{array}{c}\alpha_{\text {avers̃o }} \\
\text { US\$/Sv-pessoa }\end{array}$ & $\begin{array}{c}\mathrm{S} \\
(\mathrm{Sv} \text {-pessoa) }\end{array}$ & $\begin{array}{c}\mathrm{Z} \\
(\mathrm{US} \$)\end{array}$ & $\begin{array}{c}\mathrm{X}_{\mathrm{A}} \\
(\mathrm{US} \$)\end{array}$ & $\begin{array}{c}\mathrm{X}+\mathrm{Z} \\
\text { (US\$) }\end{array}$ \\
\hline 1 & 43,000 & $104.393,88$ & 0,046 & $4.802,12$ & $1.162,00$ & $5.964,12$ \\
20 & 17,000 & $80.667,08$ & 0,020 & $1.613,34$ & $1.759,00$ & $3.372,34$ \\
55 & 9,000 & $55.960,72$ & 0,012 & 671,53 & $2.396,00$ & $3.067,53$ \\
51 & 7,000 & $46.840,41$ & 0,010 & 468,40 & $1.687,00$ & $2.155,40$ \\
13 & 6,000 & $41.693,57$ & 0,009 & 375,24 & $1.309,00$ & $\underline{\mathbf{1 . 6 8 4 , 2 4}}$ \\
36 & 3,000 & $23.489,16$ & 0,006 & 140,93 & $1.858,00$ & $1.998,93$ \\
59 & 2,000 & $16.366,20$ & 0,005 & 81,83 & $2.878,00$ & $2.959,83$ \\
\hline
\end{tabular}


TABELA 5.14 - Solução analítica considerando $\alpha_{\text {neutro }}$

\begin{tabular}{ccccccc}
\hline $\begin{array}{c}\text { Opões } \\
\text { selecionadas }\end{array}$ & $\begin{array}{c}\mathrm{H}_{\max } \\
\mathrm{mSv} / \text { ano }\end{array}$ & $\begin{array}{c}\alpha_{\text {neutro }} \\
\text { US\$/Sv-pessoa }\end{array}$ & $\begin{array}{c}\mathrm{S} \\
\text { (Sv-pessoa) }\end{array}$ & $\begin{array}{c}\mathrm{Z} \\
(\mathrm{US} \$)\end{array}$ & $\begin{array}{c}\mathrm{X}_{\mathrm{A}} \\
(\mathrm{US} \$)\end{array}$ & $\begin{array}{c}\mathrm{X}+\mathrm{Z} \\
(\mathrm{US} \$)\end{array}$ \\
\hline 1 & 43,000 & $93.165,68$ & 0,046 & $4.285,62$ & $1.162,00$ & $5.447,62$ \\
20 & 17,000 & $46.195,12$ & 0,020 & 923,90 & $1.759,00$ & $2.682,90$ \\
55 & 9,000 & $31.742,64$ & 0,012 & 380,91 & $2.396,00$ & $2.776,91$ \\
51 & 7,000 & $28.129,52$ & 0,010 & 281,30 & $1.687,00$ & $1.968,30$ \\
13 & 6,000 & $26.322,96$ & 0,009 & 236,91 & $1.309,00$ & $\underline{\mathbf{1 . 5 4 5 , 9 1}}$ \\
36 & 3,000 & $20.903,28$ & 0,006 & 125,42 & $1.858,00$ & $1.983,42$ \\
59 & 2,000 & $19.096,72$ & 0,005 & 95,48 & $2.878,00$ & $2.973,48$
\end{tabular}

TABELA 5.15 - Solução analítica considerando $\alpha_{\text {propenso }}$

\begin{tabular}{ccccccc}
\hline $\begin{array}{c}\text { Opões } \\
\text { selecionadas }\end{array}$ & $\begin{array}{c}\mathrm{H}_{\max } \\
\mathrm{mSv} / \text { ano }\end{array}$ & $\begin{array}{c}\alpha_{\text {propenso }} \\
\text { US\$/Sv-pessoa }\end{array}$ & $\begin{array}{c}\mathrm{S} \\
\text { (Sv-pessoa) }\end{array}$ & $\begin{array}{c}\mathrm{Z} \\
(\mathrm{US} \$)\end{array}$ & $\begin{array}{c}\mathrm{X}_{\mathrm{A}} \\
\text { (US\$) }\end{array}$ & $\begin{array}{c}\mathrm{X}+\mathrm{Z} \\
\text { (US\$) }\end{array}$ \\
\hline 1 & 43,000 & $77.878,14$ & 0,046 & $3.582,39$ & $1.162,00$ & $4.744,39$ \\
20 & 17,000 & $29.371,04$ & 0,020 & 587,42 & $1.759,00$ & $2.346,42$ \\
55 & 9,000 & $23.380,01$ & 0,012 & 280,56 & $2.396,00$ & $2.676,56$ \\
51 & 7,000 & $22.220,82$ & 0,010 & 222,21 & $1.687,00$ & $1.909,21$ \\
13 & 6,000 & $21.683,27$ & 0,009 & 195,15 & $1.309,00$ & $\mathbf{1 . 5 0 4 , 1 5}$ \\
36 & 3,000 & $20.222,86$ & 0,006 & 121,34 & $1.858,00$ & $1.979,34$ \\
59 & 2,000 & $19.782,75$ & 0,005 & 98,91 & $2.878,00$ & $2.976,91$ \\
\hline
\end{tabular}




\section{CAPÍTULO 6}

\section{OUTRAS PROPOSTAS}

A otimização da proteção radiológica, como tem sido pensada até o momento, parte da premissa de que o valor de alfa seja maior para doses individuais elevadas e menor para doses individuais menores. Tal raciocínio está apoiado na filosofia assumida pela CIPR da existência da linearidade dose-efeito, ou seja, a cada incremento na dose de radiação está associado um incremento proporcional no risco de um efeito deletério à saúde.

Na história da radioproteção, no mundo, pode-se notar que já existe uma consciência global sobre o tema acima, pois as estatísticas mundiais mostram que tem sido feito um esforço no sentido de reduzir as doses provenientes das práticas com radiação ionizante. Esta questão fica evidente na publicação da CIPR-60, onde o limite anual de dose para indivíduos ocupacionalmente expostos foi mantido em $50 \mathrm{mSv} /$ ano, porém, em cinco anos de atividade a dose total não deve ultrapassar $100 \mathrm{mSv}$, ficando claro que seria recomendável uma dose anual de $20 \mathrm{mSv}$.

A partir do exposto acima, poderíamos dar outro enfoque à questão da otimização. Justamente por sabermos que doses elevadas devem ser evitadas, opções que forneçam valores elevados de dose coletiva têm pouco valor monetário. As próprias opções da mina mostram que o valor alfa aumenta enormemente com a diminuição da dose.

Um segundo exemplo de que o custo de proteção aumenta com a diminuição da dose individual pode ser verificado num simples cálculo de blindagem que fornecemos a seguir: 
Hipóteses:

a) Blindagem de fonte em forma esférica, pois não possui regiões com blindagem em excesso.

b) A fonte radioativa ocupa $1 \mathrm{~cm}$ de raio no centro da blindagem.

c) A camada semi-redutora da fonte apresenta uma espessura de $1 \mathrm{~cm}$ de chumbo.

d) $11 \mathrm{~cm}$ de espessura de chumbo fornecem uma dose efetiva individual média de $1024 \mathrm{mSv}^{-1}$.

e) O número de trabalhadores é constante para as diferentes espessuras de blindagem. Por facilidade, consideraremos um indivíduo exposto, assim a dose efetiva coletiva coincide com a dose individual média.

f) O custo do chumbo por $\mathrm{cm}^{3}$ é A.

g) $\mathrm{O}$ custo total é representado por $\mathrm{X}$.

Tese: Variação do valor alfa, Sv-pessoa, com o aumento da blindagem.

Dedução

Volume ocupado pela fonte: $\mathrm{V}_{\mathrm{f}}$

$$
\mathrm{V}_{\mathrm{f}}=\frac{4}{3} \pi R^{3}=\frac{4}{3} 3,14=4,19 \mathrm{~cm}^{3}
$$

1 - Determinação do valor alfa quando se passa de $11 \mathrm{~cm}$ para $12 \mathrm{~cm}$ de espessura de blindagem.

Volume da blindagem: V

Raio da blindagem : R

Custo da blindagem: $X=\left(V-V_{f}\right) A$

$$
\begin{aligned}
& V_{11}=\frac{4}{3} \pi R_{12}^{3}-4,19=7236 \mathrm{~cm}^{3} \\
& X_{11}=7236 \mathrm{~A} \\
& V_{12}=\frac{4}{3} \pi R_{13}^{3}-4,19=9201 \mathrm{~cm}^{3} \\
& X_{12}=9201 \mathrm{~A}
\end{aligned}
$$


Aplicando a fórmula custo eficácia da otimização $\frac{\Delta X}{\Delta S}=\alpha$, vem:

$$
\frac{\Delta X}{\Delta S}=\frac{(9201-7236) A}{(1024-512) \times 10^{-3}}=\frac{1965 A}{512 \times 10^{-3}}=3,84 \times 10^{3} A(\mathrm{~Sv} \text { - pessoa })
$$

Obs: $10^{-3}$ é a transformação de mSv em Sv.

2 - Cálculo do valor alfa quando se passa de $19 \mathrm{~cm}$ para $20 \mathrm{~cm}$ de espessura de blindagem.

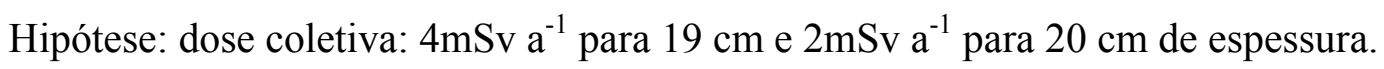

$$
\begin{gathered}
V_{19}=\frac{4}{3} \pi R_{20}^{3}-4,19=33516 \mathrm{~cm}^{3} \\
X_{19}=33516 \mathrm{~A} \\
V_{20}=\frac{4}{3} \pi R_{21}^{3}-4,19=38799 \mathrm{~cm}^{3} \\
X_{20}=38799 \mathrm{~A} \\
\frac{\Delta X}{\Delta S}=\frac{(38799-33516) \mathrm{A}}{(4-2) \times 10^{-3}}=\frac{5283 \mathrm{~A}}{2 \times 10^{-3}}=2641,50 \times 10^{3} \mathrm{~A} \quad(\mathrm{~Sv} \text { - pessoa })
\end{gathered}
$$

3 - Cálculo do valor alfa quando se passa de $20 \mathrm{~cm}$ para $21 \mathrm{~cm}$ de espessura de blindagem Hipótese: dose coletiva: $2 \mathrm{mSv}^{-1}$ para $20 \mathrm{~cm}$ e $1 \mathrm{mSv}^{-1}$ para $21 \mathrm{~cm}$ de espessura.

$$
\begin{gathered}
V_{20}=38799 \mathrm{~cm}^{3} \\
X_{20}=38799 \mathrm{~A} \\
V_{21}=\frac{4}{3} \pi R_{22}^{3}-4,19=44611 \mathrm{~cm}^{3} \\
X_{21}=44611 \mathrm{~A} \\
\frac{\Delta X}{\Delta S}=\frac{(44611-38799) \mathrm{A}}{(2-1) \times 10^{-3}}=5812 \times 10^{3} \mathrm{~A} \quad(\mathrm{~Sv} \text { - pessoa })
\end{gathered}
$$


Resultados

a) No acréscimo de $11 \mathrm{~cm}$ para $12 \mathrm{~cm}$, alfa vale $3,84 \times 10^{3} \mathrm{~A}$ Sv-pessoa, com dose coletiva evitada ou decréscimo de dose individual média de $512 \mathrm{mSv} \mathrm{a}^{-1}$.

b) De $19 \mathrm{~cm}$ para $20 \mathrm{~cm}$, alfa vale $2641,50 \times 10^{3} \mathrm{~A}$ Sv-pessoa, com dose coletiva evitada ou decréscimo na dose individual média de $2 \mathrm{mSv}^{-1}$.

c) De $20 \mathrm{~cm}$ para $21 \mathrm{~cm}$, alfa vale $5812 \times 10^{3} \mathrm{~A}$ Sv-pessoa, com dose coletiva evitada ou decréscimo na dose individual média de $1 \mathrm{mSv}^{-1}$.

É fácil entender os motivos do asserido, em doses elevadas, a melhoria da proteção pode dar-se em um único local, por exemplo, para escavadores da galeria. Quando as doses individuais diminuírem poderá ser-lhes acrescentado o serviço de transporte e carga do minério para a superfície. Quando forem ainda menores, deverão também ser acrescentado os locais de trabalho na superfície; portanto, as áreas de proteção se multiplicam.

Usando esse raciocínio, as curvas de aversão, propensão e neutralidade ao risco deveriam ser decrescentes, conforme pode ser observado na figura 6.1.

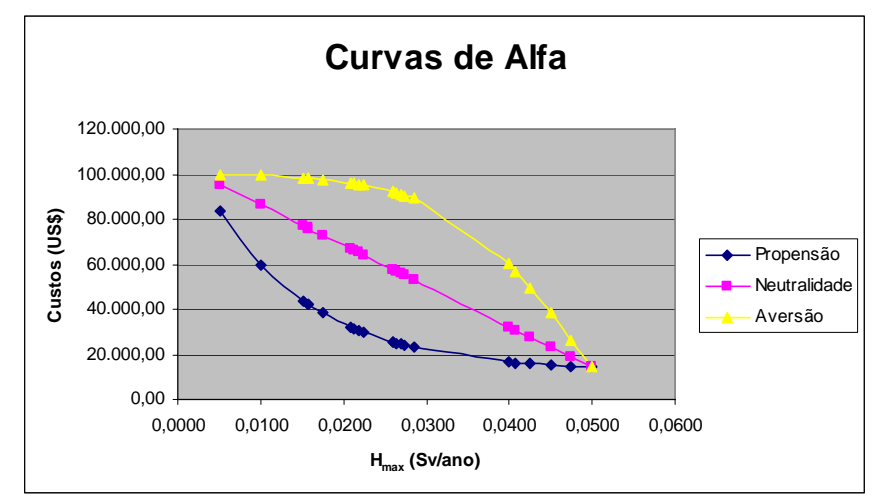

FIGURA 6.1 - Curvas de Alfa decrescentes

Para o ajuste destas curvas, usamos o ponto médio dos intervalos de beta sugeridos pela $\operatorname{CIPR}^{(4)}$ para o exemplo da pequena mina de urânio, conforme tabela 6.1 , sendo que, $\beta_{1}(\mathrm{H}<5 \mathrm{mSv})$ equivale a US\$100.000,00 e $\beta_{3}(15-50 \mathrm{mSv})$ equivale a US\$ 20.000,00. 
TABELA 6.1 - Pontos escolhidos para o ajuste da curva de alfa para risco adverso.

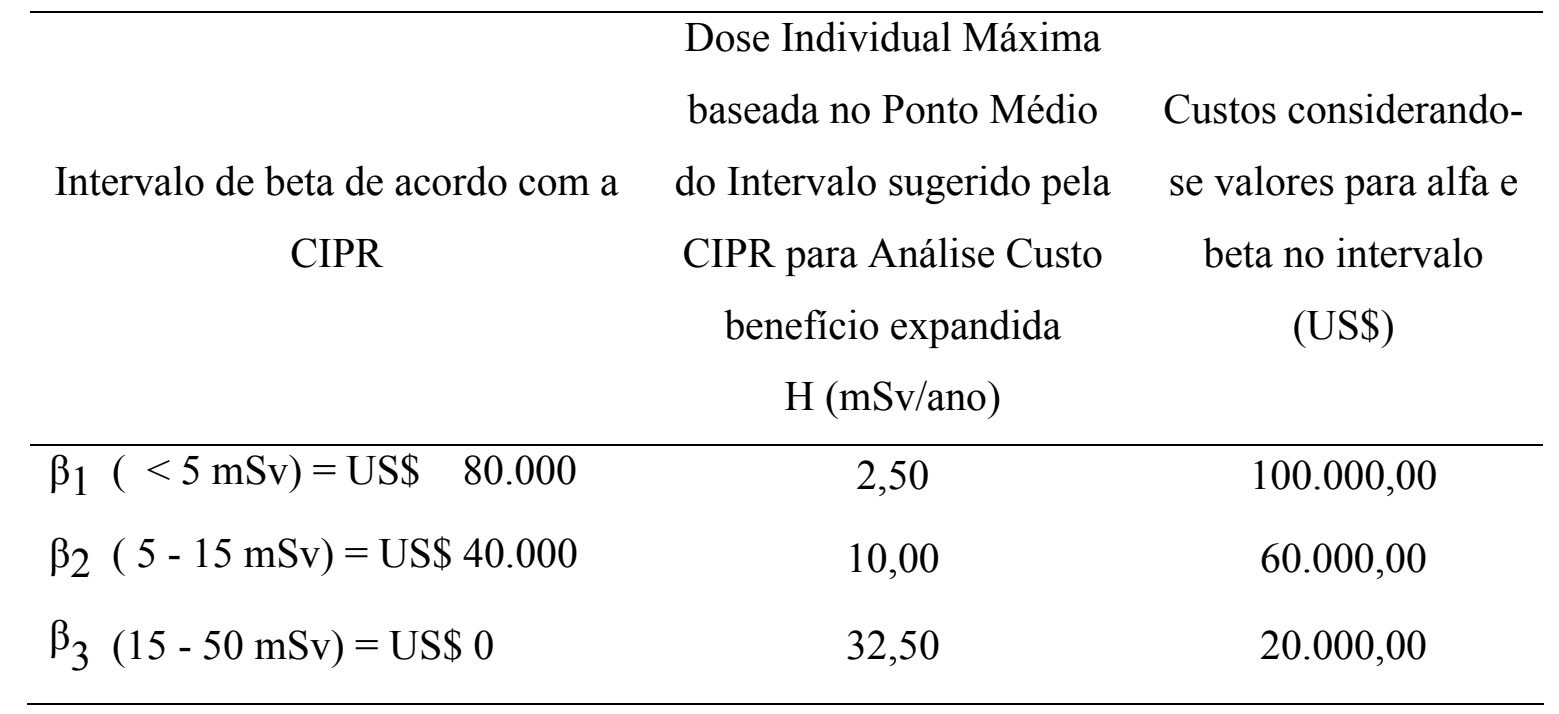

Com estes pontos ajustamos as curvas dos gráficos 6.26 .3 e 6.4 .

Curva Decrescente de Alfa para Aversão ao Risco $\alpha_{\text {aversão }}=f\left(H_{\max }\right)$

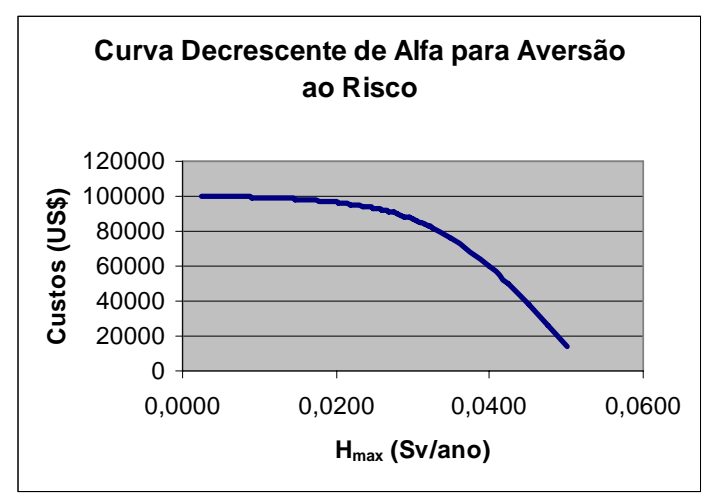

FIGURA 6.2 - Curva Decrescente de Alfa para Aversão ao Risco

$$
\alpha_{\text {Aversão }}=-46899,10+\frac{147295,94}{1+e^{\frac{H_{\max }-0,04739}{0,00759}}}
$$


Curva Decrescente de Alfa para Neutralidade ao Risco $\alpha_{\text {Neutro }}=f\left(H_{\max }\right)$

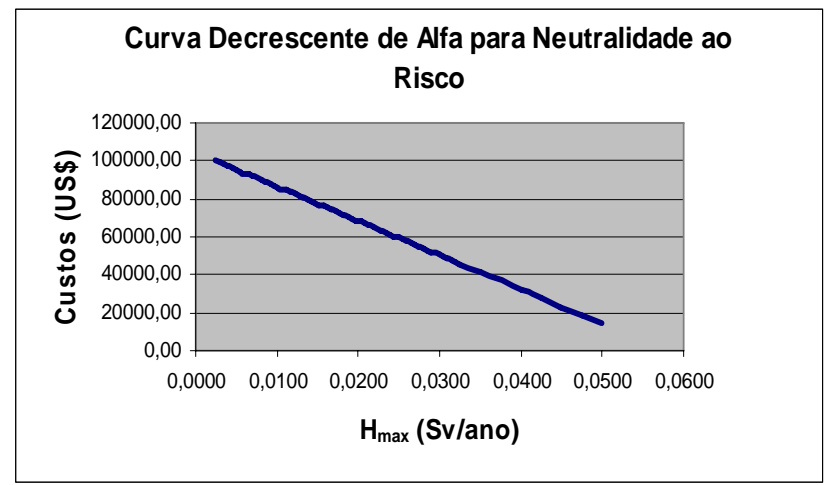

FIGURA 6.3 - Curva Decrescente de Alfa para Neutralidade ao Risco

$$
\alpha_{\text {neutro }}=-1,8 \times 10^{6} H_{\max }+104516,33
$$

Curva Decrescente de Alfa para Propensão ao Risco $\alpha_{\text {Pr openso }}=f\left(H_{\max }\right)$

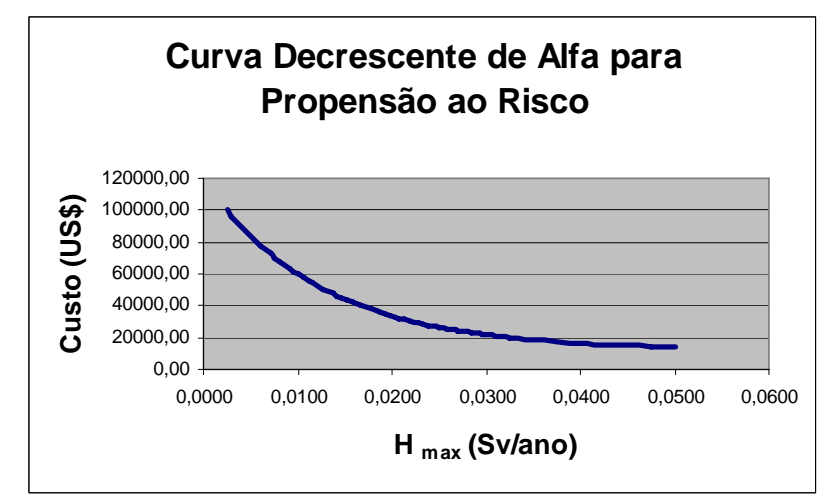

FIGURA 6.4 - Curva Decrescente de Alfa para Propensão ao Risco

$$
\alpha_{\text {propenso }}=12340,49+87659,51 e^{-\frac{H_{\max }-0,0025}{0,0123}}
$$


A seguir, apresentaremos o cálculo da otimização para o exemplo da mina de urânio, usando o método do detrimento modificado (Z). As Curvas de Alfa fornecem o valor associado ao risco individual máximo por opção, expresso pela dose individual máxima obtida em cada opção de projeto, conforme tabela 6.2 .

TABELA 6.2 - Valores de Alfa para as 5 opções da mina de urânio

\begin{tabular}{cccccc}
\hline opção & $\begin{array}{c}\mathrm{H}_{\max } \\
\text { mSv/ano }\end{array}$ & $\begin{array}{c}\mathrm{S} \\
(\text { Sv-pessoa) }\end{array}$ & $\begin{array}{c}\alpha_{\text {aversão }} \\
\text { US\$/Sv-pessoa }\end{array}$ & $\begin{array}{c}\alpha_{\text {neutro }} \\
\text { US\$/Sv-pessoa }\end{array}$ & $\begin{array}{c}\alpha_{\text {propenso }} \\
\text { US\$/Sv-pessoa }\end{array}$ \\
\hline 1 & 40,800 & 0,561 & $56.853,34$ & $30.809,91$ & $16.245,14$ \\
2 & 28,400 & 0,357 & $89.202,80$ & $53.156,68$ & $23.006,30$ \\
3 & 26,000 & 0,335 & $92.096,77$ & $57.546,55$ & $25.333,92$ \\
4 & 17,500 & 0,196 & $97.581,53$ & $72.902,05$ & $38.258,53$ \\
5 & 15,800 & 0,178 & $98.137,81$ & $75.973,16$ & $42.096,71$ \\
\hline
\end{tabular}

Nota-se que há uma variação no sentido crescente do custo à medida que a dose diminui. Nota-se ainda que o custo da opção 1 é 57,93\% do custo da opção 5 . Ou ainda, que para se ir de 1 a 5, seria necessário investir mais $72,61 \%$ de 56853,34 , que é o custo da opção 1 , que é mais barata por fornecer maior dose para o $\alpha_{\text {aversão }}$.

Como conhecemos os valores de alfa, podemos calcular os detrimentos modificados Z, definidos pela equação (5.1) que estão apresentados na tabela 6.3.

TABELA 6.3 - Valores do detrimento modificado Z para as 5 opções da mina de urânio

\begin{tabular}{cccccc}
\hline opção & $\begin{array}{c}\mathrm{H}_{\max } \\
\text { mSv/ano }\end{array}$ & $\begin{array}{c}\mathrm{S} \\
(\mathrm{Sv} \text {-pessoa) }\end{array}$ & $\begin{array}{c}Z=\alpha_{\text {aversão }} S \\
\mathrm{US} \$\end{array}$ & $\begin{array}{c}Z=\alpha_{\text {neutro }} S \\
\mathrm{US} \$\end{array}$ & $\begin{array}{c}Z=\alpha_{\text {propenso }} S \\
\mathrm{US} \$\end{array}$ \\
\hline 1 & 40,800 & 0,561 & $31.894,72$ & $17.284,36$ & 9113,53 \\
2 & 28,400 & 0,357 & $31.845,40$ & $18.976,94$ & $8.213,25$ \\
3 & 26,000 & 0,335 & $30.852,42$ & $19.278,09$ & $8.486,86$ \\
4 & 17,500 & 0,196 & $19.125,98$ & $14.288,80$ & $7.498,67$ \\
5 & 15,800 & 0,178 & $17.468,53$ & $13.523,22$ & $7.493,21$ \\
\hline
\end{tabular}


Nota-se que altas doses individuais incorrem em altas doses coletivas que poderiam ser interpretadas em porcentagem de $1 \mathrm{~Sv}$-pessoa. A opção 1, que apresenta maior dose individual, custa bem mais barato que a opção 5 e, em termos de dose coletiva, equivale a 56,10\% de $1 \mathrm{~Sv}$-pessoa . Por outro lado, doses pequenas levam a doses coletivas pequenas, a opção 5 , que embora custe muito mais caro em função de ter dose pequena, equivale a apenas $17,8 \%$ de 1 Sv-pessoa. Assim, quando calculamos o detrimento modificado $Z$, teremos que a opção ótima será, em todos os casos, a de maior dose e menor custo, o que ocorre em função da importância que terá a dose coletiva.

Nas tabela 6.4, 6.5 e 6.6 são apresentados os resultados da análise considerando os valores decrescentes de alfa para aversão, neutralidade e propensão ao risco utilizando o detrimento modificado Z. A solução ótima será o ponto onde $(X+Z)_{\min }$ que está em negrito e sublinhado em cada tabela.

TABELA 6.4 - Solução analítica considerando $\alpha_{\text {aversão }}$

\begin{tabular}{ccccc}
\hline Opção & S (Sv-pessoa) & X (US\$) & Z (US\$) & X+Z (US\$) \\
\hline 1 & 0,561 & $10.400,00$ & $31.894,72$ & $\underline{\mathbf{4 2 . 2 9 4 , 7 2}}$ \\
2 & 0,357 & $17.200,00$ & $31.845,40$ & $49.045,40$ \\
3 & 0,335 & $18.500,00$ & $30.852,42$ & $49.352,42$ \\
4 & 0,196 & $32.200,00$ & $19.125,98$ & $51.325,98$ \\
5 & 0,178 & $35.500,00$ & $17.468,53$ & $52.968,53$ \\
\hline
\end{tabular}

TABELA 6.5 - Solução analítica considerando $\alpha_{\text {neutro }}$

\begin{tabular}{ccccc}
\hline Opção & S (Sv-pessoa) & X (US\$) & Z (US\$) & X+Z (US\$) \\
\hline 1 & 0,561 & $10.400,00$ & $17.284,36$ & $\underline{\mathbf{2 7 . 6 8 4 , 3 6}}$ \\
2 & 0,357 & $17.200,00$ & $18.976,94$ & $36.176,94$ \\
3 & 0,335 & $18.500,00$ & $19.278,09$ & $37.778,09$ \\
4 & 0,196 & $32.200,00$ & $14.288,80$ & $46.488,80$ \\
5 & 0,178 & $35.500,00$ & $13.523,22$ & $49.023,22$ \\
\hline
\end{tabular}


TABELA 6.6 - Solução analítica considerando $\alpha_{\text {propenso }}$

\begin{tabular}{ccccc}
\hline Opção & S (Sv-pessoa) & X (US\$) & Z (US\$) & X+Z (US\$) \\
\hline 1 & 0,561 & $10.400,00$ & $9.113,53$ & $\underline{\mathbf{1 9 . 5 1 3 , 5 3}}$ \\
2 & 0,357 & $17.200,00$ & $8.213,25$ & $25.413,25$ \\
3 & 0,335 & $18.500,00$ & $8.486,86$ & $26.986,86$ \\
4 & 0,196 & $32.200,00$ & $7.498,67$ & $39.698,67$ \\
5 & 0,178 & $35.500,00$ & $7.493,21$ & $42.993,21$ \\
\hline
\end{tabular}

As figuras 6.5, 6.6 e 6.7 apresentam, respectivamente, os gráficos referentes às tabelas 6.4, 6.5 e 6.6 .

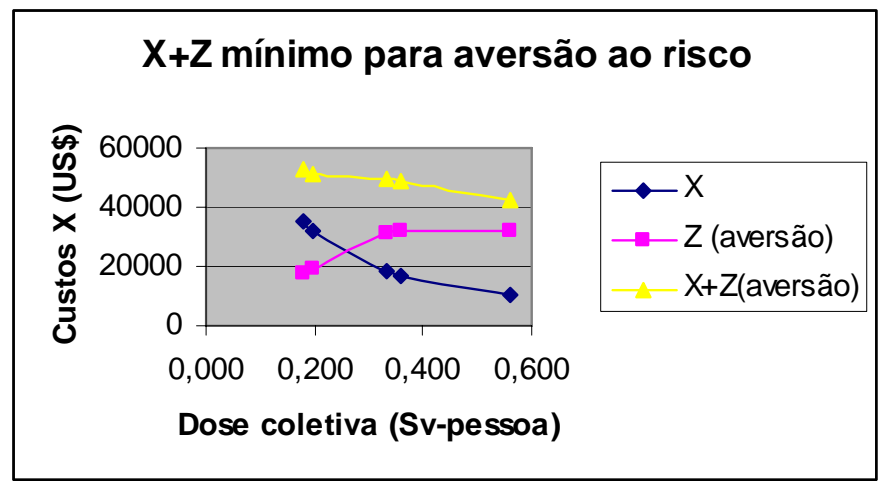

FIGURA 6.5 - Valor de $(\mathrm{X}+\mathrm{Z})$ mínimo para aversão ao risco

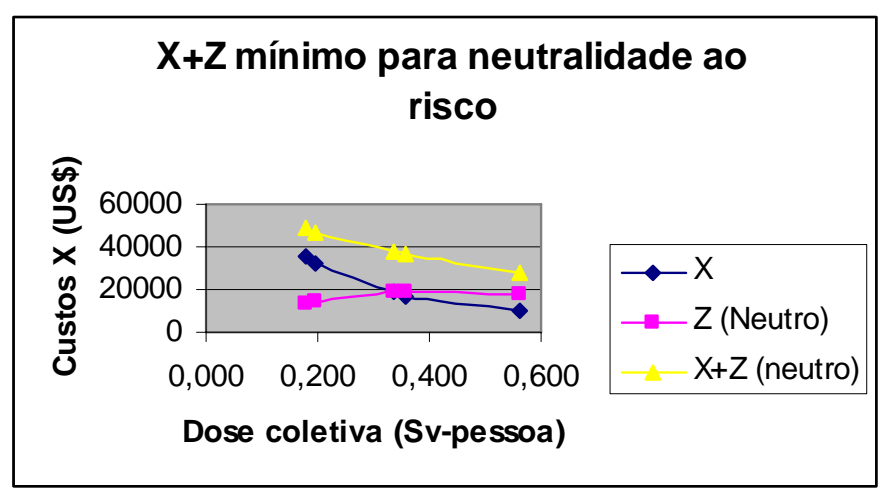

FIGURA 6.6 - Valor de $(\mathrm{X}+\mathrm{Z})$ mínimo para neutralidade ao risco 


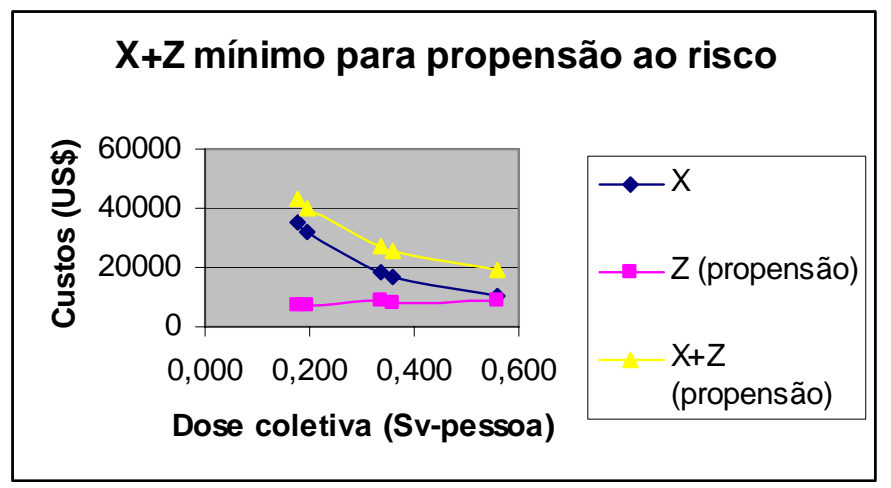

FIGURA 6.7 - Valor de $(\mathrm{X}+\mathrm{Z})$ mínimo para propensão ao risco

Do exposto até aqui podemos extrair:

1 - a filosofia vigente permite uma otimização para cada família de opções de proteção. Para uma análise mais apurada, poder-se-ia pensar na construção de outros conjuntos de famílias de opções, porém este número de famílias disponíveis, provavelmente, seria limitado. No caso da mina poderemos pensar nas seguintes famílias:

a) usos de vários EPI para os trabalhadores;

b) melhorias na carga e descarga do minério e no seu transporte;

c) melhorias nos locais de trabalho na superfície.

Depreende-se que estas famílias só atingem uma fração da população de trabalhadores.

2- na realidade, o valor de $\mathrm{X}$ varia de acordo com as diferentes atividades humanas e os investimentos necessários. Como exemplo, os investimentos necessários para a proteção em um reator de potência são completamente diferentes daqueles necessários para um medidor de espessura de papel ou de uma instalação de radiografia industrial. Assim sendo, pode-se sugerir o estabelecimento de várias funções alfa, de acordo com as variações para diferentes atividades humanas. Para melhor exemplificar o raciocínio aqui desenvolvido, iremos dar um exemplo. 
De acordo com a CIPR ${ }^{(4)}$, os custos de proteção de um empreendimento podem ser avaliados por meio da série de pagamentos mostrada abaixo:

$$
P V=P M T \times \frac{(1+i)^{n}-1}{(1+i)^{n} \times i} \quad \text { ou } \quad P V=P M T \times F V A_{(i, n)}
$$

onde:

PV- valor presente ou custo de proteção;

PMT - parcelas ou custo anual de proteção;

i - taxa anual de juros adotada;

n - período de tempo em anos ou vida útil da instalação;

$\mathrm{FVA}_{(\mathrm{i}, \mathrm{n})}$ - fator de valor atual, que pode ser encontrado em tabelas padronizadas da literatura especializada. ${ }^{(28)}$

Nestas condições, supõe-se que o capital seja tomado emprestado numa dada taxa para financiar a compra e a operação do sistema de proteção e é pago anualmente. Este método divide o capital inicial ao longo do tempo equivalente à vida útil da instalação, considerando a taxa de juros aplicada ao financiamento. Por meio deste método, estimamos o custo total de proteção de cada opção presente no exemplo da mina de urânio proposta pela $\mathrm{CIPR}^{(4)}$. Para o cálculo foi considerada uma taxa de juros anual de $12 \%$, e uma vida útil de 25 anos. Os resultados encontrados são mostrados na tabela 6.7.

TABELA 6.7 - Custo total de proteção das opções da mina de urânio

\begin{tabular}{ccc}
\hline Opção & $\begin{array}{c}\mathrm{X} \\
\text { (US\$) }\end{array}$ & $\begin{array}{c}\text { Custo Total } \\
\text { (US\$) }\end{array}$ \\
\hline 1 & $10.400,00$ & $81.568,65$ \\
2 & $17.200,00$ & $134.901,99$ \\
3 & $18.500,00$ & $145.098,07$ \\
4 & $32.200,00$ & $252.549,08$ \\
5 & $35.500,00$ & $278.431,44$ \\
\hline
\end{tabular}


Conforme se pode observar na figura 6.8, criamos uma coleção de curvas de aversão ao risco, fazendo o valor máximo atribuído ao alfa, equivalente a dose de $50 \mathrm{mSv}$, variar entre US\$ 20000 e US\$ 500.000. Nota-se que, à medida que o valor máximo de alfa cresce, a opção de proteção ótima tende a ser a que oferece menor dose, porém, a partir de um determinado valor, a otimização não teria mais sentido, uma vez que o resultado obtido seria sempre o mesmo, ou seja, a opção 5.

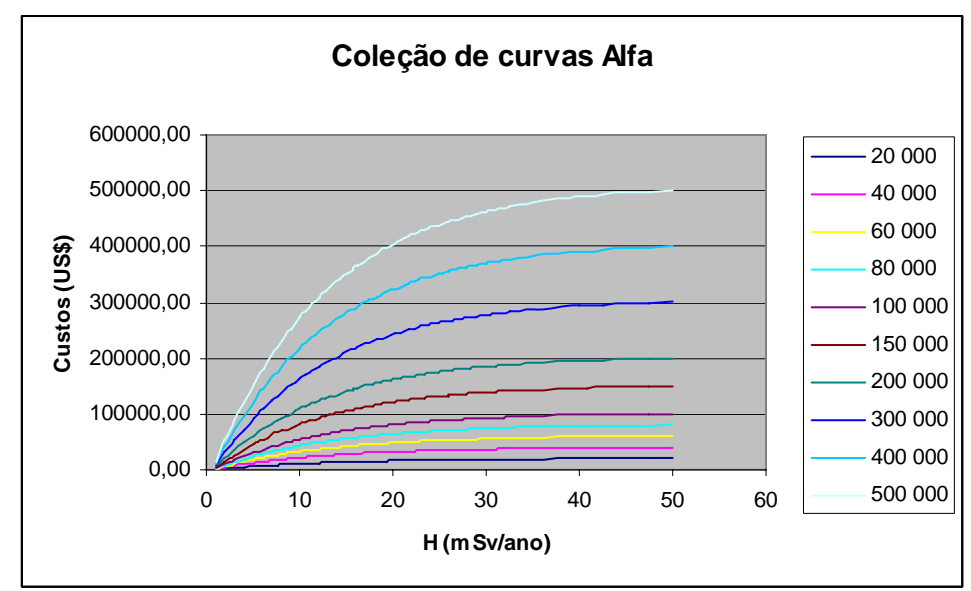

FIGURA 6.8 - Coleção de curvas para Alfa

Desta forma, parece que deva ser considerado o montante do custo de proteção da opção para que se estabeleça a escolha da curva. Uma alternativa seria que a curva alfa escolhida fosse aquela cujo valor alfa máximo fosse uma porcentagem do valor máximo do custo total da opção. Assim, para o exemplo da mina, poderíamos adotar a curva de aversão ao risco desenvolvida no capítulo metodologia, porém, multiplicada pela porcentagem que melhor se aproxima ao valor do custo total da opção, como, por exemplo, é mostrado na tabela 6.8 . 
TABELA 6.8 - Valores de $\mathrm{X}+\mathrm{Z}$ considerando o custo total de cada opção e as curvas de alfa que mais se aproximam destes custos

\begin{tabular}{cccccc}
\hline Opção & $\begin{array}{c}\text { Custo } \\
\text { (US\$) }\end{array}$ & $\begin{array}{c}\text { Total } \\
\text { (US\$) }\end{array}$ & $\begin{array}{c}\text { Curva alfa } \\
\text { escolhida }\end{array}$ & $\begin{array}{c}\mathrm{Z} \\
\text { (US\$) }\end{array}$ & $\begin{array}{c}\mathrm{X}+\mathrm{Z} \\
\text { (US\$) }\end{array}$ \\
\hline 1 & 10400,00 & $81.568,65$ & $85.000,00$ & $46.704,91$ & $\underline{\mathbf{5 7 . 1 0 4 , 9 1}}$ \\
2 & 17200,00 & $134.901,99$ & $135.000,00$ & $43.933,34$ & $61.133,34$ \\
3 & 18500,00 & $145.098,07$ & $150.000,00$ & $44.650,08$ & $63.150,08$ \\
4 & 32200,00 & $252.549,08$ & $260.000,00$ & $38.694,57$ & $70.894,57$ \\
5 & 35500,00 & $278.431,44$ & $280.000,00$ & $35.931,19$ & $71.431,19$ \\
\hline
\end{tabular}

Para evitar a tendência de se ir para opções mais baratas devido à contribuição da dose coletiva, poderia ser criada uma porcentagem a ser investida em proteção considerando-se o custo total da opção. Por exemplo, poderiam ser criados os intervalos da tabela 6.9 .

TABELA 6.9 - Porcentagem sobre o custo total para a escolha da curva alfa

\begin{tabular}{cc}
\hline $\begin{array}{c}\text { Custo Total da Proteção por } \\
\text { opção (US\$) }\end{array}$ & $\begin{array}{c}\text { Porcentagem sobre o } \\
\text { custo total para a escolha } \\
\text { da curva alfa } \\
\text { (\%) }\end{array}$ \\
\hline Até $100.000,00$ & 100 \\
De $100.000,00$ a $200.000,00$ & 80 \\
Acima de $200.000,00$ & 60 \\
\hline
\end{tabular}

Aplicando esta regra ao problema da mina teríamos: 
TABELA 6.10 - Aplicação na mina de urânio

\begin{tabular}{cccccc}
\hline & & & & \multicolumn{3}{c}{ Valor } \\
Opção & X & Custo Total & $\begin{array}{c}\text { Porcentagem } \\
\text { do custo total } \\
\text { (US\$) }\end{array}$ & $\begin{array}{c}\text { porcentagem do } \\
\text { (U) }\end{array}$ & $\begin{array}{c}\text { Curva de } \\
\text { custo total }\end{array}$ \\
& & & & $(\mathrm{USS})$ & \\
\hline 1 & $10.400,00$ & $81.568,65$ & 100 & $81.568,65$ & $85.000,00$ \\
2 & $17.200,00$ & $134.901,99$ & 80 & $107.921,59$ & $110.000,00$ \\
3 & $18.500,00$ & $145.098,07$ & 80 & $116.078,46$ & $120.000,00$ \\
4 & $32.200,00$ & $252.549,08$ & 60 & $151.529,45$ & $155.000,00$ \\
5 & $35.500,00$ & $278.431,44$ & 60 & $167.058,86$ & $170.000,00$ \\
\hline
\end{tabular}

Assumimos então que, para as porcentagens acima encontradas, escolheremos as curvas para cada opção. A partir da tabela acima, utilizando as curvas, obtivemos a solução ótima apresentada na tabela 6.11 .

TABELA 6.11 - Valores de $\mathrm{X}+\mathrm{Z}$

\begin{tabular}{cccc}
\hline Opção & $\begin{array}{c}\mathrm{X} \\
(\mathrm{US} \$)\end{array}$ & $\begin{array}{c}\mathrm{Z} \\
(\mathrm{US} \$)\end{array}$ & $\begin{array}{c}(\mathrm{X}+\mathrm{Z}) \\
(\mathrm{US} \$)\end{array}$ \\
\hline 1 & $10.400,00$ & $46.704,91$ & $57.104,91$ \\
2 & $17.200,00$ & $35.797,54$ & $\underline{\mathbf{5 2 . 9 9 7 , 5 4}}$ \\
3 & $18.500,00$ & $35.720,06$ & $54.220,06$ \\
4 & $32.200,00$ & $23.067,92$ & $55.267,92$ \\
5 & $35.500,00$ & $21.815,37$ & $57.315,37$ \\
\hline
\end{tabular}

O resultado obtido é a opção 2 , em negrito e sublinhado.

Com o conceito de derivada introduzida neste trabalho, uma segunda proposta, além do critério de aversão, neutralidade e propensão ao risco, seria uma curva de valores alfa que coincidissem com a derivada na curva dos valores de $\mathrm{X}$, em função da dose individual. Neste caso, as opções ótimas seriam aquelas estabelecidas pelos valores alfa 
em função das doses individuais e a otimização chegaria até o maior valor de alfa. Se não for alcançado o valor desejado de $5 \mathrm{mSva}^{-1}$ exigido, dever-se-ia partir, para outro conjunto de opções. O desenvolvimento desta proposta será deixado para futuros trabalhos. 


\section{CAPÍTULO 7}

\section{DISCUSSÃO DOS RESULTADOS}

\section{1- Discussão dos resultados obtidos para a mina de urânio}

A função que melhor se ajustou aos pontos referentes ao custo de proteção $X$ foi a potencial $\mathrm{X}_{\mathrm{A}}$. Este ajuste é muito bom como pode ser observado na tabela 4.2,onde são apresentados os valores do custo das opções sem o ajuste, conforme se encontra na $\mathrm{CIPR}^{(4)}$, e com o ajuste, pela função potencial $\mathrm{X}_{\mathrm{A}}$.

Apenas a título de comparação, efetuamos os cálculos de análise custo benefício e análise custo benefício expandida, conforme previsto na $\operatorname{CIPR}^{(4)}$, porém substituindo o custo de proteção $X$ pela função ajustada $X_{A}$. Os resultados obtidos são os mesmos encontrados pela CIPR , conforme mostrado nas tabela 4.4 e 4.5.

Quando são aplicadas as duas técnicas, isto é, a diferencial e a integral com detrimento modificado, nota-se que os resultados obtidos diferem para alfa de aversão ao risco, conforme se pode observar na tabela 7.1, sendo tais diferenças perfeitamente justificáveis. Nota-se que, para $(X+Z)_{\min }$, estamos trabalhando com funções discretas e, portanto, não há nenhum valor numérico entre as opções. Porém, quando usamos derivadas, estamos trabalhando com funções contínuas e, portanto, existem infinitos pontos entre as opções, inclusive os pontos $\left|\frac{d X_{A}}{d S}\right| \leq \frac{d Z_{A}}{d S}$ e o ponto exato onde $\left|\frac{d X_{A}}{d S}\right|=\frac{d Z_{A}}{d S}$. 
TABELA 7.1 -Opções ótimas obtidas com as duas técnicas para cada tipo de Alfa

\begin{tabular}{ccc}
\hline$\alpha=f(H)$ & $(X+Z)_{\min }$ & $\left|\frac{d X_{A}}{d S}\right| \leq \frac{d Z_{A}}{d S}$ \\
\hline$\alpha_{\text {aversão }}$ & 4 & 3 \\
$\alpha_{\text {neutro }}$ & 3 & 3 \\
$\alpha_{\text {propenso }}$ & 3 & 3 \\
\hline
\end{tabular}

Dado que a função composta pelas opções do problema é discreta, na prática serão assumidos como resultados ótimos os valores apresentados com a técnica do detrimento modificado Z. Por outro lado, supondo que o problema envolvesse uma função contínua, como é por exemplo o caso de uma blindagem, seria possível fazer uma reavaliação do projeto com o intuito de se utilizar o ponto ótimo verdadeiro, ou seja , o ponto onde $\left|\frac{d X_{A}}{d S}\right|=\frac{d Z_{A}}{d S}$. Apenas para ilustrar, apresentamos as doses coletivas e doses individuais máximas para os três alfas considerando $\left|\frac{d X_{A}}{d S}\right| \leq \frac{d Z_{A}}{d S},\left|\frac{d X_{A}}{d S}\right|=\frac{d Z_{A}}{d S}$, e $(X+Z)_{\min }$ conforme tabela 7.2.

TABELA 7.2 -Dose coletiva anual e dose individual máxima das opções ótimas

\begin{tabular}{c|c|c|c|c|c|c}
\cline { 2 - 7 } & \multicolumn{2}{c|}{$\alpha_{\text {aversão }}$} & \multicolumn{2}{c|}{$\alpha_{\text {neutro }}$} & \multicolumn{2}{c}{$\alpha_{\text {propenso }}$} \\
\cline { 2 - 7 } & $\begin{array}{c}S \\
(\text { Sv-pessoa) }\end{array}$ & $\begin{array}{c}\mathrm{H} \\
(\mathrm{mSv})\end{array}$ & $\begin{array}{c}S \\
(\text { Sv-pessoa) }\end{array}$ & $\begin{array}{c}\mathrm{H} \\
(\mathrm{mSv})\end{array}$ & $\begin{array}{c}S \\
(\text { Sv-pessoa) }\end{array}$ & $\begin{array}{c}\mathrm{H} \\
(\mathrm{mSv})\end{array}$ \\
\hline$\left|\frac{d X_{A}}{d S}\right| \leq \frac{d Z_{A}}{d S}$ & 0,196 & 17,5 & 0,196 & 17,5 & 0,196 & 17,5 \\
\hline$\left|\frac{d X_{A}}{d S}\right|=\frac{d Z_{A}}{d S}$ & $\mathbf{0 , 2 4 1}$ & $\mathbf{2 0 , 2 8}$ & $\mathbf{0 , 2 7 3}$ & $\mathbf{2 2 , 4 3}$ & $\mathbf{0 , 3 0 7}$ & $\mathbf{2 4 , 6 9}$ \\
\hline$(X+Z)_{\min }$ & 0,196 & 17,5 & 0,335 & 26,00 & 0,335 & 26,00 \\
\hline
\end{tabular}


Essa análise levaria o tomador de decisão a,primeiramente, escolher a melhor curva pois pode-se observar que, se a escolha fosse pela curva de aversão ao risco, haveria uma redução no custo de proteção caso se optasse pelo ponto onde $\left|\frac{d X_{A}}{d S}\right|=\frac{d Z_{A}}{d S}$, uma vez que a dose coletiva ótima seria de 0,241 Sv-pessoa ao invés de 0,196 Sv-pessoa. Por outro lado, haveria um acréscimo na dose individual máxima que saltaria de 17,5 mSv/ano para 20,28 mSv/ano, o que a afastaria do objetivo final que é chegar à dose individual máxima de $5 \mathrm{mSv} / a n o$. Assim sendo, em alguns casos, talvez o próximo passo seja a decisão quanto à melhor trajetória a ser seguida, em função da disponibilidade de investimento da empresa ou da trajetória fixada pelos órgãos internacionais competentes.

Para estimar as doses individuais no ponto $\left|\frac{d X_{A}}{d S}\right|=\frac{d Z_{A}}{d S}$, foi ajustada uma curva de dose individual máxima em função da dose coletiva, conforme tabela 7.3, gráfico da figura 7.1 e fórmula 7.1.

$$
H=-0,0097 S^{2}+0,072 S+0,0035 \quad \text { com } R^{2}=0,9986
$$

TABELA 7.3 -Dose individual máxima anual em função da dose coletiva anual das opções

\begin{tabular}{ccc}
\hline opções & $\begin{array}{c}\text { Dose Coletiva (S) } \\
\text { Sv-pessoa }\end{array}$ & $\begin{array}{c}\text { Dose Individual Máxima (H) } \\
\text { Sv }\end{array}$ \\
\hline 5 & 0,178 & 0,0160 \\
4 & 0,196 & 0,0172 \\
$\alpha_{\text {aversão }}$ & $\mathbf{0 , 2 4 1}$ & 0,0203 \\
$\alpha_{\text {neutro }}$ & $\mathbf{0 , 2 7 3}$ & 0,0224 \\
$\alpha_{\text {propenso }}$ & $\mathbf{0 , 3 0 7}$ & 0,0247 \\
3 & 0,335 & 0,0265 \\
2 & 0,357 & 0,0280 \\
1 & 0,561 & 0,0408 \\
\hline
\end{tabular}




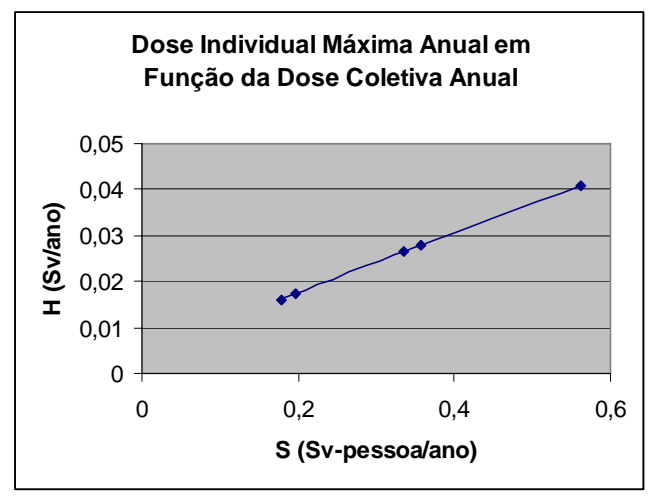

FIGURA 7.1 - Gráfico da dose individual máxima anual em função da dose coletiva anual

Conhecendo-se tal relação, podemos atribuir qualquer valor à dose individual máxima, além dos conhecidos nas opções de 1 a 5, que encontraremos a respectiva dose coletiva. Com esta dose coletiva, dado que conhecemos a função custo de proteção $\mathrm{X}_{\mathrm{A}}$, podemos encontrar o custo da opção idealizada. Sabendo-se que o objetivo final é atingir a dose individual máxima de $5 \mathrm{mSv}$, verificamos qual seria o custo associado a esta opção. Observamos que, se fosse tecnicamente possível diminuirmos a dose individual máxima até o valor de $5 \mathrm{mSv} / \mathrm{ano}$, teríamos um custo de proteção de aproximadamente US\$ 348.210,00 o que, provavelmente, inviabilizaria o projeto. Desta forma, parece-nos que nem sempre será possível atingir o valor de 5mSv/ano, considerado objetivo final do processo de otimização. Talvez seja razoável considerarmos que, além de trabalharmos com famílias de curva para alfa, devêssemos, também trabalhar com famílias de curva para custos, o que poderia ser entendido como, por exemplo, uma variação nos materiais a serem utilizados nos projetos, ou impor o valor máximo de alfa como porcentagem de um custo.

Uma outra análise possível, a partir dos dados obtidos, seria o fato de que, caso fossem adotadas pelo OIEA as curvas de alfa, sempre que se fosse realizar uma otimização, automaticamente, seria considerado o parâmetro distribuição das doses. Por outro lado, ainda restaria a questão da prioridade que se daria para alcançar a meta de $5 \mathrm{mSv} / \mathrm{ano}$, uma vez que quem decide a curva a ser adotada e quando se realizará a próxima otimização é o tomador de decisão. Para contornar essa questão, uma estratégia seria o OIEA criar uma regra onde quem determina a curva a ser seguida é o próprio organismo. Por exemplo, considerando que são três curvas para alfa, assume-se a hipótese de que um empreendimento passe por três otimizações sucessivas. Partindo desta hipótese, um 
critério seria que para empreendimentos já existentes, o intervalo de tempo entre cada otimização seja, digamos, de no máximo 5 anos, e que, para novos empreendimentos, a única curva válida seja a de aversão ao risco. Supondo a pior situação, ou seja, a de que a opção ótima de um determinado empreendimento já existente se situe na curva de risco propenso, deverão haver mais 2 otimizações, perfazendo um total de, no máximo, 10 anos. Dado que, para novos empreendimentos, a única curva válida seja a de risco adverso, em 10 anos atingiríamos a uniformidade global e, portanto, não teríamos mais um conjunto de curvas e sim apenas uma curva para alfa.

\section{2 - Discussão dos resultados obtidos para gamagrafia}

Nota-se que, neste exemplo, os custos não diminuem à medida que as doses individuais e coletivas aumentam. Tal fenômeno ocorreu devido à mistura de materiais que foram usados como blindagem nas opções, conforme se pode observar na tabela 7.4.

TABELA 7.4 - Materiais e espessuras empregados na confecção das blindagens da casamata

\begin{tabular}{ccccc}
\hline $\begin{array}{c}\text { Opções } \\
\text { selecionadas }\end{array}$ & Material $^{*}$ & $\begin{array}{c}\text { Espessura } \\
(\mathrm{cm})\end{array}$ & Material $^{*}$ & $\begin{array}{c}\text { Espessura } \\
(\mathrm{cm})\end{array}$ \\
\hline 1 & concreto & 50 & & \\
20 & concreto & 45 & barita & 6,7 \\
55 & cerâmica & 60 & barita & 10 \\
51 & cerâmica & 80 & & \\
13 & concreto & 65 & & \\
36 & concreto & 55 & barita & 6,7 \\
59 & cerâmica & 60 & barita & 15 \\
\hline
\end{tabular}

Esta é a razão pela qual não foi aplicado o método das derivadas ao problema. Mas, ainda assim, a solução ótima encontrada para as três curvas de alfa é a opção 13, que coincide com a opção encontrada no trabalho do qual foi extraído o exemplo. 


\section{CAPÍTULO 8}

\section{CONCLUSÕES}

Tanto os objetivos quanto a finalidade do presente trabalho foram alcançados.

1 - Quando trabalhamos com um valor para alfa constante, observamos que a função Y, custo do detrimento, se torna desnecessária, pois como a sua derivada é o próprio valor de alfa, o que interessa, então, é a derivada da função custo de proteção $\frac{d X}{d S}$ nos pontos onde existem as opções que, junto com o valor atribuído ao alfa, fornece a opção ótima.

2 - A idéia de se apresentar vários valores para alfa, ao invés de apenas um, é bastante interessante, pois, desta forma em qualquer otimização que se faça, sempre estará sendo considerada a distribuição das doses individuais, variável que acaba sendo desprezada quando se aplicam as técnicas de análise custo benefício, tanto diferencial quanto integral.

3 -Os valores para a construção da curva $\alpha$, que fossem sugeridos, não dependeriam mais do Produto Interno Bruto per Capita dos países, sendo função da distribuição das doses individuais máximas praticadas atualmente no mundo e da prioridade que se daria ao prazo necessário para se atingir a meta de $1 / 10$ do limite de dose anual, isto é, alcançar a região de doses individuais consideradas aceitáveis. Em função das disparidades econômicas existentes entre os países, talvez fosse interessante que esta curva fosse baseada na paridade do poder de compra (PPC). A PPC mede quanto uma moeda pode comprar em termos internacionais, já que bens e serviços têm diferentes preços de um país para outro. Evidentemente, esta discussão caberia à OIEA com base em um consenso entre as nações membros da ONU. 
4 - Da teoria, temos que o benefício líquido máximo é obtido quando $(X+Y)_{\min }$ ou $\left|\frac{d X}{d S}\right| \leq \alpha$. Assim sendo, suponhamos, para o exemplo da mina de urânio ${ }^{(4)}$, que seja tecnicamente possível diminuirmos a dose individual máxima até o valor de $5 \mathrm{mSv} / \mathrm{ano}$. Como o benefício máximo se deu para um valor de dose individual máxima de 17,5 mSv/ano, pela análise custo benefício expandida, evidentemente, para tamanha redução na dose, teríamos um grande aumento no custo de proteção, o que provavelmente inviabilizaria o projeto. Neste caso, especificamente, há ainda um agravante, pois um aumento muito elevado na taxa de ventilação da mina torna o ambiente difícil para se trabalhar, como a própria CIPR assevera. Assim, nos parece que, uma vez otimizado um projeto, se não houver nenhuma mudança provocada, por exemplo, por avanços tecnológicos que façam o comportamento da curva de custos mudar, nem sempre será possível atingir o valor de $5 \mathrm{mSv} / \mathrm{ano}$.

5 - Com a definição de $\frac{d Y}{d S^{H, C}}=\alpha$, conhecendo-se a probabilidade de morte por Sv, fornecida pela $\mathrm{CIPR}^{(1)}$, pode-se calcular o custo da vida humana, contrariamente ao que é preconizado pela CIPR e OIEA.

As equações propostas neste trabalho, isto é $(X+Z)_{\min }$ e $\left|\frac{d X_{A}}{d S}\right| \leq \frac{d Z_{A}}{d S} \quad$ com $\frac{d Z_{A}}{d S} \neq f\left(H_{\max }\right)$ não possibilitam, diretamente, este tipo de análise.

6-Diferentes limites restritos para diferentes países. Como foi detalhado no texto, estes diferentes limites entre os países poderia criar graves problemas no intercâmbio.

7- Outra questão importante é que o cálculo de $\alpha$, por estar atrelado ao PIB, pode fornecer diferentes valores de alfa para cada país. Mas, o objetivo final que é diminuição das doses até níveis admissíveis, seja o mesmo para qualquer lugar do planeta. 


\section{CAPÍTULO 9}

\section{FUTUROS TRABALHOS}

1. Classificação de intervalos de custos e investimentos em proteção para a dose individual limite com a finalidade de poder inferir curvas do valor alfa.

2. Estudo das possíveis famílias de valores alfa que poderiam ser atribuídos aos diferentes intervalos classificados no trabalho anterior.

3. Estudo dos valores alfa em função das doses individuais e da classificação de intervalos de custos e investimentos em proteção.

4. Estudo de ajuste de curvas aos custos de proteção $X$ por outras formas além daquelas consideradas neste trabalho.

5. Estudo das doses individuais máximas praticadas atualmente no mundo e da prioridade que se daria ao prazo necessário para se atingir a meta de 1/10 do limite de dose anual, isto é, alcançar a região de doses individuais consideradas aceitáveis.

6. Estudo de prós e contras por se considerar o câmbio ou a paridade do poder de compra no valor alfa de cada país.

7. Aprimorar a proposta em que os valores alfa coincidem com a derivada na curva dos valores de $\mathrm{X}$ em função da dose individual, considerando os possíveis valores máximos e mínimos. 


\section{REFERÊNCIAS BIBLIOGRÁFICAS}

1 INTERNATIONAL COMMISSION ON RADIOLOGICAL PROTECTION. 1990

Recommendations of the International Commission on Radiological

Protection.Oxford, Pergamon, 1991, (ICRP Publication No 60).

2 INTERNATIONAL ATOMIC ENERGY AGENCY. International Basic Safety Standards for Protection Against Ionizating Radiation and for the Safety of Radiation Sources. Vienna, 1996, (IAEA SS-115 Safety Series nº 115).

3 INTERNATIONAL COMMISSION ON RADIOLOGICAL PROTECTION. Implications of Commission Recommendations that Doses be kept as Low as Readily Achievable. Oxford, Pergamon, 1973, (ICRP Publication No 22).

4 INTERNATIONAL COMMISSION ON RADIOLOGICAL PROTECTION. Optimization and Decision-Making in Radiological Protection. Oxford, Pergamon, 1989, (ICRP Publication No 55).

5 INTERNATIONAL COMMISSION ON RADIOLOGICAL PROTECTION. CostBenefit Analysis in the Optimization of Radiation Protection. Oxford, Pergamon, 1983, (ICRP Publication No 37).

6 COMISSÃO NACIONAL DE ENERGIA NUCLEAR. Diretrizes Básicas de Radioproteção. Rio de Janeiro, 6 de janeiro de 2006, (CNEN-NN-3.01, Resolução No 27)

7 FILHO, J. A. Otimização do Sistema de Radioproteção nas Instalações Radiográficas de Gamagrafia. 1999.Tese (Doutorado)- Universidade de São Paulo, Instituto de Pesquisas Energéticas e Nucleares, São Paulo. 
8 STOKELL, P.J.; CROFT, J.R.; LOCHARD, J.; LOMBARD,J. ALARA:From Theory Towards Practice. Luxembourg:CEC, 1991. (Radiation Protection Series, EUR13796).

9 INTERNATIONAL COMMISSION ON RADIOLOGICAL PROTECTION. Problems Involved in Developing on Index of Harm. Oxford, Pergamon, 1978, (ICRP Publication No 27).

10 INTERNATIONAL COMMISSION ON RADIOLOGICAL PROTECTION. Quantitative Bases for Developing a Unified Index of Harm. Oxford, Pergamon, 1986, (ICRP Publication No 45).

11 SAHYUN,A.;SORDI,G.M.A.A. Wedening the Radiation Protection World. In : $11^{\text {th }}$ INTERNATIONAL CONGRESS OF THE INTERNATIONAL RADIATION PROTECTION ASSOCIATION. May 23-28, 2004. Madrid, Espanha. (IRPA 2004).

12 SAHYUN,A.;SORDI,G.M.A.A. The Evaluation of the Real Alpha Value in Brazil and its Projection until the Year 2025 . In : 10 ${ }^{\text {th }}$ INTERNATIONAL CONGRESS OF THE INTERNATIONAL RADIATION PROTECTION ASSOCIATION. May 14-19, 2000. Hiroshima, Japan. (IRPA 2000).

13 SUZUKI, F.F.Estudo de Níveis Genéricos de Intervenção para Proteção do Público em um Acidente Nuclear ou Emergência Radiológica. 2003.Dissertação (Mestrado)- Universidade de São Paulo, Instituto de Pesquisas Energéticas e Nucleares, São Paulo.

14 INTERNATIONAL COMMISSION ON RADIOLOGICAL PROTECTION. A compilation of the Major Concepts and Quantities in use by ICRP. Oxford, Pergamon, 1985, (ICRP Publication No 42). 
15 INTERNATIONAL COMMISSION ON RADIOLOGICAL PROTECTION. Recommendations of the International Commission on Radiological Protection. ICRP. Ann. ICRP 1 (3),Oxford, Pergamon, 1977, (ICRP Publication No 26).

16 UNSCEAR. Sources, effects and risks of ionizing radiation. Report to the General Assembly, with annexes, New York, UN, 1988.

17 MOONEY, G.H. The Valuation of Life. Mac Millan, London, 1977.

18 The Royal Commission on Civil Liability and Compensation for Personal Injury. London, HMSO, Comnd 7074(1978) (3 vols).

19 FERNANDES-RUSSELL, D, BENTHAM, G, HAYNES, R, KEMP, R AND ROBERTS, L. The Economic Valuation of Statistical Life from Safety Assessment. Research Report No. 5, Environmental Risk assessment Unit, University of East Anglia.

20 INTERNATIONAL ATOMIC ENERGY AGENCY. Assigning a value to transboundary radiation exposure. Vienna, 1985, (IAEA Safety Series $n^{\circ}$ 67).

21 INTERNATIONAL BANK FOR RECONSTRUCTION AND DEVELOPMENT. World Bank Atlas. Washington DC,1983.

22 NATIONAL RADIOLOGICAL PROTECTION BOARD.Optimisation of the radiological protection of the public (a provisional framework for the application of cost-benefit analysis to normal operations). London, july, 1981, (NRPB report R129). 
23 NUCLEAR RADIOLOGICAL PROTECTION BOARD. The application of costbenefit analysis to the radiological protection of the public: A consultative document. London,HMSO, 1980, (Harwell, NRPB).

24 LOMBARD, J, OUDIZ, A AND LOCHARD, J. L' analyse des determinants du coût du detriment radiologique. Paris, december, 1984,(CEPN Report No 78).

25 INTERNATIONAL ATOMIC ENERGY AGENCY. Colección de informes de seguridad No 21. Optimización de la protección radiológica em el control de la exposición ocupacional Assigning a value to transboundary radiation exposure. Viena, Áustria, 2004, (IAEA , STI/PUB/1118 ISBN92-0-302504-9 ISSN1020-6469).

26 FONSECA, J. S., MARTINS, G..A., TOLEDO, G.L. - Estatística Aplicada. Editora Atlas S.A., São Paulo, 1985.

27 SORDI, G.M. Considerations concerning the ALARA principle, the $\alpha$ value, and the choice of attributes. Anais do IRPA 11, Madrid, Espanha, 2004.

28 MATHIAS, W.F; GOMES, J.S. Matemática Financeira. 2a edição. Editora Atlas S.A, São Paulo, 1996. 